\title{
ATOP THE KADMEIA: MYCENAEAN ROOF TILES FROM THEBES IN CONTEXT
}

\author{
by Vassilis L. Aravantinos ${ }^{\mathrm{a}}$, Ioannis Fappas ${ }^{\mathrm{b}}$ and Yannis Galanakis ${ }^{\mathrm{c}}$ \\ ${ }^{a}$ Ephor Emeritus, Ephorate of Antiquities of Boeotia \\ ${ }^{b}$ Museum of Cycladic Art \\ 'Faculty of Classics, University of Cambridge
}

\begin{abstract}
Questions were raised in the past regarding the use of Mycenaean tiles as 'roof tiles' on the basis of the small numbers of them recovered in excavations and their overall scarcity in Mycenaean domestic contexts. The investigation of the Theodorou plot in 2008 in the southern part of the Kadmeia hill at Thebes yielded the single and, so far, largest known assemblage per square metre of Mycenaean tiles from a well-documented excavation. This material allows, for the first time securely, to identify the existence of a Mycenaean tiled roof. This paper presents the results of our work on the Theodorou tiles placing emphasis on their construction, form and modes of production, offering the most systematic study of Mycenaean tiles to date. It also revisits contexts of discovery of similar material from excavations across Thebes. Popular as tiles might have been in Boeotia and despite their spatially widespread attestation, their use in Aegean Late Bronze Age architecture appears, on the whole, irregular with central Greece and the NE Peloponnese being the regions with the most sites known to have yielded such objects. Mycenaean roof tiles date mostly from the mid-and late 14th c. BC to the first half of the 12th c. $B C$. A study of their construction, form, production and contexts suggests that their role, apart from adding extra insulation, might have been one of signposting certain buildings in the landscape. We also present the idea that Mycenaean tile-making was guided by a particular conventional knowledge which was largely influenced by ceramic-related technologies (potteryand drain-making). While production of roof tiles might have been palace-instigated to begin with, it does not appear to have been strictly controlled. This approach to Mycenaean tile-making may also help explain their uneven (in terms of intensity of use) yet widespread distribution.
\end{abstract}

\section{INTRODUCTION}

Mycenaean architecture, and the technologies associated with it, has attracted numerous studies over the years. From imposing tombs and monumental fortifications to domestic architecture and infrastructural projects, the focus of these studies has shifted over time from technical analyses to social syntheses of the extant evidence. ${ }^{1}$ Roofing techniques have, occasionally, formed part of these discussions. Tiles, however, whether associated with roofs or otherwise, remain a somewhat debatable and insufficiently understood aspect of Mycenaean building technology. ${ }^{2}$ Despite the fact that they have been reported in a number of sites across the southern Greek mainland, their actual numbers per site are frequently very low. ${ }^{3}$ Tiles have a high degree of adaptability and can be reused. In the past, they may have also been misidentified in archaeological reports, i.e. wrongly assigned to clay chimneys, drains, pipes, or as coming from coarse objects. The focus of Mycenaean ceramic studies on finewares may also be responsible for their low numbers, not least as many of these tiles are coarsely made. Yet the volume of excavation work in the southern Aegean in the last 150 years appears to suggest that their low numbers are not solely due to poor visibility, but rather owing to their sporadic use. ${ }^{4}$ Tiles are not shown in the extant corpus of Late Bronze Age (hereafter LBA) artistic representations. ${ }^{5}$

\footnotetext{
${ }^{1}$ E.g. Küpper 1996; Darcque 2005; Thaler 2018. Colour versions of the images appear in the online version of this article. 2 With few exceptions: Iakovidis 1990; Küpper 1996, 105-10, 266-70; Darcque 2005, 80, 124-8; Sapirstein 2008, 38-54; on later tiles, see Orlandos 1966, 81-9, with detailed references to ancient Classical sources including inscriptions; also, Heiden 1987; 1995; Merker 2006; Sapirstein 2009; 2016; Wikander 1986; 1988; Winter 1993; 2009.

${ }^{3}$ In most early excavations, coarse fragments were thrown away without proper examination which may partly account for the low numbers of reported tiles. Yet more complete examples are mentioned, and scholars seem to be aware of their possible existence as early as the beginning of the 20th c. (e.g. Keramopoullos 1917, 76-8). Papadopoulos' study (2013) on human intervention in a deserted Cretan village is highly instructive on the plethora of post-abandonment formation processes that may have altered and thus shaped what is left behind for us to study. We must therefore be cautious not to attribute the low visibility of things simply to our difficulty to find them - their use may, simply, not have been as popular as today. ${ }^{4}$ Blegen $(1928,34-5 ; 1945,41)$ was the first to advance the idea that the few pan tiles, known from Mycenaean contexts in his time, were actually not from roofs, but from drains (which are equipped with high sidewalls, $>10 \mathrm{~cm}$ ). It has to be said, however, that most of the 'tiles' used in conduits are narrower, lighter and often smaller than pan tiles (which have shorter sidewalls than drains). Sapirstein $(2008,52-3$, fig. 3.6) suggests that some cover tiles may have actually projected from the eaves of buildings as spouts keeping water away from the walls; or functioned as gutters by running along the eaves to catch water ejected from the roof funnelling it into a drainage system on the ground.

${ }^{5}$ Admittedly, superstructures and roofs do not feature much in Mycenaean art. For two-dimensional representations of horizontal roofs see Hiesel 1989, 230-4 and Krattenmaker 1991. Furthermore, and given the entanglement of Aegean archaeology in its early years with Homeric scholarship, the absence of any reference to tiles in the epics was considered by
} 
There is now sufficient evidence to suggest that both gabled and flat roofs co-existed in the LBA, at least from LH IIB-IIIA1, on the southern Greek mainland. ${ }^{6}$ Clearly these roofs need not have been tiled. The reported or published LBA roof tiles come from relatively late contexts, the vast majority dating to the 14 th and 13 th c. BC (LH IIIA2-IIIB). ${ }^{7}$ Despite their wide attestation (Map 1), only Thebes, Gla and Eleon ${ }^{8}$ (all in Boeotia) have yielded high numbers of tiles (Table 1). ${ }^{9}$ Mycenaean roof tiles include the cover and pan types which create an 'over and under' tile structure, also known in later periods in Greece, the Roman Empire and Medieval times, with examples of this structure surviving to this day (e.g. in central Italy).

Sapirstein, in his work on the emergence of ceramic roof tiles in Archaic temple architecture, has recently noted that the presently scarce and uneven distribution of pan and cover tiles in Mycenaean contexts should alert us to other uses for these objects, especially when found in very small numbers and when only pan tiles are mentioned in excavation reports. ${ }^{10}$ It is possible, following Sapirstein, that in a number of instances we are not actually dealing with roof tiles, but indeed with fragments of drains, which occupied 'a relatively small percentage of the roof area consistent with the low numbers of fragments from all Mycenaean sites'. ${ }^{11}$

Our picture and understanding of Mycenaean roof tiles remained until recently extremely fragmentary. The discovery at Thebes in 2008 , in a rescue excavation in the Stylianos Theodorou property in the southern, higher part, of the Kadmeia hill, of thousands of fragments and, amongst them, of some complete pan and cover tiles is therefore of great significance for advancing our knowledge on this subject and putting the debate over the existence of tiled roofs in Mycenaean Greece to rest.

\section{EXCAVATION AND BUILDING REMAINS}

The roof tiles that form the focus of this paper were discovered at 3 Eurydikis Street in the Stylianos Theodorou plot. ${ }^{12}$ This property, located in the southern part of the acropolis, is very close to the highest point of the Kadmeia, ${ }^{13}$ and less than a hundred meters from the

early archaeologists to correspond well to their relative paucity from Mycenaean settlement contexts. For some time too, roof tiles were caught in the debate regarding the roof of the Mycenaean 'megaron' and of Mycenaean buildings as a whole: in detail see Galanakis 2016; also, Burns 2007.

${ }^{6}$ Zavadil 2007; Galanakis 2016.

${ }^{7}$ A few fragments of 'handmade roof tiles' are mentioned in association with an early LBA (LH I) layer at Kirrha but remain unpublished (Skorda 2001-2004, 420). All other known Mycenaean tiles come from LH IIIA-IIIC contexts.

$8 \mathrm{~A}$ very large number of tiles, including complete examples, is reported from the recent Eleon excavations $(>500$ fragments of cover and pan tiles, associated with LH IIIA2/B and LH IIIC contexts: Burke et al. 2013, 20). The Northwest complex is said to have featured tiled pitched roofs. One near-complete example of a pan tile is 53.5 x $44.5 \mathrm{~cm}$ (Burke et al. 2020, 463). The material is under study by Dr Kyle Jazwa (Duke University) and its publication is greatly anticipated not least as it can complement the present study on Mycenaean tiles' form, construction and contexts of use and reuse. The morphology of these tiles is said to be demonstrably consistent with those from Thebes, Gla and Mitrou.

${ }^{9}$ As suggested elsewhere by one of the authors (Galanakis 2016, 162), the angle of the pitched roof observed in a few LH IIIIIA1 chamber tombs on the Greek mainland falls within a rather consistent range $\left(15^{\circ}-30^{\circ}\right)$. The consistency could suggest that the tomb builders followed closely established standards already applied to domestic architecture (i.e. the existence of pitched roof at least from LH II onwards, if not earlier). However, this comparison does not reveal anything directly on the use of tiles.

${ }^{10}$ Not least as cover tiles are more diagnostic than pan tiles and we would have expected a more regular mention of them in publications; see also Sapirstein 2008, 54.

${ }^{11}$ Sapirstein 2008, 54. On cylindrical terracotta pipes see Blegen 1928, 35, 37 (House B, Room 34); on rectangular pipes/drains: Schliemann 1885, 234, fig. 118; Shaw 2012. We did identify, as part of our study, two fragments that may belong to two, different, drain tiles: $\Sigma 210.32(\Sigma 8)$ and $\Sigma 210.33(\Sigma 8)$. They are both ca. $3 \mathrm{~cm}$ thick at the base, $1.8 \mathrm{~cm}$ thick on the sidewall, which is also 10.4 in height (very tall/deep for a pan tile). The body thickness is $1.7 \mathrm{~cm}$. Given that these are the only drain tiles we could identify in our corpus, we assume that they were sparingly used. On Minoan drains, where rectangular and cylindrical drains are mentioned and illustrated, see Shaw 2004 and Lenuzza 2013.

12 Aravantinos 2010a; Aravantinos and Fappas 2012; 2015a; 2015b; Galanakis 2016, 163-7; AGOnline (ID800): https://chronique.efa.gr/?kroute=report\&id=800

13 The highest point is about $222 \mathrm{masl}$ (measurements taken at modern surface level) and is situated ca. $70 \mathrm{~m}$ to the south of the Theodorou plot, near the section of Pindarou and Panagioti Drakou Streets, where important discoveries for the Middle and early LBA history of Thebes have been made in the past (Konsola 1981, maps 6, 9-10; Aravantinos and Fappas 2009, 101-102, note 42 and 107, note 64). The Theodorou plot is situated at ca. 216masl, while the 'House of Kadmos' (part of the 
south-eastern circuit of the LBA fortification wall (Map 2, no. 18). ${ }^{14}$ Its location within the Mycenaean acropolis and the presence of important architectural remains, along with the presence of large quantities of pottery of all Mycenaean phases and of significant small finds, make the Theodorou plot an incredibly informative excavation for achieving a finer understanding of the archaeology of Thebes. The meticulous excavation notebooks, the extensive photographic archive, and the numerous drawings and sketches produced at the time, all provide an excellent record of the excavation process. ${ }^{15}$

Following the removal of the top layer of disturbed mixed material that included pottery from the Ottoman, Late Byzantine, Roman as well as of all phases of the Bronze Age, and at a depth of ca. 1-1.20m from the modern ground, an impressive Late Mycenaean destruction layer was discovered. The excavation of the destruction layer, which was about $50 \mathrm{~cm}$ thick, brought to light the most extensive concentration of roof tiles to date per square metre (Figs 1-2). Most of the tiles were found broken (ca. 90\%), while a few of them were still intact. The tiles were found amassed together and in an orderly fashion, i.e. cover tiles in close proximity to or near/over pan tiles, suggesting the collapse of a tiled structure (Figs 2-3). In between the tiles were several broken and a few intact vessels, a few fragments of burnt wall paintings, burnt and unburnt mudbricks, and some charred wooden remains, reinforcing further the idea of a destruction accompanied by fire. In association with and under the destruction layer, well-built Late Mycenaean walls and floors came to light in dense arrangement.

The destruction of this area of the Kadmeia, according to the preliminary study of the pottery, is assigned to the end of LH IIIB1 or an early phase of LH IIIB2, perhaps sometime between 1300 and $1250 \mathrm{BC} .{ }^{16}$ The ceramic material from the Theodorou plot appears to be at home in LH IIIB1: e.g. type A deep bowls (FS 284), plain kylikes of conical shape (FS 274), plain mugs (FS 225, 226) among other characteristic shapes, and a limited number of motifs and the complete absence of type B or rosette deep bowls (Fig. 4). ${ }^{17}$ The material also appears to share a few similarities with that assigned to LH IIIB2 early at Mycenae and Tiryns by French and Stockhammer. ${ }^{18}$ This late LH IIIB1/early LH IIIB2 destruction appears to be documented across Thebes and in a number of different plots (e.g. the 'Treasury room', the Arsenal, the D. Koropoulis, Kordatzis, Liangas, Loukos, Stephas, Papastamelos and Liokis, and the S. Koropoulis plots, and the Panagiotopoulos-Papageorgiou plot which is adjacent to the Theodorou plot). ${ }^{19}$ The destruction therefore dated in these plots to the end of LH IIIB1 may actually be synchronous to the event that also struck the buildings in the Theodorou plot. This material is different from that associated with the destruction that appears to have brought an end to palatial administration at Thebes around the LH IIIB-C transition (ca. 1200

old palace complex) and the 'Treasury room' (forming the NE corner of the new central palace complex) are located at ca. 190-200masl; the museum site, at the north entrance of the citadel, is situated at a height of ca. 180masl.

${ }^{14}$ Symeonoglou 1985, 26-32; Aravantinos 1988; 2015b; Dakouri-Hild 2010. The citadel was fortified after a destruction probably late in LH IIIA2 or in the transitional LH IIIA2-B1 period (Aravantinos 1988). For the most recent overview of LBA Thebes see Aravantinos 2020.

15 The full publication of this excavation is currently in preparation by the authors of this paper.

${ }^{16}$ Three samples of charred wood, most likely originating from the roof's timber frame found among the destruction material from the 'central room', were analysed by Beta Analytic Inc. in Florida, USA for C14 dating. The calibrated radiocarbon dates using IntCal13 (standard deviation $1 \sigma=68.3 \%$ and $2 \sigma=95.4 \%$ for each sample) are the following: 1) Beta280959: 1495-1326 BC (68.3\%), 1505-1301 BC (95.4\%); 2) Beta-280960: 1492-1319 BC (68.3\%), 1501-1297 BC (95.4\%); 3) Beta-280961: 1511-1433 BC (68.3\%), 1608-1412 BC (95.4\%). The lower $2 \sigma$ dates from the first two samples are closer, in our view, to the possible absolute date of destruction of the Theodorou structures based on correlations with the pottery found there and the traditional dating of LH IIIB (e.g. Warren and Hankey 1989; Manning 2010; but see also Wiener 2003 and Aston 2011 for a later start of LH IIIB, which is traditionally thought to occupy the entire 13th century BC). More absolute dates are urgently needed to shed additional light on this important issue.

17 Aravantinos 2010a, 955-956; Aravantinos and Fappas 2012, 935-6, n. 21; Aravantinos and Fappas 2015a, 48. This material resembles that from Zygouries studied and published by Thomas 2005. Van Damme 2017, 84 correctly notes the rarity of the rosette bowls in Theban contexts.

18 There is good correlation in the features of pottery from the destruction level at Theodorou with the LH IIIB2 early diagnostic examples from Mycenae and Tiryns, e.g. French and Stockhammer 2009, 177 pl. 1, 182 pl. 3, 183 pl. 4. See also the important critical overview by Vitale 2006 on LH IIIB and the transition to LH IIIC.

${ }^{19} \mathrm{~A}$ full list of references for all these plots is given in Aravantinos and Fappas 2012, 935, n. 21. 
BC). ${ }^{20}$ In this respect, Thebes is similar to Mycenae, Midea and Tiryns in displaying a number of destruction horizons prior to the end of palatial administration ${ }^{21}$ (more on that issue below).

Two structures, both with a W/NW-E/SE orientation, were identified in association with the destruction layer in the Theodorou plot (Fig. 5). At the north end of the plot, three walls (nos. 12-14) delineate a free-standing quadrangular structure with a clay-coated floor, the northern extension of which was actually investigated in $1982 .{ }^{22}$ In both the 1982 and 2008 excavations, the floor bore clear and extensive traces of fire leading the excavator to call this structure the 'burnt room' (Fig. 6). The maximum external preserved dimensions of the 'burnt room' are $4.6 \mathrm{~m} \times 1.6 \mathrm{~m}$ (7.36sq.m.).

About $1.50 \mathrm{~m}$ to the south of the 'burnt room', another structure was discovered, delineated by walls nos. 2, 10 and 16, which was called by the excavators the 'central room' (Fig. 7). The plan of this structure, almost at the centre of the Theodorou plot, is unclear, not least as it extends further to the west. Based, however, on the excavation records, three reconstructions can be put forward: one with a possible entrance between walls nos. 10 and 16 (Fig. 8a), the second without an entrance (Fig. 8b), and the third with the main access from the east (Fig. 8c) ${ }^{23}$ The internal usable area is ca. $2.50 \mathrm{~m}(\max \mathrm{W}) \times 5 \mathrm{~m}$ (pres. L), i.e. a minimum of $12.5 \mathrm{sq} . \mathrm{m}$. The area almost certainly was larger in antiquity as the building continues to the west of the Theodorou plot as noted above. The maximum external preserved dimensions of the 'central room' are $7.8 \mathrm{~m} \times 5.6 \mathrm{~m}$ (i.e. an area of $43.68 \mathrm{sq} . \mathrm{m}$.). No thresholds were found in association with either structure.

The north wall (no. 10) of the 'central room' had a preserved length of $4.70 \mathrm{~m}$ and was standing to a maximum height of $0.51 \mathrm{~m}$. It was built with care: large, carefully worked stones were used in its construction, arranged in horizontal rows and with smaller stones used in the interstices. With a width of ca. $1.10 \mathrm{~m}$ and well-built corners, this wall is typical of foundations of external walls of large Mycenaean buildings at Thebes (cf. the foundation walls of the NE part of the 'Treasury room', and of its extension to the south, which is currently being excavated). ${ }^{24}$ Two 'jambs' are formed on either preserved end of wall no. 10 , which could have also provided space for shelves/storage. Wall no. 16 marks the east end of this structure and is also well-built. Wall no. 2 has a preserved length of $5 \mathrm{~m}$ and, when excavated, stood to a maximum height of $0.48 \mathrm{~m}$. It is built of large, roughly worked, stones with smaller stones placed in the interstices. The substantial thickness of this wall $(1.80 \mathrm{~m})$ may suggest the presence of a second floor, but there is no evidence in this part of the building at least for any staircase or other evidence to support this idea. We therefore

20 Andrikou 2006, 58-9; also, Aravantinos 1985; 2015b; Dakouri-Hild 2010, 698. Spyropoulos (1970, 215), Symeonoglou (1973) and Sampson $(1985 ; 1996)$ all associate the LH IIIB1 destruction with an earthquake. The Gikas plot, in the southern part of the Kadmeia, also yielded evidence for earthquake destruction which Spyropoulos (1972) dates to late LH IIIB, without unfortunately illustrating any pottery.

${ }^{21}$ On the late LH IIIB1/early LH IIIB2 destruction see also Symeonoglou 1973. Andrikou $(2006,59)$ makes an important observation: 'disasters although belonging to the same chronological horizon, did not strike the sites simultaneously, although it cannot be excluded that local variations in pottery had already started to appear before the destructions'. This point makes the comparative restudy of ceramic materials, where possible with good stratigraphic documentation, imperative if we are to refine our knowledge on this subject. On LH IIIB earthquakes at Mycenae, Midea and Tiryns and other sites see articles in Stiros and Jones 1996 and Hinzen et al. 2018, with additional references. Also, Aravantinos 2019, 187-8. That there was wider seismic activity is also suggested by the recent finds at Chania, Crete (dated sometime in the first half of the 13th c. BC): Andreadaki-Vlazaki 2015.

22 Aravantinos 1982a.

${ }^{23}$ The third version bears similarities with the reconstructed rooms $\mathrm{O}$ and $\Xi$ of the 'House of Kadmos' (part of the old palace complex: Dakouri-Hild 2001, 87, figs 2-3). There, one wall is thicker than the other (and both are of comparable dimensions to the 'central room' in the Theodorou plot). The internal space $(2.6 \mathrm{~m} \mathrm{~W})$ is also very similar to the 'central room' in the Theodorou plot.

${ }^{24}$ Aravantinos and Fappas 2012, 932; the difference is that the walls of the 'Treasury room', which forms the NE corner of the new central palace complex, continued to a height of ca $2.50 \mathrm{~m}$, thus forming the foundation and at the same time superstructure of the lower level of that particular building complex. In the case of the Theodorou plot, only the foundations seem to have been made of stone, while the elevations were built with mudbricks. On the architecture of Mycenaean Thebes see Demakopoulou 1990 (with references to tiles); Dakouri-Hild 2010. For the current excavations of the 'East Wing' of the 'new palace complex' of Thebes, see Aravantinos 2012; 2013; 2014; 2015a; 2016; 2017; 2018. 
consider the 'central room' a single-story structure. The need to strengthen the wall appears to relate to the weight of the tiled roof (more on this matter below). A transverse wall (Fig. 5), ca. $0.90 \mathrm{~m}$ in width and of similar quality of construction to wall no. 10 , was probably built in a later phase of use of the 'central room', when the floor appears to have also been raised by around $30 \mathrm{~cm}$. Its construction blocked the east end from the rest of this room. The superstructure of this wall was probably made of bricks, like the other walls of the 'central room'.

Although both the 'central room' and the 'burnt room' show signs of fire, they also bear significant differences. The floor of the 'burnt room' was badly damaged by fire (Fig. 6), unlike the floor of the 'central room', where some traces of fire were detected, but were not as extensive as in the former (Fig. 7). The foundation walls of the 'burnt room' were built with care but were of smaller size and their thickness was ca. $0.80 \mathrm{~m}$. This room was probably equipped with a gridded floor similar to the one discovered in 1982 in the adjacent plot. ${ }^{25}$ The 'central room' was architecturally more sizeable and decorated with at least one large-scale wall painting inside. ${ }^{26}$ Aravantinos and Fappas, who recently examined and published some of the painted fragments from the Theodorou plot, noted different sizes (miniature and lifesize representations), styles, colours, and painters ${ }^{27}$ in the preserved fragments. Although the excavation of the 'burnt room' did not yield any painted fragments, other rooms located to the north and to the west of the Theodorou plot were painted with representational scenes.

At the centre, and on the floor, of the 'central room', a clay bathtub basin (asaminthos) was found in situ, broken due to the collapse of material fallen from above, including several tiles (Fig. 9). The careful cleaning of the floor next to the basin revealed the impression of the underside of a burnt basket. Two stirrup jars and three piriform jars were also associated with the basket and basin. ${ }^{28} \mathrm{~A}$ large amount of pottery was recovered from this space, mostly unpainted drinking pots ${ }^{29}$ (Fig. 4).

In between the two structures, a narrow 'corridor' was formed uniting two open spaces. Drinking vessels as well as pots used for food preparation and storage were found here. To the south of the 'central room', two parallel walls were found (nos. 26-27; preserved to about $10 \mathrm{~m}$, but clearly continuing on both ends). Their W/NW-E/SE orientation, same as the two structures, reinforce the area's careful planning and possible association of these walls with the two structures found in the Theodorou plot. Although their investigation was limited, they are best interpreted as belonging to a built Mycenaean drain (Fig. 10). A similar drain, in terms of construction and dimensions, was actually found about $25 \mathrm{~m}$ to the west in the A. Theodorou plot (15 Pindarou Street, opposite the Stylianos Theodorou plot). ${ }^{30}$ With a N/NW$\mathrm{S} / \mathrm{SE}$ orientation, the extensions of the two drains would meet perpendicularly (probably in the unexcavated plot immediately to the south of 15 Pindarou Street). The uncovered sections

${ }^{25}$ Aravantinos, 1982a, pl. 101ß, recalling the gridded floors from Pylos, Mycenae and Tiryns (see also Egan 2015).

${ }^{26}$ If there was a second floor, these fragments may have also originated from there. Aravantinos and Fappas (2015b, 343-5) tentatively identify in a painted fragment found inside this structure a large-scale scene, elements of which sometimes appear on the rail of the body of horse-driven chariots $(\delta i \varphi \rho o \varsigma)$. This interpretation, coupled with their conjecture, that this structure might have been a propylon/entry-point of sorts (perhaps in its early phase of use before the internal wall was built) could find a possible contemporary parallel at Mycenae (ca. 1250 BC). There, the start of the 'Processional Way' was marked by a roofed passage, painted with horses, two men and a chariot, a composition also echoed in the 'Western Portal', i.e. the entrance to the palace proper (Kritseli-Providi 1982, 90-91 'Delta-I', pl. 27; Morgan, 2005, 162).

${ }^{27}$ Aravantinos and Fappas 2015b, 343-5 in more detail, where they also entertain the possibility one of the fragments to be from a floor painting (Fig. 24). A miniature border frieze with running Egyptian blue papyrus flowers, white circles and vivid orange bands (Fig. 23) - a theme well known from the Argolid and Boeotia - was also found amongst the fragments. ${ }^{28}$ Bathtub basins in settlement contexts appear to have had an industrial/workshop as well as ritual function. Aravantinos

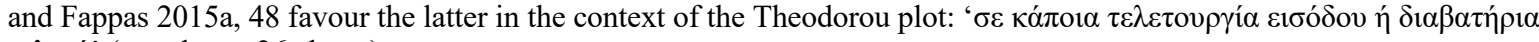
$\tau \varepsilon \lambda \varepsilon \tau \eta^{\prime}$ (see also n. 26 above).

${ }^{29}$ A few painted examples were also found as well as some glass beads.

${ }^{30}$ Faraklas 1967, pl. 159 . Dimensions: W: 1.20-1.30m (of the channel); L: 12.50m (preserved). The drain was originally covered with stones. The construction is very good and the area immediately to the west of the drain in the A. Theodorou plot is described by Faraklas as belonging to an open area (several layers of trampled earth of Mycenaean date were noted: 1965, 226). To the north and to the east, excavations in this plot yielded remains of at least two Mycenaean buildings with a $\mathrm{N}-\mathrm{S}$ orientation (i.e. different orientation from that observed in the buildings of the Stylianos Theodorou plot studied here). 
appear therefore to be part of the same Mycenaean drainage system in this area of the Kadmeia.

The area around the Theodorou plot has a long history of use and was probably the core of late Middle Bronze Age/early LBA Thebes. ${ }^{31}$ It is unclear whether the early LBA deposits in the Theodorou plot, ${ }^{32}$ the character of which is more ceremonial, could be linked with the Late Mycenaean remains suggesting continuous use of this particular space for similar purposes (actually, the impression we have is that the LH IIIB ceramic material is largely domestic in character, and it could have been used as one would expect in drinking, earing and serving occasions). Given, so far, the absence of Linear B documents and sealings from these excavations and the presence of paintings and other small finds (with a focus on drinking and eating vessels), the structures in the Theodorou plot appear to have had a nonadministrative, perhaps residential and/or ceremonial function.

Excavations in the 1970s and 1980s in adjacent plots brought to light a series of structures. Although these structures are partially known, they all have a NW-SE (or W/NW-E/SE) orientation, the same as those in the Theodorou plot (Fig. 11). The most important of these remains are located in the northernmost part of the Staikos plot, which lies immediately to the north of the Theodorou plot, and the Panagiotopoulos-Papageorgiou plot, adjacent to the west of the Staikos plot. ${ }^{33}$ Located at a somewhat lower level than the Theodorou plot structures, following the hill's natural formation, the excavation there yielded fragments of paintings, amongst which are faux-marble revetments from the lower part of a wall, a miniature scene with a bird, and at least one life-size woman, perhaps from a procession. ${ }^{34}$ Although it is unclear at present whether these structures formed one complex or were part of an agglomeration of buildings in the area, ${ }^{35}$ they provide evidence for the existence of a wellplanned quarter in the southern part of the Kadmeia. ${ }^{36}$

This agglomeration appears to have extended further to the east as the remains at 23 Dirkis Street (K. Gelis plot) suggest. ${ }^{37}$ There, well-built walls similar to those in the nearby Staikos and Theodorou plots were discovered (W: $1.10 \mathrm{~m}$ ) and assigned by its excavator to Late Mycenaean buildings. Their destruction was also accompanied by fire (on the basis of traces of fire, burnt mudbricks and charred wood) with the thickness of the destruction debris being ca. $1.50 \mathrm{~m}$. More buildings, with a N-S orientation this time, existed on the west side of Pindarou Street and to the north of Dirkis Street. ${ }^{38}$ Like the structures in the Eurydikis Street plots, these buildings to the west of Pindarou Street were also decorated with wall paintings, including fragments from ornate skirts of large-scale women and a fragment that depicts a miniature scene of a building from which two white-skinned helmeted figures peer. ${ }^{39}$

The south end of the Kadmeia, more specifically the area of and around the Theodorou plot, appears to have formed part of a planned and rather densely built quarter in Late Mycenaean times. The structures were generally well-built, many of them had painted interiors,

\footnotetext{
${ }^{31}$ As e.g. architectural remains and finds, mostly ceramics, from the Belegratis plot (21 Dirkis Street) and the Gelis plot (23 Dirkis Street) appear to suggest (Aravantinos 1981; 1982b; 1982c). On the pre-Mycenaean and early Mycenaean settlement on the Kadmeia see Konsola 1981 and Aravantinos 2010b, 54-9.

32 Under study by Ioannis Fappas.

33 Demakopoulou 1973-74a and Demakopoulou and Konsola 1975, 54, 56, pl. 2.

${ }^{34}$ Aravantinos and Fappas 2015b, 342-3 who also note that this is only the second such possible composition known at Thebes after the well-known examples from the 'House of Kadmos' (part of the old palace complex).

${ }^{35}$ Aravantinos and Fappas $(2015 \mathrm{a} ; 2015 \mathrm{~b})$ are of the opinion that in the area of and around the Theodorou plot a large rectangular building with several internal and external spaces existed in Late Mycenaean times.

${ }^{36}$ Konsola 1981, 159-170; Symeonoglou 1985; Aravantinos 1995, 615.

37 Aravantinos 1981

38 To the west of Pindarou Street: A. Theodorou Plot (15 Pindarou Street), the Staikos Plot (on Pindarou Street and south of the A. Theodorou property) and the E. Filou Plot (to the south and adjacent to the Staikos Plot) (Faraklas 1967; Spyropoulos 1970a; 1970b). To the north of Dirkis Street: in the P. Zoulamoglou plot: Demakopoulou 1976. For the issue of orientation of buildings at Thebes see Dakouri-Hild 2010, 698-9 and fig. 52.2 inset.

${ }^{39}$ From the Filou Plot: Spyropoulos 1970b, pl. 204\%; 1971a, 109-119; also, Aravantinos and Fappas 2015b, 342.
} 
displaying large-scale and miniature scenes ${ }^{40}$ appear to have had a non-administrative character, and their destruction in LH IIIB was accompanied by fire. ${ }^{41}$

\section{THE THEODOROU TILES AND THEIR STUDY}

During our study in the Archaeological Museum at Thebes, we used the field notebooks as our main guide for the identification of tiles in the course of excavation and to better understand the plot's stratigraphic sequence. Following the conservation of the tiles, we started inputting data in a custom-made FileMaker Pro database. The database includes all the 'diagnostic' cover and pan tiles. ${ }^{42}$ These entries helped us establish the minimum number of tiles in each category as discussed below. In the database, we tried to include as much information as possible: excavation details (including context), dimensions, current condition (including any restoration work), the surface and section (core) colour based on the Munsell colour system, and, in more complete examples, their weight. We also recorded any important details we were able to observe on the surface of the tiles, mostly relating to the raw materials used and the tiles' manufacture as well as any remains of fingerprints and footprints. All tiles were extensively photographed in the Archaeological Museum at Thebes, complementing in this way the already extensive photographic archive of the excavation. Following their recording, the diagnostic fragments were placed in crates or wooden drawers (depending on their size and condition of preservation) and were stored in the storerooms of the Ephorate of Antiquities of Boeotia. A small selection of the best-preserved tiles is now on display in the new Archaeological Museum at Thebes which opened to the public in the summer of $2016 .^{43}$

In total, 2476 tile fragments were examined as part of our study of the material from the Theodorou plot (after our study stored in 30 crates, ca. $2.5 \mathrm{~m}^{3}$ ). Non-mendable body sherds that preserved no distinguishable feature (e.g. one or both ends or sidewalls), were not added to the database but were recorded separately in an excel spreadsheet, where they were described briefly (as belonging to a pan or cover tile), counted and weighed, and stored in separate crates from the 'diagnostic' fragments. 1090 non-mendable body sherds were recorded in the way described above. 637 of these sherds $(38.18 \mathrm{~kg})$ belong to cover tiles, while $389(60.37 \mathrm{~kg})$ belong to pan tiles. The remaining 64 fragments belong either to clay pots or are of post-Bronze Age date.

During conservation and study of the material in the Museum at Thebes in 2013, 1386 of these 2476 fragments were thoroughly checked and joints were identified, resulting to 588 tiles-entries. ${ }^{44} 224$ of the 588 entries belong to cover tiles (37.6\%), while 364 are pan tiles $(61.2 \%)$.We might have expected a more balanced number of pan and cover tiles - this discrepancy can be explained by the fact that a lot of cover tiles were restored, while for numerous pan tile fragments (even from the same tile) it was only possible to conserve part of them.

\footnotetext{
40 The excavation in the plots of Douros and Gikas, ca. 70m SE of the Theodorou plot (Spyropoulos 1969; 1972, pls. 249250) also yielded fragments of wall-paintings, including some of the finest examples of seascapes and natural landscapes known from the Kadmeia (Aravantinos and Fappas 2015b, 329, fig. 10). These finds reinforce the idea that outside the central part of the acropolis, its southern end appears to have been equipped with a series of well-decorated structures. ${ }^{41}$ Aravantinos (2015) has recently described them as palatial annexes. The closest workshop, producing jewellery and perhaps also ivory and bone ornaments, is that in the Dimitrios Koropoulis plot, some 100m NW of the Theodorou plot at 29 Pindarou Street, where pan tiles have also been discovered (more below).

42 Bases and rims (wide and narrow ends respectively) and sidewalls are described as 'diagnostic sherds' for cover tiles. Rims (wide and narrow ends) and sidewalls, preserving at least part of the sidewall(s), and body sherds larger than $30 \mathrm{~cm}$ (i.e. $>50 \%$ of the average length of a pan tile) are considered 'diagnostic sherds' for pan tiles. All smaller finds from pan tile rims were recorded separately in an Excel database ( 98 rims, incl. narrow and wide ends], only five of which are larger than $20 \mathrm{~cm}$ ). 43 Another group of the Theban roof-tiles from the Theodorou plot was recently exhibited in the Mykene. Die Sagenhafte Welt des Agamemnon exhibition, which took place in the Badisches Landesmuseum Karlsruhe from December 2018 to June 2019 (Fappas 2018, 318 no 171, fig. on p. 147).

${ }^{44}$ Very few were the post-Bronze Age tiles in the excavation of the Theodorou plot, all fragmentary and from the uppermost layers of the excavation (mostly Byzantine or more recent in date). The tiles we examined from the destruction layer are all Mycenaean in make and date.
} 
Every entry in the FileMaker database for all the diagnostic fragments bears an individual

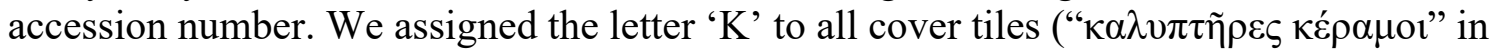
Greek literature) and the letter ' $\Sigma$ ' to all pan tiles (" $\sigma \tau \rho \omega \tau \tilde{\eta} \rho \varepsilon \varsigma \kappa \varepsilon \varepsilon \rho \alpha \mu o t$ " or " $\sigma \tau \varepsilon \gamma \alpha \sigma \tau \tilde{\eta} \rho \varepsilon \varsigma$ $\left.\sigma \omega \lambda \tilde{\eta} v \varepsilon \zeta^{\prime}\right) .{ }^{45}$ This letter is then followed by the tile's group number which is also tied to a particular trench within the excavated plot (e.g. group ' 201 ' refers to trench 'B', while group '501' refers to trench 'E', according to the letter sequence in the Greek alphabet) (Fig. 2). The group number is then followed by an individual number (starting with number '. 01 ' for every group). ${ }^{46}$ To facilitate the linkage between our database and the notebook, we also maintained the original excavation number given to particular tiles or group of tiles (e.g. 'K201.01 (K1)', i.e. a cover tile from trench B, group 201, the first to be recorded in our database, identified in the course of the Theodorou excavation as 'cover tile 1').

During excavation, 21 'units' (“o $\mu \alpha ́ \delta \varepsilon \varsigma$ ”) of cover tiles were identified (i.e. groups of fragments by find context representing individual but also bulk finds). (Figs 2-3, 12) They were assigned the numbers ' $\mathrm{K} 1$ ' to ' $\mathrm{K} 21$ ' by the excavators. The study of the 221 recorded cover tiles yielded 11 complete or almost complete examples, as well as 33 non-joining fragments which preserve a length equal to or larger than the $50 \%$ of the median body length of the intact examples (i.e. $22.7 \mathrm{~cm}$ and above). In this respect, the minimum number of cover tiles we are able to identify in the Theodorou assemblage is 44 . If we set aside the complete or almost complete cover tiles, all the other 210 cover tile fragments identified as part of our study, are classified in the following way: 94 rims (rims/narrow ends), 99 bases (bases/wide ends), and 17 large body fragments (no rim or base preserved). Therefore, the maximum number of cover tiles that we can identify in the Theodorou assemblage is 110 (11 complete or almost complete examples and 99 bases, which are helpfully different from rims). ${ }^{47}$ This is a significant number of cover tiles given the relatively small excavation area and their association with an equally small structure.

During excavation, 39 'units' (“o $\mu \alpha \delta^{\delta} \varepsilon \zeta$ ”) of pan tiles were identified (i.e. groups of fragments by find context representing individual but also bulk finds). (Figs 2-3, 13) These units were assigned numbers ' $\Sigma 1$ ' to ' $\Sigma 39$ ' by the excavators. Following the study of the 364 recorded pan tiles, we identified 9 complete or almost complete examples, as well as 58 non-joining individual fragments which preserve a length equal to or larger than the $50 \%$ of the median body length of the intact examples (i.e. $30.25 \mathrm{~cm}$ and above). In this respect, the minimum number of pan tiles we are able to identify in the Theodorou assemblage is 67 . With the pan tiles, we cannot at present achieve the same level of accuracy between narrow and broad ends, as the two rims often look very much alike and the level of preservation does not always allow us to clearly determine whether we are dealing with a narrow or a broad end. In total 98 rims, from 17 different excavation units, were recorded in our database: based on the slight tapering of the pan (with the internal width becoming wider towards the wider end, and narrower towards the narrow end) 31 of the rims (32\%) appear to belong to the narrow end and 50 rims (51\%) to the wide end. For 17 fragments (ca. 17\%), it was not possible to determine the side from which they originally came. Therefore, the maximum number of pan tiles that we can identify in the Theodorou assemblage is 117 (9 complete or almost complete, 58 fragments preserving a length equal to or larger than the $50 \%$ of the median body length of the intact examples, and 50 rims possibly originating from the wide end of

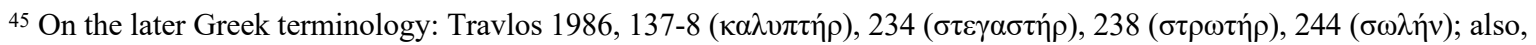
Orlandos 1966, 81-89.

${ }^{46}$ For example, the first cover tile we entered in our database from group '201' received the number ' $\mathrm{K} 201.01$ '.

47 If we add to this group, the $38.18 \mathrm{~kg}$ of body sherds belonging to cover tiles (the median weight of which is $1.73 \mathrm{~kg}$ ) then ca. 22 more tiles can be added which would raise the maximum number of cover tiles to 132. Since, however, most of the non-mendable body sherds from cover tiles may well come from the 110 possible individual examples mentioned above, we consider the latter number as more trustworthy for the purpose of our analysis here.
} 
individual pan tiles [i.e. non-joining with any of the other tiles counted here]). ${ }^{48}$ As with the cover tiles, this is a significant number of pan tiles from such a small area.

\section{TILE DISTRIBUTION AND THE ISSUE OF THE ROOF}

The tiles in the Theodorou plot covered a floor area of ca. 29sq.m. of the terrain's total 130sq.m.. As mentioned already, this is the largest concentration of tiles per sq.m. from any known Mycenaean context (an average of 85 tiles per sq.m., though clearly size and density of fragments varied, as also shown in Fig. 3). Two main concentrations were noted: one inside the 'central room' (i.e. inside walls nos. $2,10,16$ ), where $57 \%$ of the pan and $52 \%$ of the cover tiles were found (trenches B- $\Gamma$ ); and the other in the 'corridor'/open space between the two structures, where $32.5 \%$ and $40.5 \%$ of pan and cover tiles respectively were discovered (Fig. 3, trenches $\Delta, \mathrm{E}, \mathrm{Z}$ ). $10.5 \%$ of the pan and $7.5 \%$ of the cover tiles were also found immediately outside and to the east of wall no. 16 (i.e. by the 'corridor' area and open space 2 , in trench $\mathrm{H}$ ). The numbers are fairly balanced and suggests a relatively even collapse, the difference being that the tiles found inside the building fell on top of other material, probably debris from the roof's structure and dissolved mudbricks from the top of the walls. The tiles found outside the 'central room' landed directly on the floor of the corridor. Given the orientation of the tiles and the fact that no fragments were found to the west and south of wall no. 2, it appears that part of the roof collapsed inside the 'central room', while another part of it slid to the east, hitting the west wall of the 'burnt room' ${ }^{49}$

No tiles were recovered from trenches $\Theta$ and $\Sigma T$ and south of wall 2 in trench A, including the area of the drain. Also, no tiles were found inside the 'burnt room' (in both excavations, 1982 and 2008). Instead, clay fragments, most likely belonging to the sheathing of the room's roof/ceiling were found (Fig. 14). The best-preserved example $(\Delta 15,13 \times 18 \mathrm{~cm}, \mathrm{Ht} .10 .5 \mathrm{~cm}$, impure clay with inclusions) bears on its surface the imprints of six reeds (diameter: 0.7$1.2 \mathrm{~cm}$, max. L: $16.5 \mathrm{~cm}) .{ }^{50}$ The fact that no imprints of this kind were discovered inside the 'central room' could add further weight to an idea entertained a few years ago by Galanakis that the 'sheathing' often mentioned in association with tiled roofs ${ }^{51}$ may not have constituted common practice in Mycenaean times. ${ }^{52}$ At least in the case of the Theodorou plot, the tiles may have sat directly on rafters and the roof's timber frame and kept in place by their weight. This 'sheathing' might have been more appropriate as floor/ceiling packing of the first storey and as packing of flat roofs, thus providing the structure with which it was associated with additional insulation and protection. ${ }^{53}$

There is a higher number of pan tile fragments in relation to cover tiles. Plotting the percentage of large fragments (equal to or larger than the median length, as recorded in Table

\footnotetext{
48 If we add to this group, the $60.37 \mathrm{~kg}$ of body sherds belonging to pan tiles (the median weight of which is $8.85 \mathrm{~kg}$ ) then ca. 7 more tiles can be added to this group raising the maximum number of pan tiles to 124 . Since, however, most of the nonmendable body sherds from pan tiles may well come from the 117 possible individual examples mentioned above, we consider the latter number as more trustworthy for the purpose of our analysis here.

${ }^{49}$ Spyropoulos $(1970 c, 214-15)$ and Sampson $(1985 ; 1996,114)$ both observed separately very similar distributions in the Stavris and the Loukos plots, which they attributed to an earthquake that shook the buildings resulting in their roof collapse and destruction.

${ }^{50}$ Imprints of reeds on a burnt clay plaster are mentioned in the context of fallen ceiling timbers in room $\Pi$ in the 'House of Kadmos': Keramopoullos 1927, 39; Dakouri 1998, 132. On similar examples, with additional references, see Darcque 2005, 124-6.

${ }^{51}$ Adopted in Mycenaean scholarship by Iakovidis (1990) from the ancient Greek word $\delta o ́ \rho \omega \sigma l \varsigma$.

52 Galanakis 2016, 164. This option, tiles laid straight on a lattice of reeds or laths over rafters fastened to the ridge pole, is also in agreement with simple, traditional building in Greece (Iakovidis 1990, 156, fig. 11). Although acknowledged as an option by Iakovidis (also 2001, 136), he nevertheless preferred the second alternative, i.e. that Mycenaean tiles might have been placed on a clay-packed sheathing of reeds or twigs spread over a lattice and forming a sort of a ceiling. We believe that whatever timber-frame system was used, it would have allowed repairs to be made (and we take into account the point raised by Sapirstein 2008, 314, n. 773 that tiles 'would be too fragile to have been unsupported-the pans would crack under the weight of a workman repairing the roof.'

${ }^{53}$ E.g. at Gla too, similar imprints were not found in association with tiles (without context: Iakovidis 1989, 225, pl. 77 $\gamma$; and from room H3, Iakovidis 1998, 34, fig. 21ß). See also Dakouri-Hild 2001, 93. The ongoing excavations at Gla could shed more light on this issue.
} 
4) against all fragments reveals that the largest pieces came from those trenches that yielded the most fragments, but also from trenches H (for both types) and E-Z (for pan tiles), i.e. the open space between the two buildings in the Theodorou plot. Another interesting point is that while trench $\Gamma$ has yielded more cover and pan tile fragments than trench $\mathrm{H}$, there is a higher degree of fragmentation in the former, with larger pieces actually preserved mostly from the area outside of the 'central room' (i.e. trenches $\Delta$-E, E-Z, H). Larger pieces found outside the 'central room' make ca. $23 \%$ of the total studied assemblage for cover tiles and $28.70 \%$ for pan tiles, as opposed to trenches A- $\Gamma$ inside this building, where the percentages for larger fragments are $13.6 \%$ for cover tiles and $11.9 \%$ for pan tiles. ${ }^{54}$ That the tiles from inside the 'central room' present a higher degree of fragmentation probably relates to the fact that they fell on top of collapsed material, including bricks, stones and timber, ${ }^{55}$ as opposed to the tiles in the open space which fell straight into the ground and against the south wall of the 'burnt room'.

What does this distribution tell us about how the tiles fell and consequently how they might have originally been affixed to the roof? The complete lack of imprints and clay packing suggests to us that, in this case at least, the tiles were placed on rafters and battens and purlins without any bedding, a practice well-attested in Greek vernacular architecture. The axis (ridge) of the roof followed that of the building (W-E).

If the 'central room' was equipped with a mono-slope roof, then it appears that approximately one third of the roof may have fallen on the floor level of the open space between the 'central room' and the 'burnt room' (i.e. it slid away) in equal more or less numbers of cover and pan tiles (every two pan tiles requiring an almost equal amount of cover tiles to cover their sidewalls over for insulation). The other two thirds caved in falling inside the 'central room' that already had debris from the structure's collapse. The destruction appears therefore powerful and might be attributed to an earthquake (see also below similar observations by other excavators at Thebes). ${ }^{56}$ Inside the room, pan tiles are significantly more frequent that cover tiles. Cover tiles were generally recovered in smaller pieces than pan tiles, suggesting perhaps a higher degree of fragmentation from the fall (they are also lighter, thinner and their shape is more susceptible to this pattern of breakage). It is also possible that some cover tiles did not sink in as much as heavier pan tiles that landed on the collapsed debris of the 'central room' (i.e. some cover tiles stayed higher up and may have been destroyed by post-BA activity in the area). If, however, the 'central room' originally had a two-sided pitched roof, then it appears that part of its northern slope ended up in the open space between the two buildings, while another part fell onto the walls and inside the 'central room'. While most of its south slope may have indeed caved inside the 'central room', the complete lack of any tiles whatsoever from the south side of the building remains a mystery as one would have expected at least a small number of tiles to have ended up there. ${ }^{57}$

\footnotetext{
${ }^{54}$ If we include the non-mendable fragments, it is worth noting that in trenches $\mathrm{B}, \Delta-\mathrm{Z}$, the percentage of cover tiles is significantly higher (trench $\mathrm{B}=61.25 \%$ of pan tile fragments as opposed to $38.75 \%$ of pan tile fragments; trenches $\Delta$-Z: $77 \%$ cover tile fragments as opposed to $23 \%$ of pan tile fragments). In our view, these percentages may add weight to the idea that the pan tiles, more or less, landed close and in relation to their position on the roof, while cover tiles became more fragmented by the impact of the fall resulting in their dislocation and wider distribution.

55 All tiles were found in the destruction fill $(50 \mathrm{~cm}$ in height), which corresponds with the preserved height of the walls of the 'central room'. Any material that may have existed higher up, would have been removed by later activity detected in the area (i.e. post-Bronze Age).

56 The destruction layer, as we believe, was not formed as a result of gradual, natural, decay (e.g. in some of the examples discussed by Papadopoulos 2013) or post-abandonment formation processes. It is a homogenous layer accompanied by fire of uneven intensity and spread. Considerable amounts of material culture were sealed by the collapse of the roof, which fell straight onto the corridor floor (between the two identified structures in the Theodorou plot) and inside the 'central room' and over the latter's structural debris. The distribution of tiles is also compatible with seismic movement. It is possible that some intact tiles may have been removed and reused following the destruction of the 'central room', with the remaining material abandoned in rubbles.

57 To account such a discrepancy, an alternative cause of destruction should be hypothesised, one that could also account for the current state of fragmentation and distribution of the tiles; also, that material from the south side may have been removed/disturbed by later (post-Bronze Age) activity, which is detected in the area.
} 
For the two reconstructions we put forward here, we hypothesize a $25^{\circ}$ two-sided tiled roof with eaves ${ }^{58}$ (Figs 15 top, 16 top) and a mono-slope or 'lean to' roof set at an angle of $15^{\circ}$ (Figs 15 bottom, 16 bottom). With the height of the side walls set at $2.45 \mathrm{~m}$, a two-sided roof would have increased the overall height of the building by ca. $60 \%$ (with $1.45 \mathrm{~m}$ occupied by the roof structure and tiles). The total height of the structure in this case, from floor to the top of the ridge, would have been ca. $3.90 \mathrm{~m}$. In the case of the mono-slope, if the angle was set at $15^{\circ}$ (in order for it to be effective for the purpose it was built, i.e. to drain water), then the roof would have increased the height of the south side of the building by ca. $64 \%$ (adding $1.56 \mathrm{~m}$ to the south wall and raising the building's total height to $4.01 \mathrm{~m}$ ). A lower slope (especially if under $10^{\circ}$ ) would be less effective but would maintain more or less a height between 3.50 and $4 \mathrm{~m}$ for this structure. At the other end would have been a mono-plane roof set at an angle of $20^{\circ}$ which would have raised (unnecessarily in our view) the total height of this, possibly single-story, structure to ca. $5.15 \mathrm{~m}$ (i.e. an increase of $210 \%$ in relation to the height of the sidewall). Given the distribution of tiles towards the northern side of the "central room' and in the corridor between the two structures, we have assumed here that the slope is from south to north (with the downside that all the water would have been drained in the open space between the two buildings making this 'corridor' area rather impassable on a rainy day; given the slope of the ground in the area, waters would then be carried downhill).

In the two-sided pitched roof, as reconstructed here, the distance between the top of the ridge and the side wall is ca. $3.30 \mathrm{~m}$ (i.e. easily bridged) as opposed to the $6.2 \mathrm{~m}$ for a mono-plane roof set at an angle of $15^{\circ}$, or $6.6 \mathrm{~m}$ if set at $20^{\circ} .{ }^{59}$ This would be a far more demanding distance to bridge without internal supports and we have no indication that any such supports ever existed inside the 'central room'. This issue, therefore, could lend a bit more weight to the two-sided roof hypothesis, hence our indecision in committing to one or the other as both have advantages and disadvantages archaeologically and architecturally. The fact that only one wall was very thick may, for example, add support (though not exclusively) on the monoslope roof reconstruction for the 'central room'. The sloping ground in the area, with a S-N direction (Map 2, inset) could also add weight to this scenario, with the water falling in the open area between the 'central room' and the 'burnt room' (in this case, the drain ${ }^{60}$ to the south of the 'central room' may be unconnected to this building). The distribution of tiles is also more in agreement with the mono-slope hypothesis. Although we consider the monoslope roof probable, we also recognize that it is impossible to settle this issue completely with the extant evidence and we keep both options open.

In the case of a mono-slope roof, the area needed to be covered in the excavated part of the 'central room' (with the slope set at $15^{\circ}$ ) is estimated at 46.15 sq.m. Some 240 cover tiles would have been required, perhaps with another 17 to span the ridge. The roof would have also required some 192 pan tiles. The total weight of tiles for the mono-slope roof is estimated at $2.15 \mathrm{tn}$. Based on these numbers and the estimated number of tiles given about, the preservation percentages for a mono-slope roof range between $17.1 \%$ (minimum) and $43 \%$ (maximum) for cover tiles, and 34.9\% (minimum) and $61 \%$ (maximum) for pan tiles.

In the case of the two-sided pitched roof set at $25^{\circ}$, the area needed to be covered is slightly larger, ca. $49.7 \mathrm{sq} . \mathrm{m}$. Some 270 cover tiles would be required to cover this roof and some 210 pan tiles, along with 17 cover tiles for the ridge. The total weight of tiles for the mono-slope

\footnotetext{
${ }^{58}$ A pitched roof with an angle ranging between $15^{\circ}$ and $30^{\circ}$ is ideal in a Mediterranean climate. Larger angles are more appropriate for areas with considerably more snowfall (Wikander 1986). An interesting confirmation for pitches roofs at this angle in Mycenaean times actually comes from rock-cut chamber tombs: those with a two- or four-sided pitched roofs display angles consistently between $15^{\circ}$ and $30^{\circ}$ (Galanakis 2016, 162, with the measurement taken, from the few published drawings, at the eaves). For pitched roofs in Aegean LBA contexts (not necessarily tiled) see also Darcque 2005, 126-8, with additional literature.

${ }^{59}$ Spans over $5.8 \mathrm{~m}$ were possible but considered very demanding in Classical times due to the materials required: Orlandos 1966, 21-23.

60 The drain may have actually been originally covered with stones, as in the segment discovered in the nearby A. Theodorou plot (15 Pindarou Street): Faraklas 1967, pl. 159 $\alpha$.
} 
roof is estimated at $2.35 \mathrm{tn}$. In this case the preservation percentages for a two-sided roof range between $15.3 \%$ (minimum) and $38.3 \%$ (maximum) for cover tiles, and $31.9 \%$ (minimum) and 55.7\% (maximum) for pan tiles. Whatever the form of the roof, however, these numbers offer for the first-time irrefutable evidence for the existence of a tiled roof in a Mycenaean context. The amount of carbonised matter, including remains of charred timber from the excavation, reinforce this interpretation further. The question remains, however, as to why this structure needed a tiled roof, when the adjacent 'burnt room' seems not to have required it. Before returning to this question, it is worth examining first the form and construction of the tiles and their contexts of discovery in Mycenaean Thebes.

\section{Cover tiles}

\section{CONSTRUCTION, FORM, FABRIC}

Cover tiles first appear in the Aegean in the 14th c. BC, most likely forming a technological novelty of the time. ${ }^{61}$ Their inspiration may have come from cylindrical drain tiles. ${ }^{62}$ The cover tiles from the Theodorou plot are semi-cylindrical in shape and wheel-thrown (Fig. 17). Wheel marks, in the form of regular parallel grooves, are clearly visible on almost all examples inside, and in some examples also on the outside.

To make one of these cover tiles, the tile-maker threw clay onto the wheel which (s)he then pulled and raised to form a conical tube (cylinder). The upper end of the tube was then shaped with the help of the wheel to form a rim (sometimes raised and everted, other times plain), narrower than the width of the tube's flat hollow base (Table 5, W1-W2). This tapering (representing almost $30 \%$ difference in width between rim and base) allowed cover tiles to fit inside the wider front edge of the tile ahead. ${ }^{63}$ Finger and hand prints, as a result of the shaping and handling, are attested in numerous cover tiles. The walls of the cover tiles may differ in thickness as well as height (e.g. one side may often be a bit taller than the other side: Table 5). Not infrequently, some of the cover tiles are a bit wider in the middle than at the base or the top. ${ }^{64}$ Yet when all cover tiles are compared from the Theodorou assemblage, the thickness of their walls comes up as relatively consistent with 138 of the 181 cover tiles that we could measure ranging in thickness from 0.9 to $1.5 \mathrm{~cm}(76.2 \%$ of the sample studied). ${ }^{65}$

In almost all of the examined cover tiles, a slip was applied on the outside, i.e. a diluted clay solution appearing as a matt cover on the surface of the tile, giving them a smoother feel. The extra care given to cover tiles may also be explained by an effort to reduce permeability of the surface. ${ }^{66}$ The inside of the tube is left untreated. Only 11 of the 222 entries displayed a rough, untreated surface inside and outside $(<5 \%)$ and may constitute repairs (or reuse as suggested in the Appendix). The base of the tube is generally flat, but we noticed a few exceptions. E.g. a rim appears on the wide end of cover tile K210.02 (K5), i.e. the reverse of what appears in the majority of cases (Fig. 18). Could this have belonged to one of the tiles

\footnotetext{
${ }^{61}$ In appearance, Mycenaean cover tiles resemble the later Laconian tiles, and also their south Italian variants and the Roman imbrex type: Orlandos 1966, 84, fig. 56. The form of the tiles said to be of an early LBA date from Kirrha (Table 1) is not known.

${ }^{62}$ E.g. cylindrical drains, resembling cover tiles but being a bit wider $(22-25 \mathrm{~cm})$ and considerably longer (ca. $\left.60-70 \mathrm{~cm}\right)$, are known from LBA Thebes: e.g. Aravantinos 2018, 163-5, drawings 8-9 and figs 50-51 (at the same level as the LH IIIB2 destruction and underneath post-palatial wall remains). They are also known from Zygouries and Pylos (Darcque 2005, 8081 , who also correctly notes that these objects can be confused with cover roof tiles if found in fragments or out of context). Sapirstein 2008, 54 advances the idea that cover tiles may have developed from wheelmade chimney pots.

63 Sometimes cover tiles are equipped with a properly formed lip around the rim. The different rims observed in cover tiles could help establish artisanal traditions with regards to the manufacturing of cover tiles.

${ }^{64}$ For comparison, an intact cover tile from the Stavris plot at Thebes has the following measurements (all in cm): L. 36.2; external W1 (rim) 9.4, External W2 (base) 15.5, External W body 11.6, Internal W1 (rim) 8, Internal W2 (base) 13.1, Thickness End 1 (rim) 0.6, Thickness End 2 (base) 0.9, Thickness side: 1-1.12, Height End 1: 4.9, Height End 2: 7.1, weight: $1.2 \mathrm{~kg}$

${ }^{65} 14.4 \%$ of the examined material displaying a thickness $<0.9 \mathrm{~cm}$ (26 examples), while 17 examples display a thickness $>1.5 \mathrm{~cm}(9.4 \%)$.

${ }^{66}$ Rice 2015, 162-164, who considers the slip as applied before firing, with the wash applied after firing.
} 
set on the ridge if a two-sided roof covered the 'central room' over? In some examples, pressure exercised on the tube from above appears to have distorted and dented the appearance of its base. ${ }^{67}$ When still relatively wet, the tile-maker with the help of a string/wire, or a toothed cutting tool (e.g. a small saw), to judge by the marks clearly visible on the sides of the studied cover tiles (Fig. 19), cut the tube lengthwise to create two cover tiles. The cover tiles were then left to dry before firing. ${ }^{68}$ The firing of cover tiles is generally more even than that observed in pan tiles, perhaps also as a result of the better arrangement of tiles in the kiln. Discolouration on a few cover tiles may have resulted from uneven firing, or as a result of the fire that accompanied the destruction of the area.

Although different sizes can be observed in cover tiles (Figs 12, 18; Table 5), ${ }^{69}$ along with varying degrees of quality and execution, including some differences in morphology, e.g. the formation of the rim - possibly the result of different needs, episodes of tile-making and different people at work - a specific know-how/manufacturing technique appears to be at play in the making of cover tiles. In this respect, cover tiles are suggestive of a specific technological 'tradition': e.g. in the selection and processing of the well-sorted fine clay, their tempering, and interest of the tile-makers in the overall appearance of these tiles.

We identified only one fabric group macroscopically in relation to cover tiles, ${ }^{70}$ which we call the 'semi-fine grain fabric group'. Inclusions are few or moderate $(5-10 \%)^{71}$ and smaller in size than those observed in pan tiles $\left(<2 \mathrm{~mm}\right.$, sand-size in $95 \%$ of the studied sample) ${ }^{72}$ Rather unusually for tiles, the clay is generally well levigated.$^{73}$ Few spherical voids are visible (resulting from oolite or limestone bursting/powdering when a particular firing temperature is reached: Appendix, Fig. 33b,c,d). The clay source used in the making of the examined cover tiles appears to be the same as that used for the making of pan tiles (this source contains limestone and chert-sandstone inclusions naturally, as the study of Valantou and Zacharias suggests). Apart from the processing of the clay, which resembles that of fine pottery at Thebes (not least as both were wheel-thrown), no temper appears to have been added in the making of cover tiles (also supported microscopically). Firing in both of these groups ranges from incomplete to complete oxidization as suggested by the studied sections, with most cover tiles displaying even firing ( $85 \%$ of the studied tiles). Temperatures for the firing of cover tiles, on the small number of examples sampled ranged from 800 to $950^{\circ} \mathrm{C}$ (i.e. a slightly smaller temperature range than pan tiles: also, Appendix).

\section{Pan tiles}

\footnotetext{
${ }^{67}$ E.g. in K807.02 (K20).

${ }^{68}$ After firing tiles would have increased slightly in size $(<1 \%)$ and would have also become a bit lighter (estimated 4-6\% weight loss). A lot depends on the clay and temper used and experiments are necessary. On experiments of later tiles see Rostoker and Gebhard 1981; Sapirstein 2008, with detailed measurements.

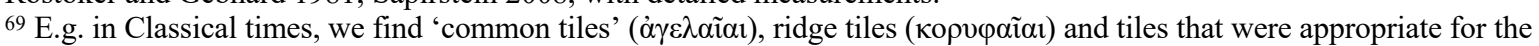

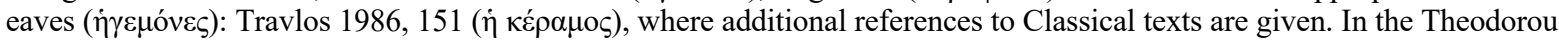
assemblage, it is not possible to establish the frequency of these different-sized tiles in the Theodorou corpus for two reasons: the fragmentation of the material, and the fact that there is no stable ratio in the length of a cover tile and its width or thickness. On the different sizes of cover tiles in the Argolid see Küpper 1990, 106-109 and 134-6.

70 The broad composition of the clay pastes used in the making of cover and pan tiles is similar microscopically. It is for this reason that we prefer to use the term 'fabric group' here. Fabric groups tend not to be petrographically distinctive and may represent products made from different clay sources or products made from the same clay source processed in a different fashion. We think that the latter case best describes our material. These clay sources tend to be of a broadly similar character and composition, suggesting the same regional origin, as we believe is the case for the cover and pan tiles from the Theodorou assemblage (also Appendix).

${ }^{71}$ Based on Orton and Hughes 2013, 282, Fig.A4 (after Mathew, Woods and Oliver 1991).

72 Most of these inclusions range from $0.2 \mathrm{~mm}$ to $0.5 \mathrm{~mm}$, which would fall between 'fine' and 'medium' size of inclusions according to the USDA conventionally used for standard sizes for sand grains and pottery characterisation: Orton and Hughes 2013, 281. It is for this reason that we call this fabric group 'semi-fine'.

${ }^{73}$ Santacreu 2014, 174 who notes that, normally, tiles are not well levigated as this aspect could weaken their effectiveness and stability.
} 
Pan tiles are attested in the Aegean as early as EH II (made of stone or clay) ${ }^{74}$ but the shape we find in the LBA, with the raised sidewalls (' $\pi \alpha \rho \alpha \chi \varepsilon \imath \lambda \omega \tau \varepsilon \dot{\varepsilon} \varsigma \kappa \varepsilon \rho \alpha \mu o{ }^{\prime}$ ' in Greek literature), appears to be a development of the 14 th c. BC. ${ }^{75}$ The inspiration for this particular shape may have come from rectangular drains, as already suggested by Sapirstein. ${ }^{76}$ As with cover tiles, therefore, pan tiles of this specific type also appear to be a novelty of this particular period (Figs 13, 20). There is variation in the size and weight of pan tiles (with more than $15 \mathrm{~cm}$ difference in length and at least $2.5 \mathrm{~kg}$ difference in weight between the smallest and the largest examples) (Fig. 21, Table 6). ${ }^{77}$ This variation probably existed to accommodate different needs (e.g. the different position of tiles on the roof and the idiosyncrasies of the areas that needed to be covered) but probably also represents repairs/reuse and different people at work (Table 6) ${ }^{78}$ More consistency is observed in their thickness, where 248 of the 344 pan tiles that we were able to measure have a thickness of $1-2 \mathrm{~cm}(72.1 \%) .{ }^{79}$ No mould appears to have been used in the making of these pan tiles (no two tiles are alike, same as with cover tiles).

All pan tiles are handmade and roughly trapezoidal in shape (with their short sides having unequal length). On their long sides, low upright sidewalls (i.e. 'curbs' or 'flanges') were raised by hand. The sidewalls are mostly vertical, but there are also examples where they lean outwards (i.e. away from the pan, $<5^{\circ}$ ). The borders of the short sides of the sidewalls curve smoothly downwards (we were able to observe at least four different types of sidewalls). The sidewalls were straightened and flattened by hand, and only rarely perhaps with the help of a flat tool (e.g. a piece of flat timber or something similar). A slight tapering is observed between the wide (W1) and narrow end (W2) of pan tiles (representing a difference of $11 \%$ in width on average in the intact examples). This tapering would allow pan tiles to slide into each other thus fixing them in place (Fig. 22; Table 6). We consider the narrow end of the cover tile to be the base and the wider end to represent the top. ${ }^{80}$ Most examples we examined feature a flat underside, but there are also examples where this part of the tile slightly curved upwards (as in the example shown in Fig. 13, section a- $\beta$, perhaps also a result of how they dried).

The study of the Theodorou tiles has yielded a hitherto unattested technical detail in Mycenaean tile-making: some sidewalls of pan tiles (about 14 in all) bear a 'nail-hole' (ca. $0.5-0.9 \mathrm{~cm}$ in diameter) on the surface of the sidewall and near one of the two ends of the pan tile (Fig. 23). ${ }^{81}$ This feature appears only on sidewalls and never on the surface of the pan tile. All the examined examples preserved the hole intact. These holes were made before firing, perhaps with the help of a piece of reed and with the aim to tie with a rope or string two pan tiles together in order to keep them in place. ${ }^{82}$ In this case, however, we may have

\footnotetext{
${ }^{74}$ Cf. the EH II 'House of Tiles' at Lerna (Wiencke 2000); also, Jazwa 2018 for a recent synthesis of the evidence. EH II pan tiles are considerably smaller than the Mycenaean examples and are of different morphology and manufacture.

75 In appearance, Mycenaean pan tiles resemble their Laconian counterparts, and also their south Italian variants and the Roman tegula type: Orlandos 1966, 84, fig. 56.

76 Sapirstein 2008, 54. For examples of drains see n. 11 above; also, Darcque 2005, 80-81.

77 Outside of this small group, however, it is not possible to establish the frequency of these different-sized pan tiles in the Theodorou corpus for the same reasons given above for cover tiles: the fragmentation of the material, and the fact that there is no stable ratio in the length of a cover tile and its width or thickness. Küpper (1990, 106-109, 134-136) in his study of tiles from the Argolid (Tiryns, Chania and Midea) identified at least three different size groups.

${ }^{78}$ Iakovidis 1990, 156, n. 67, who notes that mould-pressed tiles from 19th century houses in the modern village of Mycenae (resembling Mycenaean cover tiles) were the only ones used to cover the roof. They were $40 \mathrm{~cm}$ long, $1 \mathrm{~cm}$ thick and had diameters of 12 and $15 \mathrm{~cm}$ at their two ends.

7967 examples display a thickness $>2 \mathrm{~cm}(19.5 \%)$, while $8.4 \%$ of the examined tiles have a thickness $<1 \mathrm{~cm}(29$ examples).

${ }^{80}$ For comparison, we note here two intact pan tiles, one from the Stavris plot and one from the Liangas plot at Thebes (all measurements in $\mathrm{cm}$ ). Stavris pan tile: L. 53.6; external W1 (wide): 46.5; external W2 (narrow): 42.7; external W body: 44.7; internal W2 (wide): 43.7; internal W1 (narrow): 39.3; thickness end 1: 1.9; thickness end 2: 1.9; thickness side: 1.8; sidewall height 1: 5.7 ; sidewall height 2: 5.7 ; weight $8.5 \mathrm{~kg}$. Liangas pan tile: L. 55.2; external W2 (wide): 49; external W1 (narrow): 37; external W body: 43; internal W2 (wide): 45.5; internal W1 (narrow): 33.5; thickness end 1: 2.2; thickness end 2: 1.8 ; thickness side: $1.8-2.2$; sidewall height $1: 5.2$; sidewall height $2: 5.6$; weight $8.5 \mathrm{~kg}$.

81 The hole is indeed small in diameter. One wonders, how effective these 'nail-holes' were given the weight of pan tiles. On nail-holes in tiles, though not identical and of a later period, see Sapirstein 2008, 316-317.

82 No combination tiles were found in the Theodorou plot (combination tiles are known from the Archaic period onwards: Sapirstein 2008, 60-68). We also have no evidence for the existence of a special ridge type - if used, they may have simply
} 
expected at least a few of these holes to have been found broken (e.g. due to the impact of the collapse of the roof; we were able to identify only one such breakage, in $\Sigma 216$ [ $\Sigma 210.60$ This feature could also represent a form of repair, though similar breakages would have been expected with the fall of the roof and no repair clamps or brackets are preserved. 'Nail-holes' are limited and most of them were found on tiles that were discovered inside the 'central room' (most of them were actually found close together in trench B, eight examples; four more examples come from trenches $\mathrm{A}$ and $\Gamma$, while two were found among the tiles outside the central room in trenches $\Delta$-E). Could this effort relate to the uppermost row of tiles? As mentioned above, Mycenaean roof tiles, unlike Classical ones, were probably placed straight on the roof's timber frame. ${ }^{83}$ The narrow end of the pan tile above was inserted in the wide end of the tile below thus locking them in place. The fact that rows of interlocked pan tiles were largely kept in place by their own weight would additionally suggest an inclination of $15-25^{\circ}$ for the roof (i.e. a safe angle that would have protected them from sliding).

The process of making a pan tile starts by getting the right material. Our macroscopic and microscopic observations (the latter applying to a small sample only) suggest that both pan and cover tiles were made using similar, if not identical, sources of clays. The clay in pan tiles, however, was tempered with organic matter (straw) and possibly also with stone inclusions, perhaps to strengthen and protect it further during the making and firing process (the inclusions of stones as temper was largely macroscopically ascertained due to the very small sample of pan tiles that were petrographically examined, one of which appears to support the suggestion put forward here: Appendix) ${ }^{84}$ Some kind of support may have then been used for the preparation of the tile, though clearly most of the process involved spreading the clay by hand, smoothing the upper surface and shaping the sidewalls by raising and hand-shaping the clay. ${ }^{85}$ Similar, however, as the shape may be, there are notable differences in the final quality of the studied pan tiles: e.g. the sides are not always even, there are differences in the thickness, height and overall shape of the tiles examined, while some sides have a rectangular section and others a cylindrical one.

Given their size and weight pan tiles were most likely made on a flat surface. The underside of pan tiles (mostly or roughly flat, but in some examples slightly curved as noted above) often contains small stones, imprints of twigs and straw, probably from the surface they were worked on or the area they were left to dry - a relatively even piece of ground (Fig. 24; the 'veined' appearance of the underside of some pan tiles most likely also relates to the drying process). This part of the tile is rougher when compared to the, often but not always, smoothed (by hand) upper surface. Apart from numerous fingerprints, mainly observed on the surface of the tiles especially the upper surface and sidewalls of pan tiles, we also noted the presence of numerous animal footprints (particularly from lambs) and the footprint of an infant, ca. 11-12 cm long (perhaps 12-18 months old) (Fig. 25). ${ }^{86}$ All these prints were created before the tiles were fired offering us glimpses on the manufacturing process and their associated 'life biographies'.

been cover tiles of a slightly different size to those used on the sloping sides of the roof (variation in size of cover tiles could support the latter interpretation and is also supported by practices in vernacular architecture).

${ }^{83}$ Clay packing may have helped with insulation, but there is often no need for it as traditional architecture suggests: (e.g. in the Karditsa region: http://5a.arch.ntua.gr/project/15616/15853 and http://5a.arch.ntua.gr/project/15571/15836, last accessed 12 July 2020).

${ }^{84}$ Santacreu 2014, 168 and 175, who observes that the addition of temper, among other things, accelerates the drying time of waterproof structures and improves drainage, making them (as much as possible, given that they are tiled) lighter. The use of organic matter to temper these tiles could have enhanced their plasticity further, reduce shrinkage and prevent breakage in the drying process.

85 E.g. unlike EH II tiles (Jazwa 2018), Mycenaean pan tiles, at least those from Thebes, are not mould-made. The outer surfaces of a few sidewalls are, more or less, straight in a number of examples as opposed to the more raised inner surface this aspect could suggest that in a few instances, at least, some kind of a wooden board was used to help straighten and smooth the sidewalls of pan tiles.

${ }^{86} \Sigma 315.01$ ( $\left.\Sigma 15\right)$ : restored from 5 fragments. Body thickness $1.8 \mathrm{~cm}$. Also visible are fingerprints on the top surface and at least seven prints from hooves. Imprints of plants and grass visible on the underside. An attempt was made to straighten the sidewalls. On top of the sidewall, we notice dents possibly from an attempt to lift/hold this part of the tile; see also Fappas 2018, 318, entry no. 172 . 
The clay surface on the upper side and on the sidewalls of pan tiles, when they were still wet, were often smoothened by hand or a wet rag of some sort, as several marks on the tiles suggest. In most instances, a slip has been applied on the sidewalls and on the upper surface of the pan tile (similar to the slip observed in cover tiles), sometimes thick and sometimes thin. The slip added an extra layer on the surface reducing this way further the permeability of the tile's most exposed parts to the elements. ${ }^{87}$ The underside remains in all examined cases rough. The overall appearance of pan tiles is rougher when compared to that of cover tiles. Although different sizes can be observed in pan tiles, along with varying degrees of quality and execution, possibly as a result of different needs, episodes of tile-making, and different people at work, there is also evidence to suggest that these tiles adhered to specific know-how/manufacturing techniques: e.g. in the selection of clay, tempering, and the interest in the pan tiles' external appearance.

The clays used for the making of pan tiles, as mentioned above, appear the same as those used in the making of cover tiles (also Appendix). Two fabric groups can be identified macroscopically in the pan tiles from the Theodorou assemblage. In the first group, which we call the 'very coarse grain fabric group', inclusions are common and often numerous (20$30 \%)$, larger in size than those observed in cover tiles $(0.5$ to $4 \mathrm{~mm}$ in ca. $95 \%$ of the studied material), and with organic matter as additional temper, judging by the frequent voids on the body of the pan tiles (the organic matter probably acted as a binding agent that could have helped the clay from cracking during the drying stage of the tile, therefore adding strength to the ceramic object). ${ }^{88}$ About $40 \%$ of the pan tiles examined display characteristics consistent with this group (Appendix, Fig. 33f,g,h,i). The second group associated with the pan tiles, that we call the 'coarse fabric group', displays characteristics that resemble both those in the 'fine grain fabric group' of cover tiles and in the 'coarse grain fabric group' of pan tiles. The paste of this group has more and larger inclusions than in the 'fine grain fabric group', moderate to frequent in distribution (10-20\%, normally between 1-2mm). Moreover, the 'semi-coarse fabric group' displays frequently horizontal and irregular voids, a consistent characteristic of the 'very coarse group' as a result of the inclusion of organic matter in the temper (Appendix, Fig. 33a,e). Firing in both of these groups ranges from incomplete to complete oxidization as suggested by the sections of the studied tiles, with more pan tiles (44\%) showing incomplete firing than cover tiles (where the percentage is only 15\%). Also, both groups include tiles that are more carefully made and have a fine slip on their surface, while others are more crudely made and display less attention to detail making us wonder as to whether these discrepancies could relate to repairs/reuse and/or the position of the tiles on the roof $^{89}$ (Fig. 32, where the different quality of execution in the making of pan tiles can be observed). Temperatures for the firing of pan tiles, on the small set of examples sampled ranged from $<800$ to $950^{\circ} \mathrm{C}$ (Appendix).

In terms of fabric, firing, surface treatment, and production modes (especially for cover tiles), there are similarities between these objects and the pottery produced in LH IIIA-B at Thebes. This overlap in the clays used and the surface treatment of ceramics and tiles possibly suggests, at a macroscopic and microscopic level, a very close relationship between potters and tile-makers, who may well have been one and the same in the 14 th and 13 th c. BC. ${ }^{90}$ It is worth noting that the few existing studies on LH IIIA-B ceramics (all on finewares) from

\footnotetext{
87 The thickness and quality of the slip varies in both cover and pan tiles, but it is more consistently applied on the former than on the latter. This is also observed in the tiles from Gla: Iakovidis 1989, 247-8; 1990; 1998, 131-3; 2001, 135-7. It is worth noting that the Lefkandi examples (LH IIIC) are even coarser, an indication of variation in practice (ranging from very fine or fine finish to rough or very rough; I.S. Lemos and A. Livieratou, pers. comm.).

${ }^{88}$ Guest-Papamanoli 1978, 6, who also notes that straw is used in the making of mudbricks. We observe both elongated voids with striations down length, a result of the decomposition of grass or straw and irregular voids, most likely of calcite as also suggested by the microscopic study by Valantou and Zacharias (Appendix).

${ }^{89}$ E.g. most of the fine examples appear to have indeed come from the corridor area (trenches $\Delta-Z$ ), but a few fine examples were also found inside the central structure: e.g. $\Sigma 216.52(\Sigma 12) /$ TH8 from trench B.

90 On LH IIIA-B pottery see Andrikou 2006; also, Appendix. Given the similarities between drains and roof tiles, it seems sensible to us that the people who made the former also made the latter applying very similar skills in both cases.
} 
Thebes suggest a prevalence of pink clay (in varying tints and containing white grips or flakes) in the making of these vessels, followed by a secondary group using yellow/brown (often pale or buff) clay. ${ }^{91}$ Andrikou, who has recently published the Mycenaean pottery from the Pelopidou Street excavations, is of the opinion that a local pottery workshop at Thebes was in operation at the time. ${ }^{92}$

\section{THEBES: MYCENAEAN ROOF TILES IN CONTEXT}

Although it is reasonable to assume that a combination of roofs was in use in the LBA Aegean, the existence of tiled roofs has been the subject of heated controversy and debate since the beginning of Aegean archaeology. ${ }^{93}$ As mentioned at the start of this paper, questions regarding the use of 'Mycenaean tiles' as 'roof tiles' were raised primarily on the basis of their small numbers recovered in excavations and their overall scarcity in Mycenaean domestic contexts, palatial or otherwise. Tiles are easily adaptable and may have served a number of other purposes, e.g. from insulation to drainage. They may have also been discarded in early excavations, where the emphasis was largely on fineware pottery as already noted above. Whatever the case might be, however, and given the huge numbers of tiles frequently recovered in later contexts (e.g. Archaic, Classical, Hellenistic, Roman, and post-Roman), their use in Mycenaean times appears infrequent. In this section we attempt a brief review of the available evidence with regards to the possible use of roof tiles at Thebes in the Mycenaean period.

Apart from the Theodorou plot, five other main locations in the Kadmeia have yielded tiles (Map 2): a) the excavation in Agion Apostolon and Kadmou Streets and the Sotirios Koropoulis plot in the NW edge of the acropolis; $b$ ) the area around the 'House of Kadmos' (part of the old palace complex) and of the new palatial complex (with the 'Treasury room' forming part of it), including the nearby Liokis-Papastamelos, Antoniou, Stavris and Tzortzis plots); $c$ ) the Pelopidou Street area (including the Tsigris-Makris, Ploumis, Loukos and Stephas plots); $d$ ) the SE edge of the acropolis (Christodoulou-Liangas-Stamatis plots and the Elektrai gates); and $e$ ) the Dimitrios Koropoulis plot, not far from and to the NW of the Theodorou plot. In all contexts, tiles come from destruction layers accompanied by fire and associated predominantly with LH IIIB pottery (Table 7).

On the NW edge of the Kadmeia, in the Sotirios Koropoulis plot (Map 2, no. 1), 'many pan tiles' were found, and Mycenaean walls were noted in the area. The tiles came from the destruction fill, which dates to LH IIIB $1 .{ }^{94}$ Not far from this plot, and during infrastructure works in Agion Apostolon and Kadmou Streets (Map 2, no. 2), a Mycenaean building with a NE-SW orientation was partially investigated (wall A, the building's best-preserved element, had a width of $0.65 \mathrm{~m}) .{ }^{95}$ The most important discovery was a leaf-shaped tablet inscribed in Linear B near wall A, with this findspot representing the northernmost point of distribution of Linear B tablets in the Kadmeia. ${ }^{96}$ Apart from pottery, the dig also yielded a few small fragments of wall paintings, and roof tiles. Despite the salvage and partial nature of this investigation, Aravantinos put forward the idea that the finds from this excavation should be associated with Mycenaean workshop installations in the area. ${ }^{97}$

Spyropoulos was of the opinion that the 'baked flat slabs' mentioned by Keramopoullos in the excavations of the 'House of Kadmos' (part of the old palace complex at Thebes) were

\footnotetext{
${ }^{91}$ E.g. Andrikou 2006, 15-16 (on the Pelopidou Street material), with additional references; also, Demakopoulou and Crouwel 1984; Jones 1986, 134-8; Tzavella-Evjen 2014, 15.

92 Andrikou 2006, 15; also, Mommsen et al. 2002.

93 Galanakis 2016.

${ }_{94}^{4}$ Demakopoulou 1978; 1990, 314-16, fig. 6; Aravantinos and Fappas 2012, 935-6, n.1.

95 Aravantinos 1996.

96 Aravantinos 2015.

97 Aravantinos 1996.
} 
actually tiles $^{98}$ (Map 2, no. 3). Dakouri-Hild's identification of an undoubted (but unstratified) pan tile from the old excavations appears to confirm the presence of tiles. ${ }^{99}$ Pan tiles are reported from a mid-LH IIIB destruction fill excavated by the side of the Papastamelos and Liokis plots near the old palace of Thebes, ${ }^{100}$ where Mycenaean walls were also found ${ }^{101}$ (Map 2, no. 4). More remains came to light in this area, in the Tzortzis Plot (60 Pindarou Street) (Map 2, no. 5), where two Mycenaean rooms were revealed at a depth of $6.60 \mathrm{~m}$. Demakopoulou identified these remains with storerooms and an ivory workshop. ${ }^{102}$ The walls, with a NE-SW orientation, are carefully constructed with large stones and preserved to a good height ( $>1 \mathrm{~m}, \mathrm{~W}: 0.80 \mathrm{~m})$. Cover and pan tiles are mentioned among the destruction layer (LH IIIB1), which is accompanied by traces of fire (almost certainly associated with the destruction observed in the adjacent Papastamelos and Liokis plots).

The Stavris plot, perhaps an eastern extension of the new palace complex (Map 2, no. 6), yielded large quantities of pan and cover tiles ( $1 \mathrm{~m}$ deposit above the floor level) with most of them inside the walls of a building, and some in a corridor outside (as in the case of the Theodorou plot). ${ }^{103}$ Spyropoulos, the excavator of the Stavris plot, based on the distribution of tiles was led to hypothesize the collapse of this roof due to an earthquake (which might have been accompanied by fire, though in the case of the Stavris plot the fire was not as extensive as in the nearby plots or elsewhere in the city). ${ }^{104}$ Adjacent to the south of the Stavris plot, on the corner of Pindarou and Antigonis Street is the Antoniou plot (Map 2, no. 7): near the NE end of the plot, remains of buildings were found surrounded by an open area. ${ }^{105}$ Under the first (of three layers) found covering this open area, LH IIIB potsherds came to light along with a few clay figurines, stone whorls and beads, a bronze tweezer and fragments of tiles.

A bit further to the east is the Tsigris-Makris plot (Map 2, no. 8). There 'numerous fragments' (only of pan tiles) were found according to the information provided in the preliminary report. ${ }^{106}$ Although they are associated with a LH IIIB destruction layer with clear traces of fire, no walls or floors were identified in the area with which this material could be associated. In Dologlou Street, and very close to and to the west of the Pelopidou Street excavations, is the Ploumis plot (Map 2, no. 9). Part of a room of a Mycenaean building with a NW-SE orientation, was explored. Its walls, which were not that well-built according to the preliminary report, were ca. $0.50 \mathrm{~m}$ thick and had a preserved height of $0.90 \mathrm{~m}$. On the floor and amidst destruction debris, there were a few potsherds, along with white- and red-painted plaster fragments and numerous broken tiles. ${ }^{107}$

\footnotetext{
${ }^{98}$ Spyropoulos 1970c. Clay tiles, first referred to by Keramopoullos as 'fired bricks' (1909, 70 and 72), were actually found throughout the excavation and in association with rooms $\Lambda$, $\Xi$, and $\Pi$ in the 'House of Kadmos' (Keramopoullos 1927, 3940; Symeonoglou 1985, 43 and 223). Two complete examples measured $32 \mathrm{~cm}$ square and $0.3-0.5 \mathrm{~cm}$ thick, and $27 \times 26 \mathrm{~m}$ and $2 \mathrm{~cm}$ thick (i.e. different from all other known examples from Mycenaean Thebes). The function of these tiles is unclear. Keramopoullos believed that pan tiles were of Mycenaean origin, but he clearly states that these were not coming from a roof and probably formed part of a drain of sorts (Keramopoullos 1909, 70; 1917, 76-78). See also Dakouri 1998, 111-114. ${ }_{99}$ Dakouri-Hild 2001, 94, 'a handmade coarse pan tile with a gritty slip'; the potential (though uncertain) association of a tiled roof over some of the rooms where workshop activity is attested (Dakouri-Hild 2014, 166, fig. 6) is of interest as tiles appear to be associated with such spaces.

100 Spyropoulos $1971 \mathrm{~b}$.

101 On the construction of the roof of 'House of Kadmos' (old palace complex) see Symeonoglou 1985, 44-5 and Dakouri 1998, 111-116.

102 Demakopoulou 1979; 1990, 314, no. 12; on the date also Andrikou 2006, 56. On the various workshops around the Kadmeia, see Dakouri-Hild 2010; Demakopoulou 2014.

103 Spyropoulos 1970c.

104 Spyropoulos 1970c, 215 dates the destruction at the end of LH IIIB on the basis of deep bowls, which he does not illustrate. Given, however, the proximity of this plot to those on the other side of the road where LH IIIB1 destructions have been observed (and with a similar archaeological signature as that observed by Spyropoulos in the Stavris plot), we wonder whether the material from Stavris is not actually LH IIIB1/B2 early in date.

105 Touloupa 1964; 1965; Symeonoglou 1985, 233-4 (site 5).

106 Demakopoulou 1975b; Symeonoglou 1985, 303-304 (site 247).

107 Demakopoulou 1973-4c; Symeonoglou 1985, 293 (site 206).
} 
'A great number' of pan and cover tiles were found in deposit $2 \mathrm{~b}$ (where also Linear B tablets came to light) and deposit 1c in the Pelopidou Street excavations (1993-1995), near the Arsenal (Pavlogiannopoulos Plot) ${ }^{108}$ (Map 2, no. 10). A few more tiles came from deposits $2 \mathrm{a}, 3 \mathrm{a}$, and $3 \mathrm{~b}$. The pan tiles are said to be twice as many as the cover tiles, though no specific numbers are given. They were all found in fragmentary condition and a very small sample was selected from each deposit for publication (six pan tile and three cover tile fragments). Pan tiles are made from coarse clay and include large grits, and occasionally straw, as temper, with the upper surface being smoother than the underside. Dimensions (based on thickness and height of sidewalls) are identical to those from the Theodorou plot. Cover tiles were made of better levigated clay than the pan tiles and were covered with a slip. The importance here lies in that tiles are associated with three different destruction horizons: deposits $3 b-c$ are associated with a destruction at the end of LH IIIA2, deposits 2a-b with a destruction at the end of LH IIIB2, while deposit 1c belongs to an early LH IIIC destruction horizon. ${ }^{109}$ Therefore, the Pelopidou Street excavation offers, at present, the only secure context for the use of cover and pan tiles in the Kadmeia from late in the LH IIIA2 (14th c. BC) to LH IIIC early (early 12 th c. BC). ${ }^{110}$

At the SE edge of the Pelopidou Street excavations is the Loukos plot (31 Pelopidou Street) ${ }^{111}$ (Map 2, no. 11). A Mycenaean building with at least three plastered rooms and, most likely, a mudbrick elevation, had two thick, well-built, outer walls. Preserved to a height of ca. $1.20 \mathrm{~m}$, their thickness suggested to the excavator that it might have been two-storey. Inside the rooms, a LH IIIB1 destruction layer (1.20-1.30m in thickness) was found. ${ }^{112}$ The upper part of this layer yielded roof tiles among mudbricks, charred wood, and various objects, including numerous worked ivory fragments that suggested the possibility this space to have been an ivory workshop. ${ }^{113}$ More tiles were also found to the south and east of this building. The roof of the building is described by the excavator as 'two-sided and covered with tiles'. Their distribution, context (among carbonised parts of wood and mudbricks) and the thickness of this layer $(0.50-0.60 \mathrm{~m})^{114}$ bear very close resemblance to the situation we observe in the Theodorou plot. Further south in Pelopidou Street is the Stephas plot (25 Pelopidou Street) (Map 2, no. 12), where two rooms with clay floors of a Mycenaean building were excavated $(0.70 \mathrm{~m}$ wide and preserved up to $1 \mathrm{~m}$ in height). A lot of pan and cover tiles as well as lead sheets were associated with a destruction layer dated to LH IIIB1. ${ }^{115}$ That this destruction also had victims is suggested by the young woman (20-25yo) found among the debris. ${ }^{116}$

More tiles came to light during the excavation of the Liangas plot (1 Oidipodos Street), ${ }^{117}$ very close to the acropolis' fortification wall and the location of the later Homoloïdes gates ${ }^{118}$

\footnotetext{
108 Andrikou 2006, 54-5.

109 Andrikou 2006, 55-6. Some scant tile fragments are also said to come from the LH IIIC 'floors' identified in the course of this excavation, some of which date to LH IIIC middle (Andrikou 2006, 49-51 and 54). However, in the publication the floor numbers for the scant fragments are not given so it is not possible at present to ascertain if some of these tiles continued to be used until LH IIIC middle. For Mycenaean tiles in a LH IIIC context, see also Walberg 2007, 169 (Midea, Shrine area) and Eleon (Burke et al. 2013; 2020).

${ }^{110}$ For the end of LH IIIB and LH IIIC at Thebes see Aravantinos 2019; 2020.

111 Sampson 1980; 1985; 1996.

112 Sampson 1996, esp. 114. Andrikou has suggested that this destruction may actually be either late LH IIIB or early LH IIIC (Andrikou 2006, 57-8).

113 As argued by Sampson 1980; 1985; 1996.

114 Sampson 1985; 1996, 114.

115 Demakopoulou 1975a. At Thebes, lead sheets are frequently found in destruction layers, often deformed as a result of the fire that accompanied the destruction. They could be associated with the roof's timber frame; also, Aravantinos 2018, 146-7. 116 Fountoulakis 1986, who notes injuries on the skull (e.g. fracture in the middle of the cranium vault produced by a violent blow from a sharp material, perhaps from the fallen roof); Sampson 1996, 114. There are some similarities with the recently identified sacrifice of a young woman in LM IIIB Chania (Andreadaki-Vlazaki 2015), but whether there is any connection between the two cases is way beyond the remit of this paper and our knowledge.

117 Piteros 1981; 1983; Piteros et al. 1990. Remains found there are clearly associated with those discovered in the adjacent Christodoulou plot, immediately to the west (Aravantinos 1983), where fragments of tiles were also noted (Aravantinos pers. comm.).

118 Part of the wall was discovered in the Stamatis plot immediately to the east of the Liangas plot: Piteros $1983,133$.
} 
(Map 2, no. 14). At a depth of 6.50-7.50m, an undisturbed layer of Mycenaean occupation was excavated. A complex of three buildings was brought to light, all with an E-W orientation and separated by narrow stone-lined corridors. Both cover and pan tiles were found among pottery in the corridor between buildings 1 and 2 and inside the two rooms $(\Gamma-$ $\Delta$ ) of building $2,{ }^{119}$ which had strongly been affected by fire (the base of the walls showing signs of calcification). In room $\Gamma$, a clay bathtub/basin was found fixed on the clay floor.

The excavation of building 3 yielded additional tiles. Located at the north end of the excavation in the Liangas plot, building 3 was the most important - in terms of its contents and best-preserved of the three structures found there. ${ }^{120}$ Here too, there was a clay bathtub/basin (in room Z1) $)^{121}$ and a large concentration of tiles. In the adjacent room (Z2), a number of inscribed nodules were discovered that have since made this plot famous in Mycenaean literature. From the present evidence, it appears that building 2 may have been equipped with a tiled roof and perhaps part of building 3 (namely room Z1). Interestingly, these are the spaces in the Liangas plot also associated with clay bathtub/basins, as was the case in the Theodorou plot. ${ }^{122}$ The tiles from the Liangas plot appear to be associated with the last of the two 13th c. BC destructions (LH IIIB2 late). ${ }^{123}$ The Liangas plot complex had an administrative and artisanal function.

To the same building complex ('Eastern Complex') belong also the architectural remains excavated in the two immediately adjacent plots: Christodoulou to the West ${ }^{124}$ and Stamatis to the East (Map 2, nos. 13 and 15 respectively). Both have yielded fragments of roof tiles, ${ }^{125}$ whereas a fragment of a clay bathtub with pictorial decoration comes from the Stamatis plot. ${ }^{126}$ Based on the findings, the buildings excavated in these two plots seem to have been used for storage and craft activities. However, some kind of administrative function may have served the building in the Christodoulou plot, where a clay sealing and a glass seal have been found. ${ }^{127}$

In the SE edge of the hill, Keramopoullos identified Mycenaean remains in the layers beneath the east tower of the Elektrai gates (Map 2, no. 16). These layers, most likely of a LH IIIB date, were packed with pottery and roof tiles, while similar finds came from the area of the west tower. ${ }^{128}$

Finally, the excavation of the Dimitrios Koropoulis plot (29 Pindarou Street), not far and to the NW of the Theodorou plot, brought to light fragments of tiles, many belonging to the pan type $^{129}$ (Map 2, no. 17). Beneath a deep fill of LH IIIB2 date, an earlier destruction horizon full of heavily burnt building materials overlay a floor on which, among other objects, were both halves of a jeweller's mould, bronze and bone tools, a whetstone and fragments of rockcrystal. The tiles were found in a thick destruction layer $(0.50 \mathrm{~m})$, amongst carbonised wooden beams, mudbricks, and coloured stucco, which covered the floor of a room and was accompanied by clear traces of fire. This layer was dated to LH IIIB1. Only part of a wall was preserved $(\max \mathrm{W}: 0.60 \mathrm{~m})$. Tools, moulds, and various jewelleries led to the identification of a jewellery workshop. A trial trench to the north of this plot yielded a clay

\footnotetext{
${ }^{119}$ Room $\Gamma$ measures $3.60 \mathrm{~m} \times 3 \mathrm{~m}$ and room $\Delta: 2.50 \mathrm{~m}$ x $3.10 \mathrm{~m}$. The walls were preserved to a height of $0.50-0.60 \mathrm{~cm}$ : Piteros 1983, 132.

${ }^{120}$ Building 3 was $11.80 \mathrm{~m}$ long x 3.70m wide (internal dimensions): Piteros 1983,132 . The walls were $0.50-0.70 \mathrm{~m}$ in width and preserved to a height of ca $1 \mathrm{~m}$ (Piteros et al. 1990, 105).

${ }^{121}$ Room Z1 measures 2.80x3.70m: Piteros 1983, 132.

122 Possibly also in the Dimitrios Koropoulis plot (29 Pindarou Street).

123 On the date see also Dakouri-Hild 2010, 700; Andrikou 2006, 57 suggests that this second destruction may be LH

IIIB2/IIIC early but notes that only the full publication of the Liangas excavation can help clarify this issue.

124 Aravantinos 1983.

${ }^{125}$ F. Rougemont and M.-E. Alberti, pers. comm.

126 V. Aravantinos, pers. comm. For a picture of the bathtub fragment see Aravantinos 2010b, 96

127 Alberti et. al. 2012, 93-4.

${ }^{128}$ Keramopoullos 1917, 14 and 76, fig. 58 (where only pan tiles are illustrated); Symeonoglou 1985, 234-5 (site 7).

${ }^{129}$ Demakopoulou 1973-4b; Demakopoulou 1974, 165-166, who notes that some of the pan tile fragments bear imprints of reeds; Symeonoglou 1985, 283 (site 165). On the date also Andrikou 2006, 56-7.
} 
bathtub fragment with painted decoration (the basins from the Liangas and Theodorou plots, noted above, are both plain).

From this brief overview of available contexts, we hope to have shown that roof tile usage at Thebes was widespread without, however, covering every single structure. It is also worth noting that contexts, where destructions have been noted, would allow for a better preservation of the material that was available at the time of the roof's collapse, unlike contexts where there is evidence of continuity or overlapping layers of habitation, where materials would be more susceptible to reuse therefore becoming archaeologically more difficult to identify. Moreover, while roof tiles are attested at Thebes from the late LH IIIA2/B1 to the early part of LH IIIC, most of the examples come from contexts associated with a destruction at the end of LH IIIB1/IIIB2 early. This destruction appears to have been the result of a powerful earthquake that shook many of Kadmeia's buildings - despite the severity of this event (perhaps connected with or at least part of the seismic activity that was responsible for destructions also observed at numerous sites in the Argolid), life and administration continued at Thebes for some time still, until another destruction or series of events in the LH IIIB-C transition appears to have brought palatial administration to its end.

\section{COMPARISON OF THE THEODOROU TILES WITH OTHER KNOWN EXAMPLES}

For comparative purposes, we were able to examine in the Archaeological Museum of Thebes two pan tiles and a cover tile from each of the Stavris and Liangas excavations. The pan tiles from the former are particularly carefully made, among the finest known examples to date from Thebes (Figs 26-27). ${ }^{130}$ They have a very pale brown slip on their surface and a reddish-brown section and identical dimensions to the examples from the Theodorou plot $(53.6 \mathrm{~cm} \mathrm{~L} \mathrm{x} 43-46.5 \mathrm{~cm} \mathrm{~W})$. Their sidewalls are $5.3-5.7 \mathrm{~cm}$ in height, while the pan is ca. 1.5$2 \mathrm{~cm}$ thick. They weigh $8 \mathrm{~kg}$ each and both bear on the sidewall (i.e. on the surface facing the pan) a well-incised lambda-shaped sign $(\Lambda)$, perhaps an artisan's mark, ca. $3.5 \mathrm{~cm}$ in height. The sign was incised prior to firing, while the clay was still wet (Fig. 28). We know of only one certain other case, where a sign on a pan tile is recorded: the recently discovered example from Eleon, which the team there interprets as 'perhaps meant to label a batch of tiles or denote the tile's future recipient' (of similar size to our example, but less fine in its carving) ${ }^{131}$ In terms of manufacture and morphology, the Stavris and Liangas tiles are very similar to the Theodorou examples. The cover tile from the Stavris plot $(36.2 \mathrm{~cm} \mathrm{~L} \mathrm{x} \mathrm{9.4-}$ $15.5 \mathrm{~cm} \mathrm{~W}$ ) has a very pale brown surface and a pink section (Fig. 29). It has a thickness of 1$1.1 \mathrm{~cm}$ and a weight of $1.2 \mathrm{~cm}$. It is very well made, and its outer surface is nicely smoothed. Grooves, from its wheel manufacture are visible inside. As with the pan tiles, the cover tile from Stavris finds excellent parallels among the examples from the Theodorou plot assemblage.

The same picture emerged from an inspection of the Liangas examples. Their quality, though still overall good, is a bit less refined than the Stavris tiles (e.g. note the rougher texture: Fig. 30). In terms of manufacture they bear again very close resemblance to the examples from the Stavris and Theodorou plots. The intact pan tile we were able to examine is $55.2 \mathrm{~cm} \mathrm{~L} \mathrm{x}$ $37-49 \mathrm{~cm} \mathrm{~W}$. The sidewalls have a height of 5.2-5.6cm and the pan has a thickness of 1.8 $2.2 \mathrm{~cm}$ and weighs $8.5 \mathrm{~kg}$. Sidewalls and upper surface have been smoothed while the

\footnotetext{
${ }^{130}$ It is probably because of their quality that they were kept and for this reason we should not assume that all tiles from that excavation were of such fine quality.

${ }^{131}$ Burke et al. 2020, 464, online fig. 10, found in a LH IIIC context. The sign that appears on the flat surface of the tile, not on the sidewall, is less carefully incised than the Stavris example, and the tile at Eleon seems, overall, less refined than the Stavris example. Keramopoullos (1917, 28, fig. 25) illustrates a fragment of a tile, possibly Mycenaean, and found in a post-Bronze Age tomb. The fragment, which is about $5.3 \times 8 \mathrm{~cm}$ (note Keramopoullos' erroneous height dimension), also bears an incised mark (cross in a circle) on what appears to be a flat side of a pan tile (the size of the mark is comparable to that from the Theodorou plot and Eleon, being ca. 4x4cm). On LBA and EIA marks (some similar in appearance), see Bikaki 1984; Papadopoulos 1994; Hirschfeld 1999; Lindblom 2001; on post-Bronze Age marks and stamps on tiles see e.g. Orlandos 1966, 93-5.
} 
underside is rough. The tile-maker's movements to smooth the surface are actually visible on the outer surface and on the sidewalls of the intact pan tile (with toolmarks and possible fingerprints discernible). Possible animal prints (e.g. two pairs of hooves) are visible near the broad end. Both the surface and section colour of this example are pink. The other, fragmentary, pan tile and the fragmentary cover tile from the Liangas plot find excellent parallels among the Theodorou plot material (e.g. very pale brown surface and light reddishbrown section, and very similar morphology).

The Stavris and Liangas examples that we examined are comparable to the finest examples attested in the Theodorou plot assemblage (Figs 20, 26 right, 30-31). Despite small variations in size, colour and refinement/texture, the cover and pan tiles from Stavris and Liangas display the same morphology and construction principles as the Theodorou material suggesting a considerable degree of standardisation in the making of cover and pan tiles (i.e. a shared 'know-how'). ${ }^{132}$ The makers of tiles in the Liangas and Stavris plots were following very similar steps and principles in the making of these objects, akin to those attested in the Theodorou plot, perhaps suggestive of apprenticeship relations through which tile-making might have been maintained. It is more difficult to interpret the artisan's mark - it could denote labour specialisation/organisation, perhaps suggesting a special batch of tiles from a particular tile-maker. It does not appear accidental, though, that the mark is found on two of the finest examples of pan tiles known to date from any Aegean LBA site.

As mentioned at the start of this paper, most of the tiles outside of Thebes are either small in number, partially studied, and infrequently showing a direct association between pan and cover tiles (with Eleon forming an exception). This picture has necessitated the proposition of different interpretations as to their function. However, the best published parallel for the situation observed in Thebes comes from Gla in northern Boeotia. ${ }^{133}$ There, a total of at least 183 cover and 185 pan tiles have been found, mostly from destruction deposits dated to LH IIIB2. ${ }^{134}$ Iakovidis considers the tiles of Gla the site's greatest discovery. ${ }^{135}$ Cover and pan tiles have been found together, but in very small numbers $(<25$ examples, often $<15$ per location) in several areas. ${ }^{136}$ The largest, however, concentration of cover tiles (ca. $80 \%$ of all known examples from Gla) comes from one area - a stockpile of cover tiles found stacked together in a corner outside complex Z. Almost $48 \%$ of all known pan tiles also come from one location, namely complex $\mathrm{M}$ in the south enclosure. Widespread, therefore, as their distribution may look, their numbers are extremely low in the citadel of Gla, except for the two areas mentioned above where, at least the cover tiles, appear to have been stored and not in use at the time of destruction in LH IIIB.

Sapirstein offers several compelling reasons against Iakovidis' suggestion as to why the largest buildings at Gla never had a tiled roof, ${ }^{137}$ putting forward the idea that these objects may have functioned as drains. ${ }^{138}$ Irrespective of how these objects were used in Gla, technologically, they bear striking similarities in the make, shape, clay composition, and size to the examples from the Theodorou plot and other Theban plots. Coarse gritty clay mixed with straw was used for the construction of pan tiles, the only difference they have with the

\footnotetext{
132 Iakovidis 1990, comparing the tiles from Gla to examples from Berbati, Chania, Chalandritsa etc., reached a similar conclusion.

133 The important material from Eleon (Burke et al. 2013; 2020) will, however, undoubtedly also shed additional light on the morphology, construction and use of Mycenaean tiles in Boeotia as will the new excavations at Gla

(https://www.culture.gov.gr/el/Information/SitePages/view.aspx?nID=3024, last accessed 12 July 2020).

134 Iakovidis 2001, 135-137 for a summary of the evidence with additional references.

135 Iakovidis 1989, 246.

${ }^{136}$ E.g. from the Double Gate, the south entrance to the Central Enclosure, and inside rooms of Buildings E, H, K, N. Pan tiles alone (in fragments and again in very small numbers) have been found at the North Gate, the West Enclosure, the Melathron, and Building B in the South Enclosure (Iakovidis 1989, 246-8; 1998, 9-61, 69-71, 76-92, 105-13, 131-3; Sapirstein 2008, 45-9).

137 Sapirstein 2008, 44, 47-9.

${ }^{138}$ Given that the known buildings at Gla cover an area of $>4,600$ sq.m., the existing corpus from this particular site is extremely small to support Iakovidis claim $(1990 ; 2009)$, especially when compared to the assemblage from the Theodorou plot in Thebes (discovered in an area of just 30-35sq.m.).
} 
examples from Thebes being that they have a rougher appearance (the further one seems to go away from main administrative centres, the rougher the appearance of this material becomes the Eleon material can therefore add additional light on this subject when published). Cover tiles are made of well levigated clay and are covered with a slip, same as their Theban counterparts. Moreover, we find the association of cover and pan tiles with a number of entry points (to the citadel or buildings within it) of some significance (i.e. signposting certain locations). Tiled roofs, highlighting entrances, apart from their obvious practical role, may have also functioned as marking out specific spaces and areas of use within certain sites. While Iakovides may not have been right, in thinking that all buildings at Gla were equipped with a low-pitched, tiled roof in Mycenaean times, ${ }^{139}$ he did get one thing right: that tiled roofs did exist. At Gla, they may have provided protection over specific areas of this idiosyncratic citadel, and they may have had other uses too (e.g. as drains).

\section{CONVENTIONAL KNOWLEDGE IN MYCENAEAN TILE-MAKING}

We do not have many ethnographic studies on tile-making, but those that exist are highly illuminating. ${ }^{140}$ The most important study remains that by Hampe and Winter, ${ }^{141}$ who between 1958 and 1962 traversed the central and east Mediterranean in search of traditional tile-making practices that were fast disappearing at the expense of cheaper, industrially produced tiles. ${ }^{142}$ The value of these studies is that they bring to the fore very similar practices, be it in south Italy or Greece, with a lot (but not all) of the details of tile-making having bearing also on their production in the 14th and 13th centuries BC.

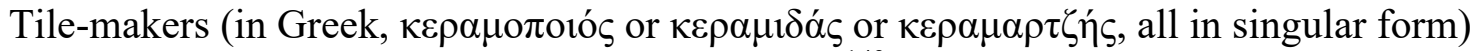
worked seasonally, mostly in the summer months. ${ }^{143}$ They were often, but not always, also brick makers and potters. The work was demanding, with very few daily breaks. They mostly worked outdoors. To make tiles, they had to first mine the right clay: after sourcing it, most commonly from a location nearby, they opened a pit where they deposited the raw material and started mixing it with water (most frequently by treading the mix with their bare feet). They often aimed at making a paste that was wetter and easier to work with by hand than the past used for making pots. They then moved a quantity of this clay mix onto their workstation ( $\alpha \lambda \omega \dot{v i)}$, where they kneaded it two or three times. Next to the workstation, there was usually a table (of wood, bricks, or stones), while sand and water were also readily available to add to the paste if and as required (the sand for temper; organic material like straw was also used). The right quantity was brought to the table where with the help of a trapezoidal frame (either made of wood or metal, called $\kappa \alpha \lambda \circ v i \pi \mathrm{l}$ ) and a forming tool shaped like a tapered half

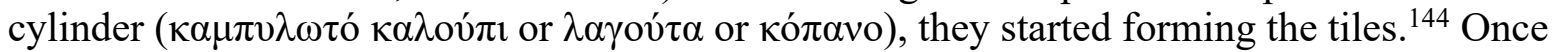
formed, they smoothed the upper surface by hand or with a wet cloth, to close any voids and to give the tile a shine, before pulling a string that helped to cut the edges of the tile loose. ${ }^{145}$ The person who was responsible for 'cutting' the tiles was called кó $\varphi \tau \eta \varsigma$ ('cutter'). While still on the form, the tile was lifted and placed on the drying area. Only then was the cylindrical forming tool removed, with the newly-made tile on the ground left to dry (in the vast majority of cases, these tiles were of a single type and resembled the common cylindrical roof tile of antiquity - be it Laconian, Roman or Byzantine - i.e. long, curved and tapering

\footnotetext{
139 Iakovidis $1990,160$.

140 Hampe and Winter 1965; Birmingham 1967; Matson 1973, 121-5; Rostoker and Gebhard 1981; Blitzer 1990; Terzoudis 2001, 69-73; Merker 2006, 137-8; for a useful summary: Sapirstein 2008, 79-85 and 96-7; on Byzantine tiles (mostly from textual sources): Gerolymou 2017. A useful short summary of the process of tile-making is given in

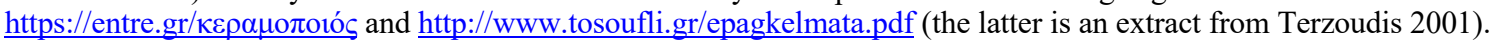
(last accessed, 12 July 2020).

141 Hampe and Winter 1965.

142 See e.g. Antoniou 2009.

143 This synthesis is largely based on information provided by Hampe and Winter 1965 and Sapirstein 2008, 79-85 and 96-7.

${ }^{144}$ For specific terminology the work of Hampe and Winter 1965 remains extremely useful as is also the work of Blitzer 1990. On the mould see: Hampe and Winter 1965, pl. 42; Birmingham 1967, 34; Blitzer 1990, pl. 109e. The trapezoidal frame could also be used for the making of flat tiles.

145 Sapirstein 2008, 80.
} 
tiles, similar to Mycenaean cover tiles, but often wider in the middle). They then left them to dry directly under the sun, before grouping them and storing them in a shaded, wellventilated space or indoors to complete the drying process. When the right number of tiles was ready for firing, then they moved the tiles to the kiln taking care of their position inside (usually stacked vertically, with the narrow side towards the kiln's floor). They kept the fire going for about $24 \mathrm{~h}$. When firing was over, the tile-maker left them for 2-3 days inside the kiln, before removing them and stacking them up ready for sale or use.

Although the aforementioned process refers to the making of one type of tile with the use of a mould (i.e. unlike the situation in Mycenaean times), this information gives us valuable insights with regards to the process, labour, people and variables involved in the making of these objects. Pan tiles would have been more demanding to make due to their size and weight and most likely required a team of at least two people, unlike the wheel thrown cover tiles which would be faster to make and would only require one individual). Pan tiles would also be more demanding in terms of their firing, both when it comes to the fuel needed but also space. Tile makers often worked as part of a group, usually of two or three workers. To this group, Sapirstein is of the opinion that at least 'three or four additional workers [were] needed to gather clay and fuel, rearrange drying tiles, and manage the kiln. ${ }^{146}$ These may well have been small family workshops, as suggested by the study of Hampe and Winter in which women and young members of the family are all put to work. ${ }^{147}$ Judging by the footprint of a baby on one of the studied tiles from the Theodorou plot, this may well have been also the case for at least some of our studied tiles. ${ }^{148}$

This exercise also brings to the fore the variables that were at play in the making of these objects, ${ }^{149}$ especially in relation to modes of production: from the raw materials that had to be sourced (e.g. clay, temper, water, and fuel), the time and people involved (including part-time and/or full-time labour), to the organisation and division of roles, the seasonality of this practice and the tools and facilities needed for their making (e.g. wheel, saw, drying shed, open space, kiln, storage areas and stockpiling capacity). As Lemmonier has pointed out in his excellent study on technological choices, sometimes the techniques used appear to our modern eyes to be 'arbitrary' and in a way 'irrational': ${ }^{150}$ e.g. the tile-makers of Hampe and Winter could have used the wheel to make conical tiles, but instead preferred to use a mould (in what may look to us as a rather odd choice and process); and the Mycenaean tile-maker could have used a mould for their cover and pan tiles, but used the wheel for the cover tiles and their hands for the pan tiles instead (perhaps because they were following practices already established, e.g. in relation to making clay drains). Yet these objects were produced less with respect to the efficiency of a particular action on matter (e.g. the less timeconsuming, more efficient and typified mould-type production ${ }^{151}$ ) and more according to accepted ways of doing things, as a result of technical knowledge transmitted from one generation to the next; a knowledge that Lemmonier calls 'conventional'. ${ }^{152}$ This particular arbitrariness or conventional knowledge in Mycenaean tile-making reveals in our view the existence of a particular tradition of practice which has, until now, gone largely unnoticed by scholarship; a practice that probably procured its know-how from related technologies, such as pottery- and drain-making.

As we hope to have shown, the tile-makers of the examples we examined from Thebes seem to have been knowledgeable potters whose expertise in mixing clays, constructing large

\footnotetext{
146 Sapirstein 2008, 97.

${ }_{147}$ Hamper and Winter 1965, throughout; also, Terzoudis 2001, 69-73.

148 Hampe and Winter 1965, 13 mention and illustrate the case of a potter from Camerota in Campania in Italy, who during

his break would visit his grand-child, still in a Moses basket, placed in a room next to where he was making his pots.

149 See also Hasaki 2011, with additional references.

${ }^{150}$ Lemmonier 1993.

${ }^{151}$ E.g. Hampe and Winter 1965, 133 who note that a husband-and-wife team Sta Kanatadika on Euboea would make 16001800 roof tiles a day following the mould-making way.

${ }^{152}$ Lemmonier 1993, 6. See also Santacreu 2014, esp. 173-6 on the functionalism of ceramic building materials.
} 
objects, and operating kilns were prerequisite to manufacturing tiles. ${ }^{153}$ Perhaps drawing inspiration from clay water channels/drains, ${ }^{154}$ no mould appears to have been used for the making of these tiles, unlike for example earlier (EH II) and later (Archaic period onwards) tiles, which made use of frames and moulds. As a result, no two tiles are the same, be it of the cover or pan type. ${ }^{155}$ The tiles we were able to examine comparatively, but also those described and illustrated in publications, support this notion that a conventional knowledge did indeed exist in relation to the making of these tiles across the Greek mainland from the $14^{\text {th }}$ to the early $12^{\text {th }} \mathrm{c}$. BC. According to this knowledge, cover tiles had to be wheel-thrown and hand finished, have a more or less specific thickness, and be more refined that their pan counterparts. Pan tiles were completely handmade, rougher (though their quality varies significantly), included temper and followed some general rules in terms of their dimensions. Variations are observed in the size of tiles and their overall quality which we attribute to different needs (including repairs) or different batches of tiles (as they were produced, including reused tiles), but also (as other scholars have noted ${ }^{156}$ ) to multiple makers at work. These makers may well have worked at a family-base level, as suggested by the ethnographic studies, or more organised workshops (if this is how the mark on the Stavris tile mentioned above should be understood). Some tiles may therefore have been produced under palatial control, but overall their production does not appear to have been strictly regulated (they do not appear to have had caught the administrators' interest to the point that they needed to record such information in their Linear B documents). We are of the opinion that tile-making operated at different scales and was there to fulfil the needs of different commissioners. Furthermore, from our analysis of the extant material it appears that Mycenaean tile-makers and their commissioners may not have been interested in achieving complete visual homogeneity, and repairs made to the roof or reuse of earlier material may have added further to its slightly mismatched appearance - a situation also observed in later contexts for practical reasons (i.e. instead of making new tiles for the whole roof). ${ }^{157}$

The relatively small roof area of the excavated part of the 'central room' in the Theodorou plot (ca. 46.15-49.7sq.m.) would have required hundreds of tiles weighing in total between 2.15-2.35tn (excluding the weight of the timber frame, which would have also been considerable). ${ }^{158}$ The process of making the tiles as described above, the fuel needed to fire the required amount of tiles, the construction of the building (with the thick wall probably connected to the weight of the roof above) and its timber frame (including the selection of the right beams depending on the span that had to be covered), all point to considerable labour behind the construction of what at first glance may look like a modest structure. This reconstruction, of the process of making tiles but also of the 'central room' in the Theodorou plot, help, in our view to visualize better the organization required for the making of cover tiles, be household-based or organised at a more complex level - an organization that involves people, materials, energy and interest in using such a roof structure.

\section{MYCENAEAN TILE-MAKING: A PALACE-RELATED BUT NOT PALACE-EXCLUSIVE ACTIVITY?}

Tiles in their Theban context seem to have been produced on demand and their use was widespread but does not appear to have covered all buildings which must have displayed a number of different roof forms (e.g. flat, pitched but not tiled, or combinations of the above). Although they may have provided extra insulation, these other roofs must have been equally effective for this purpose and for this type not to be completely adopted. They could have

\footnotetext{
153 Sapirstein 2016, 57.

${ }^{154}$ A simultaneous development of the two, i.e. drains and tiled roofs, should also not be excluded.

${ }^{155}$ Unlike the complex Archaic tiles (Sapirstein 2009), for example, there is no need in Mycenaean tiles to interlock seamlessly.

${ }^{156}$ E.g. Küpper 1990, 106-109 and 134-6, figs 122, 210-16; Burke et al. 2020, 463.

157 E.g. a tiled roof from a Classical context at Nemea see Birge et al. 1992, 122.

158 On the complexities of the timber frame see e.g. the classic publications: Hodge 1960; Orlandos 1966; Coulton 1977.
} 
been an element of embellishment, helping both insulate certain buildings further but also highlighting their presence in the landscape (i.e. an attempt to signpost them).

We are so used to the sight of tiles today that we forget that once they formed a novelty. In Mycenaean Greece, there was certainly knowledge of them, which travelled great distances and probably speaks of know-how relations - but our extant record, with the rather infrequent and uneven distribution and use of tiles, suggests that their use was, on the whole, a rather irregular feature of LBA mainland architecture. Even more so, tiled roofs did not form a common sight in the roofscapes of the LBA Aegean. In this respect, tiles and tiled roofs are not only technologically novel, but also a special architectural feature of the period around 1300-1200 BC on the southern Greek mainland. In a few instances, their use (or reuse) continued for some time also in the 12th c. BC (e.g. Thebes, Eleon and Midea; Map 1). When tiles re-appeared in the EIA (around 700 BC), they were associated with the most important sanctuary buildings (temples and treasuries) of the Greek world. ${ }^{159}$ Their use, possibly as a further element of embellishment and visibility in the landscape, was not just for insulation. ${ }^{160}$ While eventually becoming more widespread including houses and other types of buildings from late Archaic and Classical times, roof tiles remained costly ${ }^{161}$ with their production often closely regulated (possibly from Classical times but also in the Roman period). ${ }^{162}$

The Theodorou plot excavation yielded some 2500 fragments providing much-needed contextual information with regards to the use of tiles in Mycenaean Greece. With the exception of Iakovidis, all other scholars have displayed, in one way or another, doubts over the existence of roof tiles and the presence, as a consequence, of tiled roofs. Our study suggests that in the case of the Theodorou plot, we have the first conclusive evidence for the use of a tiled roof in the LBA Aegean. The 'central room', with which the tiles are associated could structurally have supported a tiled roof as its architecture suggests (e.g. the thickness of its walls, their well-built corners, and relatively narrow space inside required covering).

However, the fact that the 'central room' in the Theodorou plot may have been equipped with a tiled roof does not automatically or indiscriminately suggest that the use of tiled roofs was universally applied to Mycenaean buildings. At Thebes, where we possess to date the best and most extensive contextual information of any Mycenaean site, tiles have been reported from ca. $14 \%$ of the city's excavated plots. ${ }^{163}$ Clearly popular as their use might have been in the acropolis of the Kadmeia, even there it was far from wholesale (a clear concentration of buildings with tiled roofs can be observed on the NW to SE slopes of the Kadmeia, from the areas of the 'old' and 'new' palace to the Christodoulou-Liangas-Stamatis plots; in this large area, $72 \%$ of all known plots with tiles are located). Not only the vast majority of excavated contexts in the LBA Aegean apparently lack tiles, but also in several cases where tiles are reported (however briefly) their numbers are very low (with the exception of the three sites in Boeotia, which could reveal a regional preference). This low frequency may be suggestive of 'tiles' having other uses in the LBA Aegean, e.g. as gutters or drains on the sides of buildings with flat roofs, not least when pan tiles are only mentioned with no association of any cover

\footnotetext{
${ }^{159}$ A similar, special, use appears to have been reserved for the almost contemporary to the Greek mainland first use of roof tiles in Etruria and Anatolia: see e.g. Wikander 1986 (Etruria); Glendinning 2005 (Lydia).

160 Discussed by Sapirstein 2009; 2016; also, Winter 2009.

161 Orlandos 1966, 89-92 on costs. In an inscription from the early 2nd c. AD from Thera, those who paid from their own pocket for the roofing of the stoa, including its timber frame and tiles, received honours (IG XII 3, 324).

${ }_{162}$ As suggested by the famous standard for tiles found in the Athenian Agora, for Laconian pan and cover tiles (Stevens 1950). The standard though dating to the Roman period has the same dimensions as 5th c. BC Athenian tiles, therefore the use of such standards may indeed go back in time. See also Orlandos 1966, 92, fig. 63, on the marble model for Laconian and Corinthian tiles from Assos.

${ }^{163}$ In 18 of the 127 excavated plots (the latter number comes from Dakouri-Hild 2010, 696). Given that more plots have been investigated in recent years, the percentage is even lower than the one given here. Obviously, caution should be exercised not least as earlier excavations had a tendency to focus exclusively on fine pottery ignoring coarsewares (tiles undoubtedly included). It may also be no accident that most tiles have been found in areas where comparative material already existed (e.g. by Iakovidis in Boeotia and by Åkeström in the Argolid). The more systematic study of coarseware ceramic material from excavations could indeed reveal more tiles; we hope this article gives a steer in this direction.
} 
tiles. Taking into account issues of preservation and visibility, low quantities should not be ignored and may indeed represent limited use of tiles and tiled roofs in Mycenaean Greece. ${ }^{164}$

Technologically, Mycenaean tiles are simple, in the sense that they are not like the more complex combination tiles of the first millennium BC. ${ }^{165}$ Contrary to past scholarship, the study of the Theodorou plot tiles suggests that they were placed straight on the roof's timber frame without any sheathing in between. Moreover, we noted on a few pan tile fragments 'nail-holes', which might reveal that extra care was taken to secure them in place (if that was indeed how these holes functioned). That they are coarse, however, does not mean that they are of poor quality - coarse objects also require investment and tend to be very practical in their respective contexts of use. In the case of the Theban tiles, care was certainly taken to smoothen the surface of both cover and pan tiles. This element would have improved their visual appearance, but more importantly perhaps have helped with the function tiles had to perform, i.e. to drain water primarily from the roof's sloping sides.

The specific steps in this production sequence and the distinctive and consistent techniques used, at least in the examples we have been able to study, suggest that we are dealing with a 'taught' practice in tile-making and that it was within specific patterns of interaction that this technical knowledge was exchanged. ${ }^{166}$ Choices can still be detected, e.g. in the overall quality of the finished product, the sourcing of raw materials, the existence or absence of certain features (e.g. different types of rims on cover tiles and nail-holes on pan tiles) as well as their dimensions (though all admittedly falling within a specific range of set dimensions). ${ }^{167}$ As suggested above, it is not unreasonable in our view to think that the Mycenaean tile-makers were probably potters or were trained by them and both worked close together.

As far as contexts are concerned, the truth of the matter is that only in a few cases we can ascertain the function of the room(s) in which tiles have been found (Table 7). A variety of functions appear to have been performed by the structures with which tiles were associated. 11 of the 18 known plots with tiles at Thebes appear to have had or at least included a certain or possible 'workshop' function. ${ }^{168}$ In the Theodorou, Liangas, Stamatis and possibly D. Koropoulis plots, tiles were found in direct association or in proximity to bathtubs, which may have had also a workshop-related use. ${ }^{169}$ Although this association might be significant, not all plots with tiles have yielded also basins, while there are basins without any tiles, e.g. in the so-called 'wool workshop' in Epaminonda Street, ${ }^{170}$ and in 10 Dirkis Street. ${ }^{171}$ Although tiled roofs may therefore have had an important connection with workshop spaces (and entrance points, as noted above for both Thebes and Gla), clearly their use was not limited to structures with one function alone. The material yielded in these excavations, as might be expected, often appears to suggest that different functions may have taken place in

\footnotetext{
164 The theory that tiles appear in low quantities in Mycenaean contexts because they might have been scavenged in later times (e.g. Winter 1993, 11, among others) should always be kept in mind, not least as the examples from Eleon in LH IIIC appear to suggest (Burke et al. 2013; 2020).

165 Iakovidis was, in our view, well-justified in calling the Mycenaean roofing systems that involved tiles 'hybrid' (1990, 132).

166 Jazwa 2018, 171, in his study of the EH II tiles, observes similar teacher-apprentice relations and their importance in helping us identify networks of social interaction. Specifically, on the transmission of technical knowledge see Gauss et al. 2015.

${ }^{167}$ Also, in the case of the Theodorou plot, differences in the colour of the clay (surface and core) and in the overall execution of tiles (including the rims of cover tiles) could suggest that they formed part of different 'batches' or 'workshops' (i.e. it is possible that some of the tiles might have been replaced in the structure's lifespan or that different 'batches' were brought together for the roofing of this particular structure).

168 E.g. the Tzortzis, Loukos and D. Koropoulis plots. The finds from Agion Apostolon and Kadmou Streets have also been tentatively associated with a possible 'workshop' in the area (above and Table 7).

169 On the possible workshop-related use of bathtub basins see Fappas 2009-10, 152, 258, 260-1; also, Alberti et al. 2012 and Alberti et al. 2015. For the connection of similar-looking bathtubs in the East Mediterranean and wool-processing see Mazow 2014 (e.g. Tel Abu Hawam and Tel Miqne-Ekron). A bathtub is also reported from Eleon, from Room 1 in what is currently interpreted as an enclosed courtyard in the Northwest complex: Burke et al. 2020, 464. Clearly, however, bathtubs would have had multiple uses hence on their own they cannot ascertain the existence of a 'workshop'.

${ }^{170}$ Spyropoulos 1970d; Spyropoulos and Chadwick 1975; Shelmerdine 1997; Demakopoulou 2014, 144.

171 Aravantinos 2005, 401.
} 
the same location (Table 7). Tiles are also associated with contexts that appear to have solely a residential or storage function, and in at least three cases they are found in contexts that have yielded administrative material (Linear B tablets and inscribed sealings).

It might be worth noting that outside of Thebes and Boeotia in general, roof tiles also appear in association with workshops, e.g. the 'potter's factory' at Berbati, which in its second phase (LH IIIB) was a large establishment, with a tiled roof and ritual installations. ${ }^{172}$ In other cases, however, they are discovered in non-administrative contexts, associated with drinking/eating/serving vessels, painted fragments and elaborate (by Theban standards) architecture suggesting perhaps a domestic and/or ritual setting. ${ }^{173}$ Although our difficulty in finding a pattern may indeed suggest a mixed use for roof tiles, it could also denote that the division of spaces (between 'workshop'/'industrial' versus 'domestic'/'religious') was not as clear cut as our modern labels suggest and that some of these areas and associated buildings performed multiple functions: as residences of high officials that also operated or were in charge of specific workshops. ${ }^{174}$ In all known instances at Thebes, at least, roof tiles appear to be associated with relatively small areas in sq.m. and with building remains described by the excavators as well-built and sturdy (i.e. structures that could have potentially supported a tiled roof).

The Theodorou plot remains, situated at the highest, southern, part of the Kadmeia form part of an agglomeration of buildings in an area that was active in the first half of the 13 th $\mathrm{c}$. BC. Buildings with the same orientation as those in the Theodorou plot have been discovered in adjacent plots suggesting that we are dealing here with a well-planned quarter of the acropolis. Within this quarter, no administrative records have yet come to light in this area. Instead, what we do find are numerous painted fragments, from both miniature and largescale compositions with figural, natural and more abstract subject matters. Located near the possible core of the early Mycenaean settlement, this quarter (part of which the Theodorou plot is) appears to have had a domestic/residential character in LH IIIA-B. At least for Thebes, therefore, our study suggests that roof tiles had an elite association and were also linked to administrative and workshop spaces. Their use does not appear arbitrary and is limited to specific socio-economic structures and areas of activity.

For a long time, comparisons between palatial sites were limited to a counter-examination of their plans. Important as plans may be, elevations are equally significant and, as much as the evidence allows, should form part of our investigation in identifying and assessing similarities and differences in the cityscapes of Mycenaean Greece. With a widespread (spatially speaking), yet limited (in terms of plot numbers), distribution of pan and cover tiles, the impression we get of the Theban roofscape in ca. 1300-1200 BC is one of diversity of forms: flat, pitched in different combinations, and with or without tiles. Coupled with a dense and dispersed layout, with the exception of the SW part where remains are still scant, the Kadmeia may have stood out visually and in terms of a 'visitor's' experience navigating this acropolis from the other Mycenaean (largely Peloponnesian) citadels. The material from Thebes suggests that tile-making is best understood as a mid- to late 14th $\mathrm{c}$. BC that reached a peak in the 13th c. BC in association with specific contexts. Their use (or reuse) in postpalatial times was short-lived and may represent a remnant of the past.

If our reading of the extant evidence is correct, then tile-making is best understood as a palace-instigated activity in the 14th c. BC. Around 1300-1200 BC, this practice was still largely limited to major administrative centres or their satellites, but it also became more

\footnotetext{
172 Åkerström 1968, 50, where he mentions pan tiles (some of which were found almost intact and are indeed very similar to those from the Theodorou plot) but also notes that only two fragments of cover tiles were identified.

173 E.g. something similar has been observed at Midea: Walberg 1998, 94-95 (LH IIIB house), 2007, 169 (LH IIIC, Shrine area).

${ }^{174}$ Cf. the Petsas House, a residence and a ceramic workshop (Shelton 2010), and the other complexes outside the citadel at Mycenae. Residential spaces were, most commonly, located on the upper floors (Mylonas-Shear 1987) and for this reason are the least detectable archaeologically (with basements and ground floors being the ones mostly recoverable in excavations).
} 
widespread now including installations in the periphery of these centres or even outside of them (from farmsteads, like the one excavated by Brown at Prophetes Elias in Boeotia, to small settlements, like Chalandritsa in Achaea: Table 1). ${ }^{175}$ Tiles, therefore, were for the elites (palatial or otherwise), but not exclusively of the elites. While master potters/tile makers may have occasionally been involved in the making of these objects, judging by the quality and fine finish of some of the examined examples, we think that a number of tile-makers were actually at work at Thebes, some (if not the majority perhaps) working at a family-based level similar to that described by the ethnographic studies mentioned above. ${ }^{176}$ In this respect, they conform to current models of pottery production ${ }^{177}$ in that they can be produced locally or regionally, often under palatial control, ${ }^{178}$ but not under any strict palatial supervision, therefore operating at different scales and possibly also for different interest groups. The conventional knowledge we have observed in the making of these tiles suggests that a short-lived 'tradition' developed which soon spread via networks of potters, perhaps as a solution to draining roofs (flat and pitched), but also as an element of signposting across most of the Mycenaean world of mainland Greece. The fact that this practice is not observed after LH IIIC makes their connection to, but not exclusive use for, palace life and the worlds around them all the more significant. Having lasted for some 150-200 years, this Mycenaean practice was eventually forgotten, with tiles making a reappearance more than four centuries later following different practices ${ }^{179}$ and in an altered form.

We hope that this study prompts many more similar publications. Tiles should not be treated as second-rate objects, receiving a quick mention, no study, no photographs and no drawings they should be examined like other artefactual classes, properly recorded and published. They should also be discussed in relation to the contexts of their discovery. All in all, we need more contexts to be able to reach a wider understanding of their use and significance in Mycenaean architecture and society. We hope this publication is a first step towards this direction.

\section{ACKNOWLEDGEMENTS}

Apart from the authors, the 2013 study team consisted of Kiki Karagianni (ceramics conservator), Eleanor Maw and Emily Pulsford (Classics students, University of Cambridge). The project team expresses its gratitude to INSTAP for its long-term support to the Theban excavations and for funding this study. We are also grateful to the University of Cambridge, especially the Faculty of Classics and Sidney Sussex College, for facilitating our research and supporting financially our work at Thebes. The study took place in the Museum of Thebes in July and August 2013. We express our heartfelt thanks to the Director of the Ephorate of Boeotia (EAB), Dr Alexandra Charami, and to the entire staff of the Ephorate and the Museum of Thebes who created the ideal conditions for our work and offered generous hospitality. The Ephorate also provided free accommodation to the two Cambridge students who worked tirelessly and offered unstinting support to the project - for their help, we extend our warm thanks and gratitude. Special thanks to Kalliopi Mitsopoulou for the drawings of

\footnotetext{
175 A pattern also observed by Vitale 2012, 1158, fig. 7, table 2 and van Damme 2017, 99.

176 The analysis of 152 Mycenaean ceramic examples from Thebes by Mommsen and his team yielded multiple chemical signatures corresponding to different ceramic choices and 'recipes' and possibly also different workshops at play (Mommsen et al. 2002, 610 'one or only a few regionally centralised workshops producing for the palace and/or for the Boeotian markets'). However, within each of the identified group, they also note that production appears to have comprised different wares ranging from coarse products like roof tiles to pottery of the highest quality. On different players making pots, and their palatial/non-palatial relationship, see also Dakouri 2006, 185-6.

177 As first suggested Halstead 1993, 64 and 72 ('wheel-made pottery, surely the product of craft-specialists but not apparently made under palatial control'); more recently, this point features extensively in the work of Galaty in Messenia (Galaty 1999; 2007; 2010). On the Mycenaean palaces as 'Palace ${ }^{\mathrm{TM}}$ ' oriented-industries see Bennet 2008.

${ }_{178}$ Keramopoullos $(1911,148-9)$ thought that a pottery kiln abutted the west façade of the 'House of Kadmos'. Dakouri-Hild (2006, 185-186) dates its construction to 'after the building was constructed and before it was destroyed' since it was attached to the complex and it was buried under the fused superstructure of the 'House of Kadmos' (for its location see Dakouri-Hild 2014, 166, fig. 6). This possible kiln, therefore, appears to lend support to pottery production being also palatially-related and controlled (see also the 'royal potter' from Pylos: Palaima 1997).

${ }^{179}$ A new system of terracotta tiling to roof sanctuary buildings was invented in the 7th c. BC (Sapirstein 2009; 2016, 47).
} 
the tiles, and to Sotiris Kazakidis for the digital drawings of the excavation and the digitisation of the tile drawings. The architectural reconstructions were made by Kali Kapsali, to whom we extend our gratitude. We benefited immensely from the comments and suggestions we received from the two anonymous reviewers and we are particularly thankful to them, and to the Editors of the Annual who also patiently dealt with all our requests. We are also grateful to the following for comments, suggestions, advice and help with this publication: Maria Emanuela Alberti, Polina Kapsali, Angeliki Karathanou, Eleni Konstantinidi-Syvridi, Irene Lemos, Antonia Livieratou, Konstantinos Nikolentzos, Françoise Rougemont, Philip Sapirstein, Sue Sherratt, Vasiliki Valantou, Trevor van Damme, Nikolaos Zacharias. Any errors remain with the authors.

ig298@cam.ac.uk

\author{
APPENDIX \\ ANALYTICAL AND TECHNOLOGICAL STUDY OF SOME ROOF TILES \\ FROM THE THEODOROU PLOT AT THEBES
}

by

Vasiliki Valantou and Nikolaos Zacharias ${ }^{\mathrm{d}}$

dUniversity of the Peloponnese

The technological study presented here aims to complement the preceding discussion and shed additional light on the production of Mycenaean roof tiles from Thebes, through the examination of a small sample from the Theodorou assemblage, as there is a lack presently of relevant studies in the field. Furthermore, it focuses upon compositional issues, the selection of raw materials and firing practices. Our study examined nine roof tiles from the Theodorou plot, selected by the study team for analysis on the basis of their characteristics, from which six are pan tiles and three are cover tiles (Table 8, Fig. 32). This study forms part of a wider investigation of Mycenaean roof tiles from the Kadmeia currently stored at the Archaeological Museum of Thebes. ${ }^{180}$

\title{
Analytical Methods
}

For the study of the assemblage a multi-technique approach was applied, for their microscopical, analytical and mineralogical examination. The ceramic body of all samples was first examined using Optical Microscopy (OM) with a Fiber Optics Microscopy (FOM/iscope, Moritex) aiming at a preliminary distinction into groups according to the macroscopic and microscopic characteristics of the clay paste.

On site, portable X-Rays (p-XRF) analysis was applied on the complete tiles since the technique allows for a fast-analytical screening ${ }^{181}$ to ease a first classification of the assemblage. Taking into consideration the high heterogeneity of the samples, due to the coarseness of the fabric, and the acknowledged medium- to high-accuracy when measuring light elements with $\mathrm{p}-\mathrm{XRF}$, the technique was primarily used for the determination of the

\footnotetext{
180 The authors gratefully acknowledge permits granted by the Greek Ministry of Culture and Sports to enable the study of the assemblage. We also extend our thanks to Dr E. Nodarou (INSTAP, Crete) for the preparation of the thin sections. Only one other Mycenaean tile, that we know of, has been analytically examined from Thebes (Mommsen et al. 2002, 608), where it is presumed to be of local manufacture and is used to establish group ' $b$ ' of the pots analysed by this team as of local manufacture; this group was further enhanced and securely established as of local production with the addition of 122 analysed samples of pottery from Hellenistic Boeotia (Schwedt et al. 2006, 1069, referred in this paper as group 'A'), providing also further confirmation of the diachronic exploitation of local clays by the potters of the region. Otherwise, the emphasis of analytical studies of Mycenaean pottery from Thebes have almost exclusively focused on provenance, with a special interest in the inscribed stirrup jars (e.g. Haskell et al. 2011).

${ }^{181}$ Liritzis and Zacharias 2010.
} 
minor and trace elements of the clay. The samples were not polished prior to the analysis. An effort was made, however, to select homogeneous and representative surfaces for each sample following the macroscopic observations and the OM recorded images. A portable Bruker Tracer III SD was used and data quantification was made using S1PXRF software. ${ }^{182}$ In order to optimise the analytical range, two settings were used: (1) an unfiltered low-energy excitation mode (high voltage set at $15 \mathrm{kV}$ ) for the analysis of major and minor elements with an atomic number, Z, between 11 and 26; and (2) an Al/Ti filtered high-energy excitation mode (high voltage set at $40 \mathrm{kV}$ ) for the analysis of minor and trace elements with an atomic number $\mathrm{Z}>26$.

The chemical composition was further examined in the Laboratory of Archaeometry at the University of the Peloponnese using a Scanning Electron Microscopy coupled with an Energy Dispersive Analyser (SEM/EDS). ${ }^{183}$ Fresh fractures of the tiles were prepared and analysed further with a JEOL JSM-6510LV device, coupled with an EDS by Oxford Systems. The analytical data were obtained using an INCA software. The analyses were conducted at $20 \mathrm{kV}$ accelerating voltage and with a count time of $120 \mathrm{sec}$. the analysed surfaces were approximately $300 x 400 \mu \mathrm{m}$ (spot size:40). The accuracy of the SEM/EDS settings was checked using a standard clay sample (Soil 7) (Table 9). EDS values shown in Table 9 confirmed the high accuracy of the quantitative data, with the exception of potassium, which is ca. $20 \%$ overestimated. ${ }^{184}$ In addition to the analytical techniques, Petrographic Analysis (PA) was undertaken due to the coarse nature of the material, using a LEICA DMEP polarizing microscope, in an attempt to reveal the clay mineralogical composition and their technological process. ${ }^{185}$

\section{Results and Discussion}

\section{Microscopic Characterisation}

Based on the macroscopic and microscopic observation of the samples, most of the studied tiles were well-fired. Three (TH5, TH6, TH7) samples showed a grayish or blackish core, suggesting incomplete oxidation (Fig. 33e,f,g). All analysed samples are coarse. A large amount of various small aplastic inclusions, coarse sand size $(<2 \mathrm{~mm})$ and granule size $(2-$ $4 \mathrm{~mm})$, sub-angular and sub-rounded, is attested in all examined samples. ${ }^{186}$ In addition, elongated and round voids are commonly present (Fig. 33a-h). Cover tiles show more small size inclusions and less voids, especially round in shape. On the contrary, pan tiles demonstrate a lot of elongated voids aligned with the margins of the surface and an abundance of granule-grained inclusions.

The amount of inclusions and the presence of organic material were also observed under SEM. All samples contained small and large size silica aggregates with cornered edges that belong to quartz minerals (Fig. 34a). Voids of burnt organic materials, probably straw, due to their elongated shape and imprint, and in one case the remains of a carbonised piece, were detected (Fig. 34b). Moreover, calcite particles were detected throughout the examined areas of the samples which led to varied vitrification state of the samples.

\section{Chemical Characterisation}

As mentioned before, the composition of major oxides was estimated by SEM/EDS, taking three measurements in various areas of each sample in order to obtain more accurate data

\footnotetext{
182 Zacharias et al. 2018.

183 Palamara et al. 2016

184 Liritzis et al. 2011, where overestimations of up to $30 \%$ in calcitic clay matrices for potassium oxide values that range between $2-3 \mathrm{wt} \%$, were reported and therefore calibration curves were produced regarding the accurate evaluation of the analytical data.

185 Quinn 2013.

186 Rice 2015.
} 
(Table 10). Due to the coarseness of the material, and the subsequent presence of large amounts of aggregates, the concentration of calcium oxide showed high variability in different areas of the same sample. Based on the average calcium concentration, all samples can be categorised as calcareous ( $\mathrm{CaO}$ concentration higher than $6 \mathrm{wt} \%) .{ }^{187}$

Based on the calcium oxides content of the clay fabric, the assemblage can be initially divided into 3 groups: (1) samples containing up to $10 \% \mathrm{CaO}$ oxides, (2) samples from $10 \%-15 \% \mathrm{CaO}$ and, finally, (3) a group with $\mathrm{CaO}$ oxides more than $15 \%$. The differentiation of the samples may indicate variation in organic matter added and is not based on the type of tiles, as cover tiles are included in all three groups. In addition, it should be noted that the amount of iron oxide does not vary significantly among the studied tiles, which could indicate the presence of iron as a natural component of the clay pastes used for the production of tiles. The high amount of silicon oxide was expected, taking into consideration the large amount of quartz inclusions in the clay body.

To better understand the compositional trends, a bi-plot diagram was made using $\mathrm{CaO}$ versus the ratio of $\mathrm{Al}_{2} \mathrm{O}_{3} / \mathrm{SiO}_{2}$ (Fig. 35) based on the SEM/EDS data. Based on this plot, it appears that the clay fabric of all samples shares similar chemical characteristics, varied only in calcium oxides. The increased $\mathrm{Al}_{2} \mathrm{O}_{3} / \mathrm{SiO}_{2}$ ratio corresponds to the finer samples which is also supported by the microscopic examination and should be attributed to differences in grain size within the same clay source and not to the use of different raw materials. Also, as finer samples should be attributed to cover tiles, the diagram suggests no evident distinction (apart from cover tile TH2).

In Table 11, the chemical composition of trace elements, estimated by $\mathrm{p}$-XRF is presented. It should be noted that barium $(\mathrm{Ba})$ and phosphorus $(\mathrm{P})$ cannot be used for comparison between samples, due to the large variability of the composition noted within the same sample.

Overall, the data of Table 11 indicate that raw materials of similar composition were used in the manufacture of the tiles, further supporting the outcomes of the analysis of the major composition.

To better understand the correlation between elements, a dendrogram was performed to highlight probable clustering (Fig. 36). From the dendrogram, a homogeneous group is formed creating two sub-groups mainly related to $\mathrm{Ca}$ amounts. Finally, a Principal Components Analysis (PCA) was conducted using Statistica software (StatSoft 2014) by employing the composition of major and minor elements from SEM/EDS and the composition of trace elements by $\mathrm{p}$-XRF. Taking into consideration that any dataset comprising of both major and trace elements is highly skewed, the common logarithm of the value of each elemental composition was estimated and incorporated in the PCA (Fig. 37). The plot shows that all samples form one homogeneous group. The only minor exception is sample TH7 (a pan tile), which slightly differs from the other examples in $\mathrm{Na}, \mathrm{Ti}, \mathrm{Sr}, \mathrm{Ca}, \mathrm{Ni}$ variables.

\section{Firing temperature}

Previous studies have proven that it is possible to evaluate the firing procedures (temperature and atmosphere), based on the chemical composition, and more specifically the calcium content, and the vitrification state of a ceramic sherd. ${ }^{188}$ The vitrification state of the samples of the present study was examined via SEM; the examined fresh fractures demonstrated significantly varied degrees of vitrification, ranging from 'Non-vitrification' to 'Continuous vitrification' (Figs 38a-b).

\footnotetext{
${ }^{187}$ For the preference of calcareous clays for the making of tiles and other building materials see Santacreu 2014, 173-6.

${ }^{188}$ Maniatis and Tite 1981; Kilikoglou et al. 1988.
} 
Table 12 summarizes the colour description, using a Munsell Color Chart, the calcium oxide content, the vitrification state as estimated by SEM and the subsequent firing temperature estimations. Overall, the estimated firing temperatures vary between $750^{\circ} \mathrm{C}$ and $950^{\circ} \mathrm{C}$, although the majority of the samples were fired at temperatures below $850^{\circ} \mathrm{C}$. It is interesting to note that cover tiles demonstrate a slightly smaller temperature range (between 800 and $950^{\circ} \mathrm{C}$ ) compared to pan tiles, as well as show complete oxidation during firing; analysis of more samples is required to verify whether this trend can indeed be attributed to a better control of the firing temperature in the production of cover tiles.

\section{Mineralogical analysis}

In the wider project of investigating Mycenaean tiles from different plots across Thebes, samples were selected for petrographic analysis. From the Theodorou plot, two samples belonging to pan tiles were selected due to their coarseness, as to reveal more information with regards to their geological background. The dominant inclusions in both samples were sandstone and chert fragments (Fig. 39a) limestone inclusions, containing a lot of elongated voids maybe left by burnt straw (Fig. 39b). The identified minerals are in good agreement with the geological formations around the city of Thebes, which consist of sedimentary rocks formed on Pliocene to Pleistocene in lacustrine environment. Sediments of conglomerate, sandstones, clays and marls are dominant in the area, as well as a limestone unit. ${ }^{189}$ Therefore, the mineralogical analysis further supports a local origin for the raw materials of the analysed tiles. ${ }^{190}$

\section{Concluding remarks}

The data from the multi-analytical study of a sample of Mycenaean tiles from the Theodorou plot shows that these objects were made using local clays attested in the surrounding area of Thebes ${ }^{191}$ and, in the case of pan tiles, were tempered with organic material (straw). Variations in the amounts of calcium oxide show either that there were multiple sources of raw materials or that there was variation of the composition of the clay within the same source. ${ }^{192}$ The coarseness of the samples reveals deliberate technological choices to produce tiles resistant in the outside temperatures. The more elaborate production of the cover tiles is probably connected with the plasticity needed for their formation. Moreover, variations in the clay paste of tiles found in the same excavated area, belonging to the same roof, could indicate a reuse of older tiles which were recovered intact from previously destroyed buildings. ${ }^{193}$

The variation in the vitrification state is probably a result of the coarseness of the samples as well as the amount of calcium oxide that they contain. Generally speaking cover tiles tend to be formed from the same finer clay paste and show marks of wheel made formation. However, there were indications of a more careful control of the firing temperature for the production of cover tiles (for the identification of possible fabrics and differences between the cover and pan tiles, we refer the reader to the main body of this article by Aravantinos, Fappas and Galanakis).

A comparison of the analytical results of the whole assemblage of tiles from different excavated plots around the city of Thebes has revealed variation in firing temperature and their vitrification state. Despite these differences, however, the samples we have examined, from the Theodorou and other Theban plots, all seem to share the same geological

\footnotetext{
${ }^{189}$ I.G.M.E. 1970; also, Jones 1986, 136: 'Thebes lies on the ridge overlooking the alluvial plain. The immediate geological surroundings are Pleistocene sediments - conglomerates, sandstone, sand and red loam. The hills to the N. of the Theban plain are composed of dolomitic limestone, sometimes oolitic with hornstone nodules.'

${ }^{190}$ Mommsen et al. 2002 also mention that in their study of 152 samples from Thebes local products prevail.

191 I.G.M.E. 1970.

192 Hilditch et al. 2008.

${ }^{193}$ Iakovidis, 1990, 155.
} 
background (i.e. all were locally produced). A forthcoming article by the authors will discuss the results of this multi-analytical study further. We hope similar studies will follow in order to shed more light on this important, though largely ignored, body of material.

\section{REFERENCES}

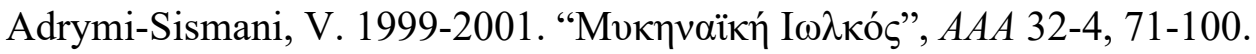

Adrimi-Sismani, V. 2007. 'Mycenaean Northern Borders Revisited: New Evidence from Thessaly', in Galaty, M.L. and Parkinson, W.A. (eds), Rethinking Mycenaean Palaces II, Second Edition, Cotsen Institute of Archaeology at UCLA Monograph 60, Los Angeles, 159-77.

Åkerström, A. 1941. 'Zur Frage der mykenische Dacheindeckung,' Opuscula Archaeologica 2, 164-73.

Åkerström, A. 1968. 'A Mycenaean Potter's Factory at Berbati near Mycenae', in Atti e Memorie del $1^{\circ}$ Congresso Internazionale di Micenologia. Incunabula Graeca 25:1-3, Roma, 48-53.

Alberti, M.-E., Aravantinos, V. L., del Freo, M., Fappas, I., Papadaki, A. and Rougemont, F. 2012. 'Textile Production in Mycenaean Thebes. A First Overview', in Laffineur, R. and Nosch, M.-L. (eds), KOSMOS, Proceedings of the 13th International Aegean Conference, University of Copenhagen, 19-23 April 2010. Aegaeum 33, Leuven and Liège, 87-105.

Alberti, M.-E., Aravantinos, V.L., Fappas, I., Papadaki, A., Rougemont, F., Andersson Strand, E., Nosch M.-L. and Cutler, J. 2015. 'Textile tools from Thebes, Greece', in Andersson Strand, E. and Nosch, M.-L. (eds), Tools, Textiles and Contexts. Investigating Textile Production in the Aegean and Eastern Mediterranean Bronze Age, Oxford, 279-92.

Alzinger, W. 1978. 'Aigeira 1976/77', AAA 11, 147-56.

Andreadaki-Vlazaki, M. 2015. 'Sacrifices in LM IIIB: Early Kydonia Palatial Centre', Pasiphae 9, 29-42.

Andrikou, E. 2006. 'The Late Helladic III Pottery', in Andrikou, E., Aravantinos, V., Godart, L., Sacconi, A. and Vroom, J. 2006. Thèbes. Fouilles de la Cadmée II.2. Les tablettes en linéaire B de la Odos Pelopidou: Le contexte archéologique. La céramique de la Odos Pelopidou et la chronologie du linéaire B, Pisa-Roma, 11-179.

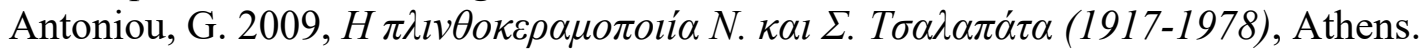

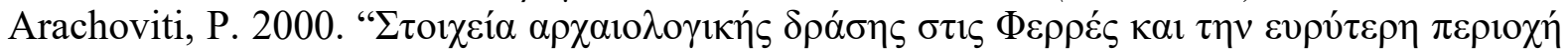

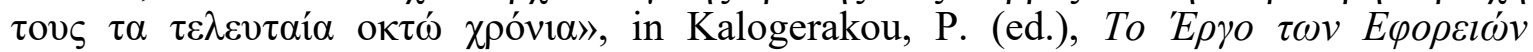

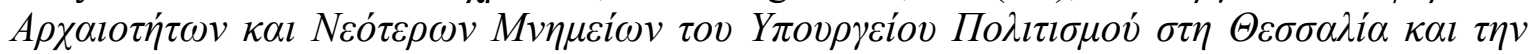

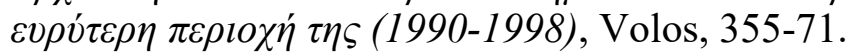

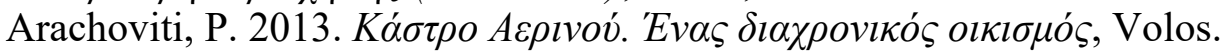

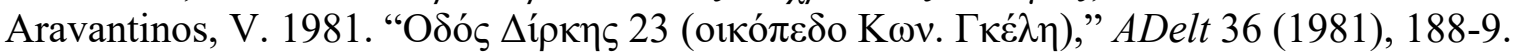

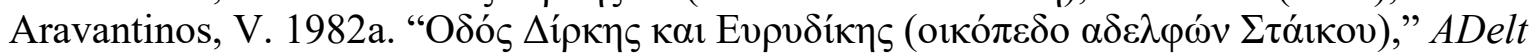
$37,165$.

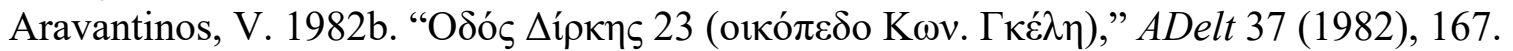

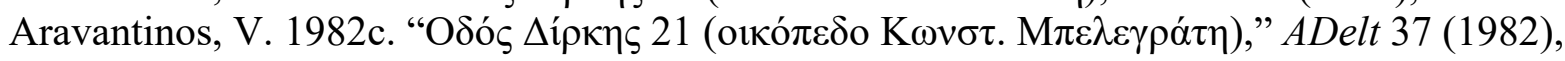
169.

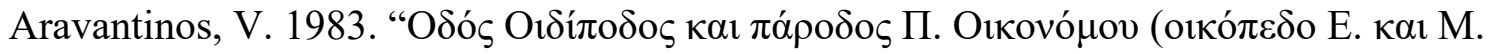

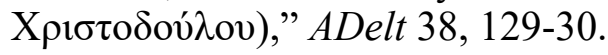

Aravantinos, V. 1985. 'Nuovi elementi sulle catastrofi nella Tebe micenea. Osservazioni preliminari', in Musti, D. (ed.), Le Origini dei Greci: Dori e mondo egeo, Roma and Bari, 349-57.

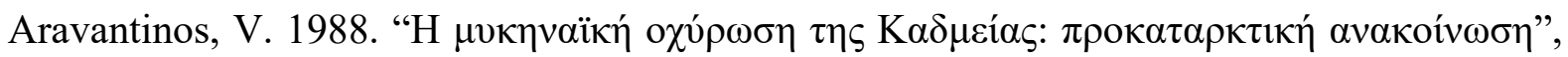

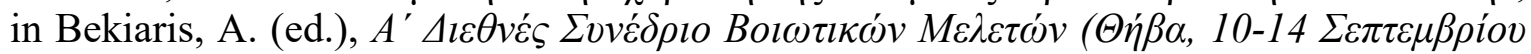
1986), Athens, 113-36.

Aravantinos, V. 1995. 'Old and New Evidence for the Palatial Society of Mycenaean Thebes: An Outline', in Laffineur, R. and Niemeier, W-D. (eds), Politeia: Society and State in the Aegean Bronze Age. Proceedings of the 5th International Aegean Conference / $5 e$ 
Rencontre égéenne internationale, University of Heidelberg, Archäologisches Institut, 1013 April 1994. Aegaeum 12, Liège and Austin, 613-22.

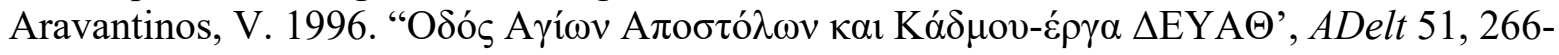
267.

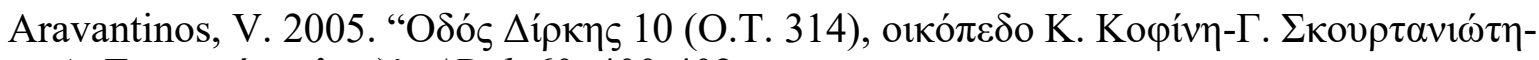

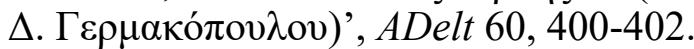

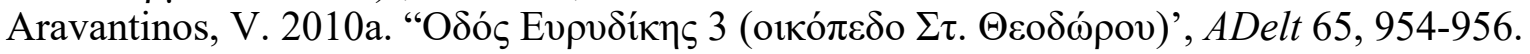

Aravantinos, V. 2010b. The Archaeological Museum of Thebes, Athens.

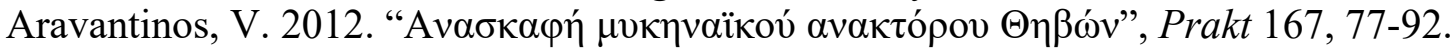

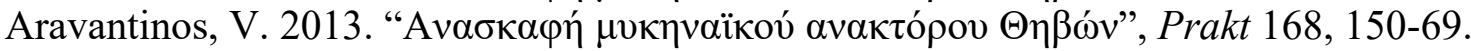

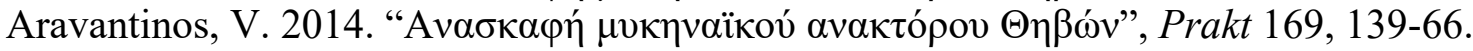

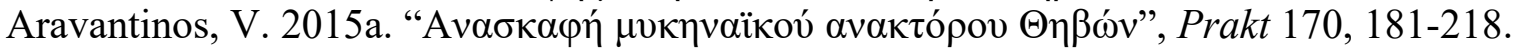

Aravantinos, V. 2015b. 'The Palatial Administration of Thebes Updated', in Weilhartner, J.

and Ruppenstein, F. (eds), Tradition and Innovation in the Mycenaean Palatial Polities,

Österreichische Akademie der Wissenschaften Philosophisch-historische Klasse

Denkschriften 487, Mykenische Studien 34, Vienna, 19-49.

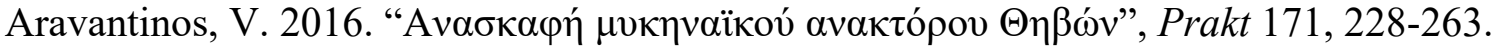

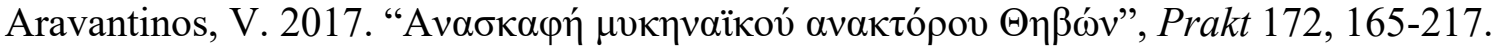

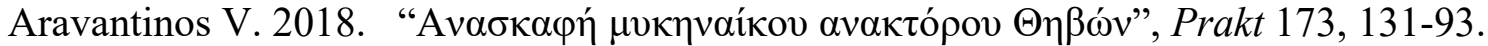

Aravantinos, V. 2019. 'Old Memories versus New trends in Postpalatial Thebes', in Borgna, E., Caloi, I., Carinci, F.M. and Laffineur, R. (eds), MNHMH / MNEME. Past and Memory in the Aegean Bronze Age. Proceedings of the 17th International Aegean Conference, University of Udine, Department of Humanities and Cultural Heritage, Ca' Foscari University of Venice, Department of Humanities, 17-21 April 2018, Aegaeum 43, Leuven and Liège, 187-197.

Aravantinos, V. 2020. 'Thebes and Boeotia', in Lemos, I.S. and Kotsonas, A. (eds.), $A$ Companion to the Archaeology of Early Greece and the Mediterranean, Oxford, 763-85.

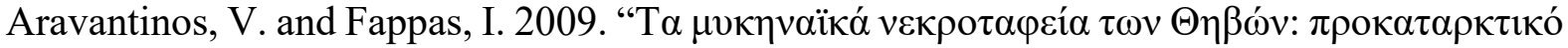
$\sigma \chi \varepsilon ́ \delta 10 \mu \varepsilon \lambda \varepsilon \dot{\tau}\rceil \eta \varsigma^{\prime}$, in Loukos, C., Xifaras, N. and Pateraki, K. (eds), Ubi dubium ibi libertas:

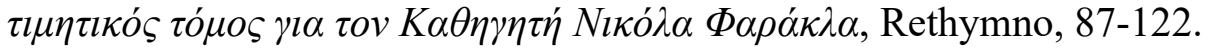

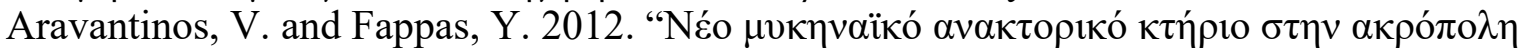

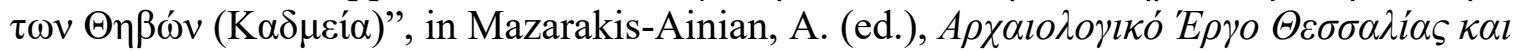

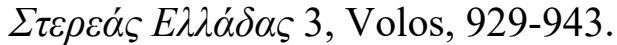

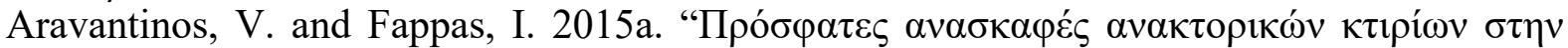

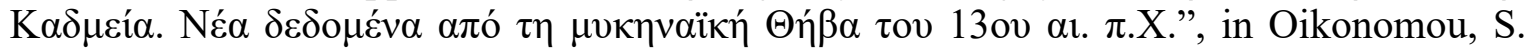

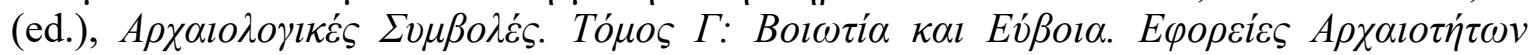

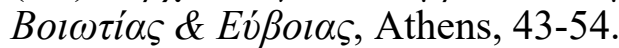

Aravantinos, V. and Fappas, I. 2015b. 'The Mycenaean Wall Paintings of Thebes: From Excavation to Restoration', in Brecoulaki, H., Davis, J.L. and Stocker, S.R. (eds), Mycenaean Wall Painting in Context: New Discoveries, Old Finds Reconsidered (Meletemata 72), Athens, 316-53.

Aston, D.A. 2011. 'The LH IIIA2-IIIB Transition: The Gurob and Saqqara Evidence Reassessed', in Gauß, W., Lindblom, M., Smith, R.A.K. and Wright, J.C. (eds.), Our Cups Are Full: Pottery and Society in the Aegean Bronze Age. Papers Presented to Jeremy B. Rutter on the Occasion of his 65th Birthday, Oxford, 1-12.

Bennet, J 2008. 'PalaceTM: Speculations on Palatial Production in Mycenaean Greece with (Some) Reference to Glass', in Jackson, C.M. and Wager, E.C. (eds.), Vitreous Materials in the Late Bronze Age Aegean, Sheffield Studies in Aegean Archaeology 9, Oxford, 151-72.

Bikaki, A.H. 1984. Ayia Irini: the Potters' Marks (Keos, IV), Mainz.

Birge, D.E., Kraynak, L.H., Miller, S.G. 1992. Excavations at Nemea, Topographical and Architectural Studies: the Sacred Square, the Xenon, and the Bath, Los Angeles and Oxford.

Birmingham, J. 1967. 'Pottery Making in Andros', Expedition 10, 33-9. 
Blegen, C.W. 1928. Zygouries: A Prehistoric Settlement in the Valley of Cleonae, Cambridge.

Blegen, C.W. 1945. 'The Roof of the Mycenaean Megaron', AJA 49, 35-44.

Blitzer, H. 1990. 'Koroneika: Storage-jar Production and Trade in the Traditional Aegean', Hesperia 59:4, 675-711.

Broneer, O. 1939. 'A Mycenaean Fountain on the Athenian Acropolis,' Hesperia 8, 317-433.

Brown, A.C.B. 1905-1906. 'Excavations at Schimatari and Dilisi in Boeotia', BSA 12, 93 100.

Burke, B., Burns, B., Charami, A. and Kyriazi, O. 2013. 'Eastern Boeotia Archaeological Project: Preliminary Report on Excavations 2011-2013', Teiresias 43:2, 9-25.

Burke, B., Burns, B., Charami, A., Herrmann, N., Lis, B. and Van Damme, T. 2020. 'Fieldwork at Ancient Eleon in Boeotia, 2011-2018', AJA 124:3, 441-76.

Burns, B.E. 2007. 'Epic Reconstructions: Homeric Palaces and Mycenaean Architecture', in Morris, S.P. and Laffineur, R. (eds), Epos: Reconsidering Greek Epic and Aegean Bronze Age Archaeology, Proceedings of the 11th International Aegean Conference / 11e Rencontre égéenne internationale, Los Angeles, UCLA - The J. Paul Getty Villa, 20-23 April 2006. Aegaeum 28, Liège and Austin, 141-9.

Coulton, J.J. 1977. Greek Architects at Work, Oxford.

Dakouri, A. 1998. The House of Kadmos at Mycenaean Thebes: A preliminary reexamination of the architecture, Unpublished MA thesis, Durham University (http://etheses.dur.ac.uk/4747/)

Dakouri-Hild, A. 2001. 'The House of Kadmos in Mycenaean Thebes reconsidered: architecture, chronology and context', BSA 96, 81-122.

Dakouri-Hild, A. 2006. 'Something old, something new: current research on the 'Old Kadmeion' of Thebes', BICS 48, 173-86.

Dakouri-Hild, A. 2010. 'Boeotia', in Cline, E.H. (ed.), The Oxford Handbook of the Bronze Age Aegean (ca. 3000-1000 BC), Oxford, 614-30.

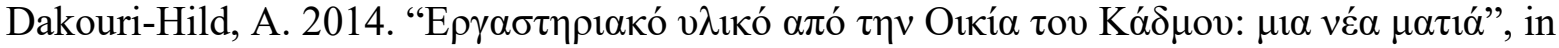

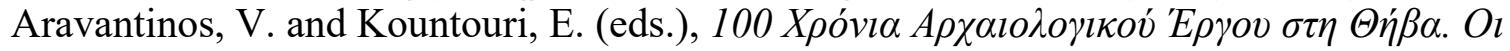

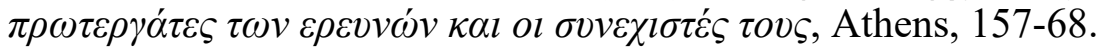

Darcque, P. 2005. L'Habitat Mycénien: Formes et Fonctions de l'Espace Bâti en Grèce Continentale à la Fin du IIe Millénaire avant J.-C. (BEFAR 319), Paris.

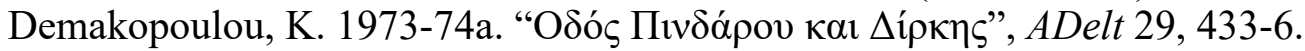

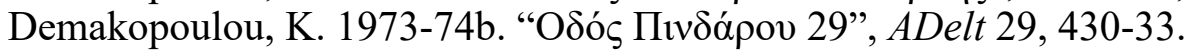

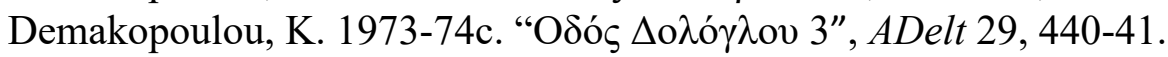

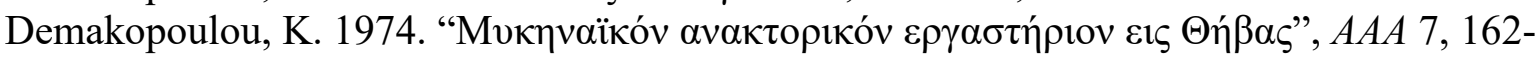
73.

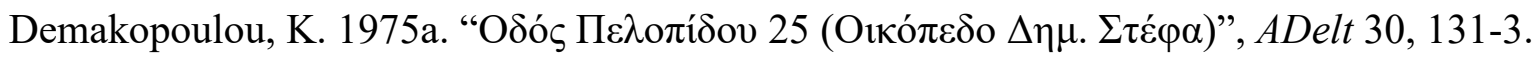

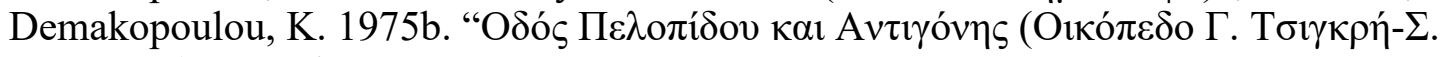
Mакри́)”, ADelt 30, 133.

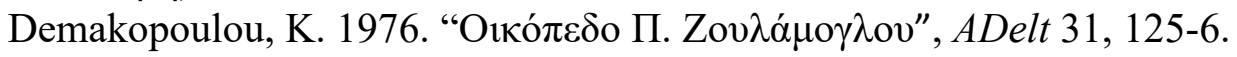

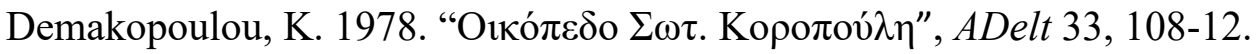

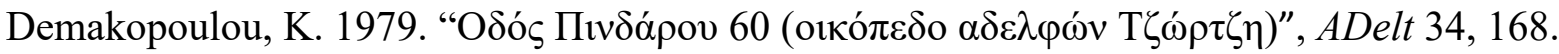

Demakopoulou, K. 1990. 'Palatial and Domestic Architecture in Mycenaean Thebes', in Darcque, P. and Treuil, R. (eds), L'Habitat Egéen Préhistorique, BCH Suppl. XIX, Paris, 307-317.

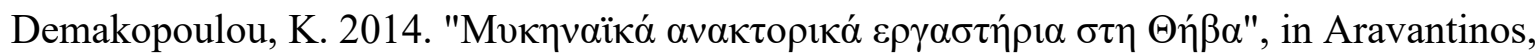

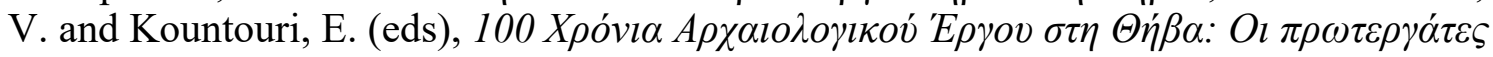

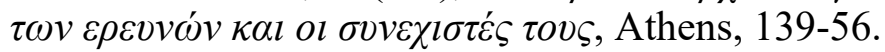

Demakopoulou, K. and Crouwel, J. 1984. 'Some Mycenaean Pictorial Pottery from Boeotian Thebes', BSA 79, 37-48.

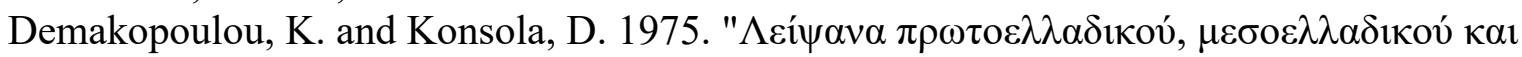

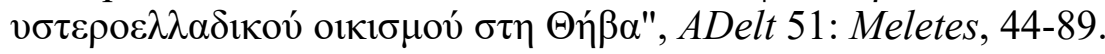


Egan, E.C. 2015. 'Working within the Lines: Artists' Grids and Painted Floors at the Palace of Nestor', in Lepinski, S. and McFadden, S. (eds), Beyond Iconography:

Materials, Methods, and Meaning in Ancient Surface Decoration, Boston, 187-204.

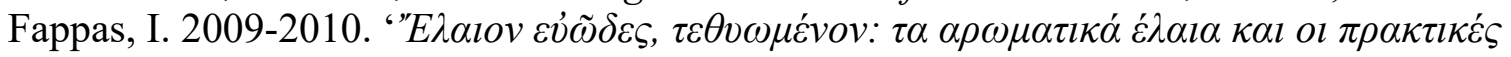

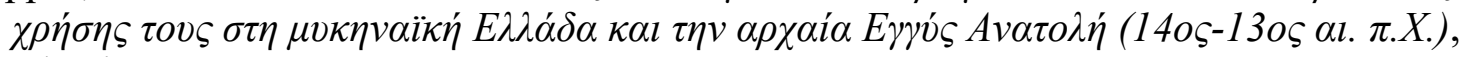
Chania.

Fappas, I. 2018. 'Dachziegel \& Fragment eines Dachziegels', in Steinmann, B.F. (ed.), Mykene. Die sagenhafte Welt des Agamemnon, Karlsruhe, 318.

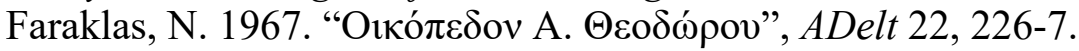

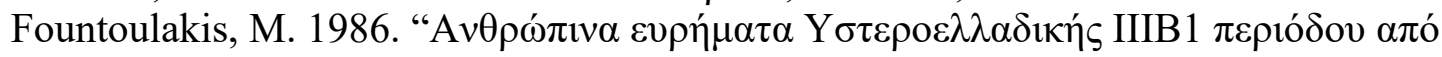

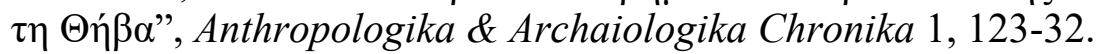

French, E.B. and Stockhammer, P. 2009. 'Mycenae and Tiryns: the Pottery of the Second Half of the Thirteenth Century BC - Contexts and Definitions', BSA 104, 175-232.

Galanakis, Y. 2016. 'A Roof for the Dead: Tomb Design and the 'Domestication of Death' in Mycenaean Funerary Architecture', in Dakouri-Hild, N. and Boyd, M. (eds), Staging Death: Funerary Performance, Architecture and Landscape in the Aegean, Berlin and Boston, 155-77.

Galaty, M.L. 1999. Nestor's Wine Cups: Investigating Ceramic Manufacture and Exchange in a Late Bronze Age "Mycenaean" State, Oxford.

Galaty, M.L. 2007. 'Wealth Ceramics, Staple Ceramics: Pots and the Mycenaean Palaces', in Galaty, M.L. and Parkinson, W.A. (eds), Rethinking Mycenaean Palaces II, Revised and expanded second edition, Cotsen Institute of Archaeology at UCLA Monograph 60, Los Angeles, 74-86.

Galaty, M.L. 2010. 'Wedging Clay: Combining Competing Models of Mycenaean Pottery Industries', in Pullen, D. (ed.), Political Economies of the Aegean Bronze Age: Papers from the Langford Conference, Florida State University, Tallahassee, 22-24 February 2007, Oxford and Oakville, 230-47.

Gauss, W., Klebinder-Gauss, G., and von Rüden, C. (eds) 2015. The Transmission of Technical Knowledge in the Production of Ancient Mediterranean Pottery. Proceedings of the International Conference at the Austrian Archaeological Institute at Athens 23rd-25th November 2012. Österreichisches Archäologisches Institut Sonderschriften Band 54, Vienna.

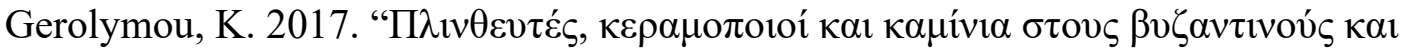

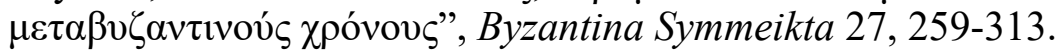

Glendinning, M. 2005, 'A Decorated Roof at Gordion: What Tiles are Revealing about the Phrygian Past', in Kealhofer, L. (ed.), The Archaeology of Midas and the Phrygians. Recent Work at Gordion, Philadelphia, 82-100.

Guest-Papamanoli, A. 1978. 'L'emploi de la brique crue dans le domaine égéen à l'époque néolithique et à l'âge du bronze', $B C H$ 102, 3-24.

Halstead, P. 1993. 'The Mycenaean palatial economy: Making the most of the gaps in the evidence', $P C P S$ 38, 57-86.

Hampe, R. and A. Winter 1965. Bei Töpfern und Zieglern in Süditalien, Sizilien, und Griechenland, Mainz.

Hasaki, E. 2011. 'Crafting Spaces: Archaeological, Ethnographic and Ethnoarchaeological Studies on Spatial Organization in Pottery Workshops in Greece and Tunisia', in Lawall, M. and Lund, J. (eds.), Pottery in the Archaeological Record: Greece and Beyond, Aarhus, 12-24.

Haskell, H.W., Jones, R.E., Day, P.M. and Killen, J.T. 2011. Transport Stirrup Jars of the Bronze Age Aegean and East Mediterranean, INSTAP Prehistory Monographs 33, Philadelphia.

Heiden, J. 1987. Korinthische Dachziegel: Zur Entwicklung der korinthischen Dächer, Frankfurt.

Heiden, J. 1995. Die Tondächer von Olympia (Olympische Forschungen 24), Berlin.

Hiesel, G. 1989. Späthelladische Hausarchitektur, Mainz am Rhein. 
Hilditch, J., Kiriatzi, E., Psaraki, K. and Aravantinos, V. 2008. 'Early Helladic II Pottery from Thebes: An Integrated Typological, Technological and Provenance Study', in Facorellis, Y., Zacharias, N., Polikreti, K. (eds), Proceedings of the 4th Symposium of the Hellenic Society of Archaeometry, Athens, 263-8.

Hinzen, K.-G., Maran, J., Hinojosa-Prieto, H., Damm-Meinhardt, U., Reamer, S.K., Tzislakis, J., Kemna, K., Schweppe, G., Fleischer, C., Demakopoulou, K. 2018. 'Reassessing the Mycenaean Earthquake Hypothesis: Results of the HERACLES Project from Tiryns and Midea, Greece', Bulletin of the Seismological Society of America 108 (3A), 1046-70.

Hirschfeld, N.E. 1999. Potmarks of the Late Bronze Age Eastern Mediterranean. Unpublished $\mathrm{PhD}$ dissertation, University of Texas at Austin.

Hodge, A.T. 1960. The woodwork of Greek Roofs, Cambridge.

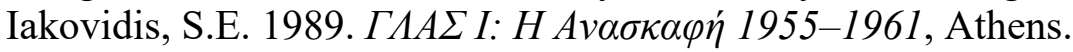

Iakovidis, S.E. 1990. 'Mycenaean roofs: form and construction', in Darcque, P. and Treuil, R. (eds), L'Habitat Égéen Préhistorique, BCH Suppl. XIX, Paris, 147-60.

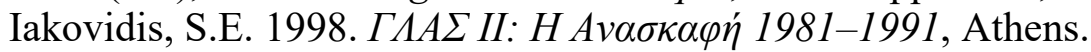

Iakovidis, S.E. 2001. Gla and the Kopaïs in the 13th c. B.C., Athens.

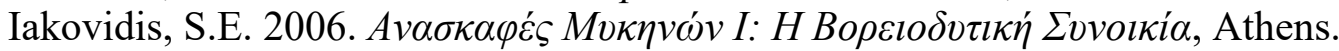

Iakovidis, S.E. 2009. 'Habitation in the Mycenaean Period', Lagopoulos, A.P. (ed.), $A$ History of the Greek City, Oxford, 99-107.

I.G.M.E. 1970. Geological Map of Thebes, Scale = 1:50,000, Athens.

Jazwa, K.A. 2018. 'The Construction of Early Helladic II Ceramic Roofing Tiles from Mitrou, Greece: Influence and Interaction', Mediterranean Archaeology and Archaeometry 18.2, 153-73.

Jones, R. 1986. Greek and Cypriot Pottery: A Review of Scientific Studies, London.

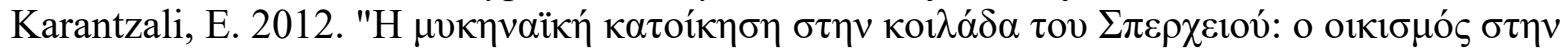

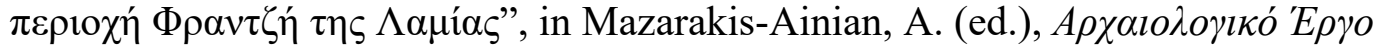

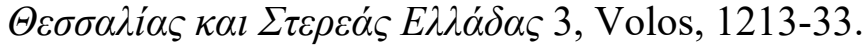

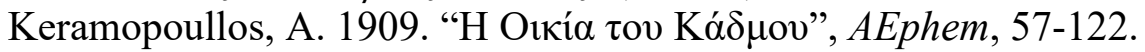

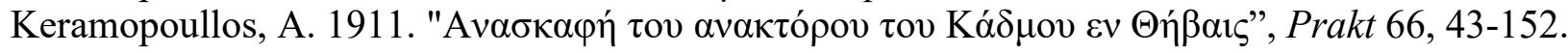

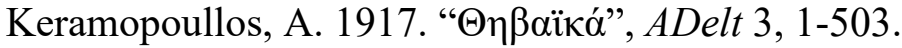

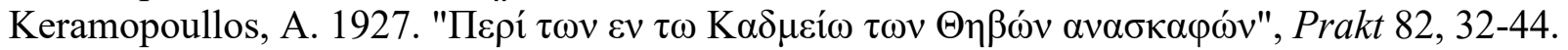

Kilikoglou V., Vassilaki-Grimani, M., Maniatis Y. and Grimanis, A.P., 1988. 'A study of Ancient Roof Tiles found in Pella, Greece', MRS Proceedings 123.

Kolonas, L. 2009. Network of Visitable Mycenaean Settlements and Cemeteries in the Prefecture of Patras: Chalandritsa, Katarraktis, Mitopoli, Spaliareika, Elaiochorion, Portes, Athens.

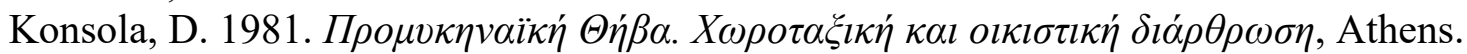

Krattenmaker, K. 1991. Minoan Architectural Representation, Unpublished Ph.D. dissertation, Bryn Mawr College.

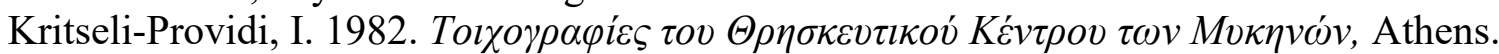

Küpper, M. 1996. Mykenische Architektur. Material, Bearbeitungstechnik, Konstruktion und Erscheinungsbild, Espelkamp.

Lemmonier, P. 1993. Technological Choices. Transformation in Material Cultures since the Neolithic, London.

Lenuzza, V. 2013. 'Of Roofs and Roof Drainage: A Survey of the Evidence in Bronze Age

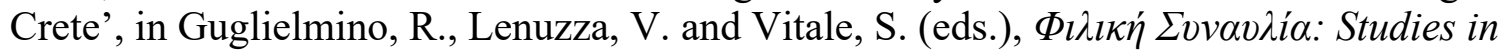
Mediterranean Archaeology for Mario Benzi, Graziadio, Oxford, 79-98.

Lindblom, M. 2001. Marks and Makers. Appearance, Distribution and Function of Middle and Late Helladic Manufacturers' Marks on Aeginetan Pottery, Jonsered.

Liritzis, I. and Zacharias, N. 2010. 'Portable XRF for Use in Archaeology', in Shackley, S. (ed.), XRF Technology and Modern Applications, New York, 109-42.

Liritzis, I., Mavrikis, D., Zacharias, N., Sakalis, A., Tsirliganis, N., Polymeris, G.S. 2011. 'Potassium determinations using sem, faas and xrf: Some experimental notes', Mediterranean Archaeology and Archaeometry 11:2, 169-79. 
Maniatis Y. and Tite M.S. 1981. 'Technological Examination of Neolithic- Bronze Age Pottery from Central and Southeast Europe and from Near East', JAS 8, 59-76.

Manning, S.W. 2010. 'Chronology and Terminology', in Cline, E.H. (ed.), The Oxford Handbook of the Bronze Age Aegean (ca. 3000-1000 BC), Oxford, 11-28.

Maran, J. and Papadimitriou, A. 2016. 'Gegen den Strom der Geschichte: Die nordlich Understadt von Tiryns: ein gescheitertes Urbanisierungsprojekt der mykenischen Nachpalastzeit', $A A, 19-118$.

Mathew, A.J., Woods, A.J. and Oliver, C. 1991. 'Spots before your eyes: new comparison charts for visual percentage estimation in archaeological material', in Middleton, A.P. and Freestone, I.C. (eds.), Recent developments in ceramic petrology, British Museum Occasional Paper 81, London, 211-63.

Matson, F.R. 1973. 'The Potters of Chalkis', in Borza, E.N. and Carruba, R.W. (eds.), Classics and the Classical Tradition: Essays presented to Robert E. Dengler on the Occasion of his Eightieth Birthday, University Park, PA, 117-42.

Mazow, L.B. 2014. 'The Root of the Problem: On the Relationship between Wool Processing and Lanolin Production', JMA 27:1, 33-50.

Merker, G.S. 2006. The Greek Tile Works at Corinth: The Site and the Finds (Hesperia Supplement 35), Princeton.

Mommsen, H., E. Andrikou, V. Aravantinos, and J. Maran. 2002. 'Neutron activation analysis results of Bronze Age pottery from Boeotia including ten Linear B inscribed stirrup jars of Thebes', in Erzsébet, J. and Biró, K.T. (eds.) Archaeometry 98: Proceedings of the 31st Symposium, Budapest, April 26 - May 3 1998, Vol. II, Oxford, 607-12.

Morgan, L. 2005. 'The Cult Centre at Mycenae and the duality of life and death', in Morgan, L. (ed.), Aegean Wall Painting: A Tribute to Mark Cameron, BSA Studies 13, London, 159-71.

Mountjoy, P. 1983. Orchomenos V: Mycenaean Pottery from Orchomenos, Eutresis and Other Boeotian Sites, Munich.

Mylonas-Shear, I. 1987. The Panagia Houses at Mycenae, Philadelphia.

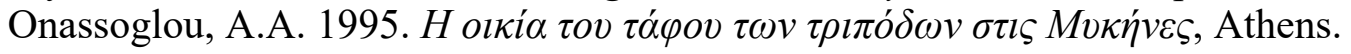

Orlandos, A. 1966. Les matériaux de construction et la technique architecturale des anciens Grecs I, Paris.

Orton, C. and Hughes, M. 2013. Pottery in Archaeology, second edition, Cambridge.

Palaima, T.G. 1997. 'Potter and Fuller: The Royal Craftsmen', in Laffineur, R. and Betancourt, P.P. (eds.), TEXNH: Craftsmen, Craftswomen and Craftsmanship in the Aegean Bronze Age. Proceedings of the 6th International Aegean Conference, Philadelphia, Temple University, 18-21 April 1996 (Aegaeum 16), Liège, 407-12.

Palaiologou, H. 2015. 'The Mycenaean building at Chania of Mycenae', in Schallin, A.-L. and Tournavitou, I. (eds), Mycenaeans Up To Date: the Archaeology of the NE Peloponnese. Current Concepts and New Directions, Stockholm, 53-78.

Palamara, E., Zacharias, N., Papakosta, L., Palles, D., Kamitsos, E.I., Pérez-Arantegui, J. 2016. 'Studying a Funerary Roman Vessel Glass Collection from Patras, Greece: An Interdisciplinary Characterisation and Use Study', STAR: Science \& Technology of Archaeological Research 3:2, 1-14.

Papadopoulos, J.K. 1994. 'Early Iron Age Potters' Marks in the Aegean', Hesperia 63:4, 437507.

Papadopoulos, C. 2013. 'An Evaluation of Human Intervention in Abandonment and Postabandonment Formation Processes in a Deserted Cretan Village', JMA 26:1, 27-50.

Peacock, D.P.S. 1977. 'Ceramics in Roman and Medieval Archaeology', in Peacock, D. (ed.), Pottery and Early Commerce: Characterization and Trade in Roman and Later Ceramics, London, 21-33.

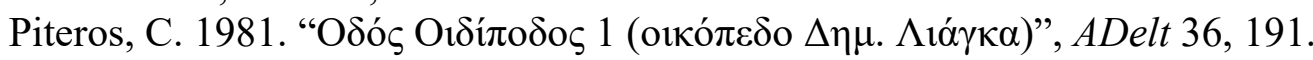

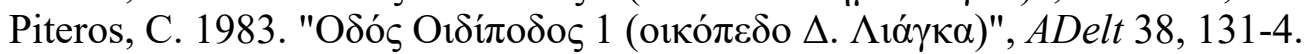

Piteros, C., Olivier, J.-P. and Melena, J.L. 1990. 'Les inscriptions en linéaire B des nodules de Thèbes (1982): La fouille, les documents, les possibilités d'interprétation', BCH 114, 103-81. 
Quinn, P.S. 2013. Ceramic Petrography. The Interpretation of Archaeological Pottery \& Related Artefacts in Thin-Section, Oxford.

Rice, P. 2015. Pottery Analysis: A sourcebook, second edition, Chicago.

Rostoker, W. and E. Gebhard. 1981. 'The Reproduction of Rooftiles for the Archaic Temple of Poseidon at Isthmia, Greece,' JFA 8, 211-27.

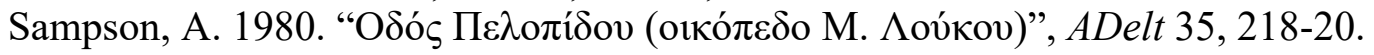

Sampson, A. 1985. 'La destruction d'un atelier palatial mycénien à Thèbes', $B C H$ 109, 21-9.

Sampson, A. 1996. 'Cases of Earthquakes at Mycenaean and Pre-Mycenaean Thebes', in Stiros, S. and Jones, R.E. (eds), Archaeoseismology. Fitch Laboratory Occasional Paper 7, Athens, 113-17.

Santacreu, D.A. 2014. Materiality, techniques and society in pottery production. The technological study of archaeological ceramics through paste analysis, Warsaw and Berlin.

Sapirstein, P. 2008. The Emergence of Ceramic Roof Tiles in Archaic Greek Architecture. Unpublished PhD dissertation, Cornell University.

Sapirstein, P. 2009. 'How the Corinthians Manufactured Their First Roof Tiles', Hesperia 78:2, 195-229.

Sapirstein, P. 2016. 'Origins and Design of Terracotta Roofs in the Seventh Century BCE', in Miles, M.M. (ed.), A Companion to Greek Architecture, Oxford, 46-59.

Schäfer, J. 1980. Tiryns IX: Grabungen in der Unterburg 1971, Mainz.

Schäfer, J. and P. Grossman. 1975. Tiryns VIII, Mainz.

Schliemann, H. 1885. Tiryns. The Prehistoric Palace of the Kings of Tiryns. The Results of the Latest Excavations, London.

Schwedt, A., Aravantinos, V., Harami, A., Kilikoglou, V., Kylafi, M., Mommsen, H. Zacharias, N. 2006. 'Neutron Activation Analysis of Hellenistic Pottery from Boeotia, Greece', JAS 33, 1065-74.

Shaw, J.W. 2004. 'Roof drains and parapets in the southern Aegean', BSA 99, 173-88.

Shaw, J.W. 2012. 'Bathing at the Mycenaean Palace of Tiryns', AJA 116:4, 555-571.

Shelmerdine, C.W. 1997. 'Workshops and Record Keeping in the Mycenaean World', in Laffineur, R. and Betancourt, P.P. (eds), TEXNH: Craftsmen, Craftswomen and Craftsmanship in the Aegean Bronze Age. Proceedings of the 6th International Aegean Conference, Philadelphia, Temple University, 18-21 April 1996. Aegaeum 16, Liège and Austin, 387-96.

Shelton, K. 2010. 'Citadel and Settlement: A Developing Economy at Mycenae, the Case of Petsas House', in Pullen, D.J. (ed.), Political Economies of the Aegean Bronze Age: Papers from the Langford Conference, Florida State University, Tallahassee, 22-24 February 2007, Oxford and Oakville, 184-204.

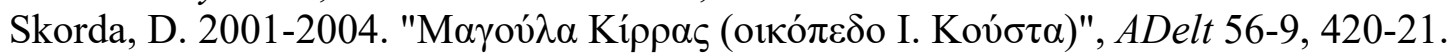

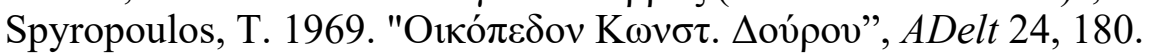

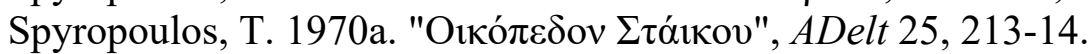

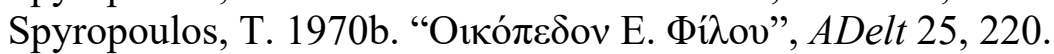

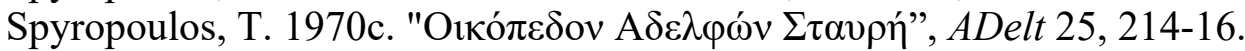

Spyropoulos, T. 1970d. 'The Discovery of the Palace Archives of Boeotian

Thebes', Kadmos 9, 170-72.

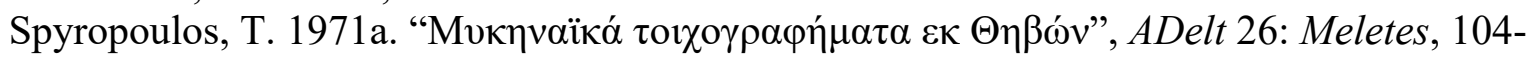
19.

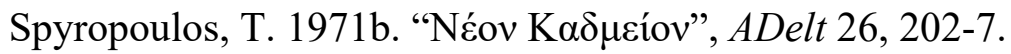

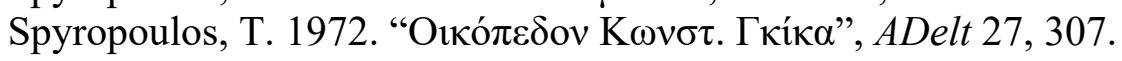

Spyropoulos, T. and Chadwick, J. 1975. The Thebes Tablets II, Minos Suppl. 4, Salamanca.

Stevens, G. P. 1950. 'A Tile Standard in the Agora of Ancient Athens', Hesperia 19, 174-88.

Stiros, S. and Jones, R.E. (eds.) 1996. Archaeoseismology. Fitch Laboratory Occasional Paper 7, Athens.

Symeonoglou, S. 1973. Kadmeia 1: Mycenaean finds from Thebes, Greece: excavations at 14 Oedipus Street, Goteborg. 
Symeonoglou, S. 1985. The Topography of Thebes from the Bronze Age to Modern Times, Princeton.

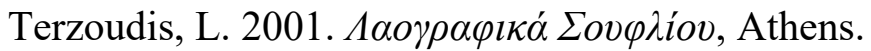

Thaler, U. 2018. me-ka-ro-de mykenische Paläste als Dokument und Gestaltungsrahmen frühgeschichtlicher Sozialordnung, Bonn.

Thaler, U. 2020. 'Architecture', in Lemos, I.S. and Kotsonas, A. (eds), A Companion to the Archaeology of Early Greece and the Mediterranean, Oxford, 377-406.

Thomas, P.M. 2005. 'A Deposit of Late Helladic IIIB1 Pottery from Tsoungiza', Hesperia $74: 4,451-573$.

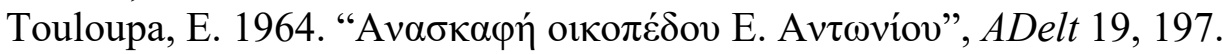

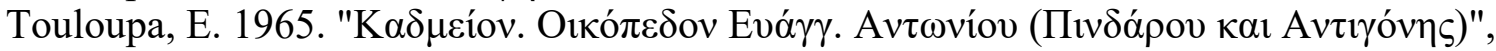
ADelt 20, 233.

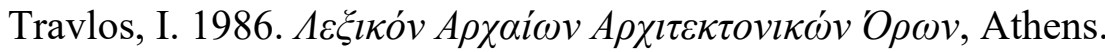

Tzavella-Evjen, H. 2014. Mycenaean pottery and figurines: Keramopoullos excavations from the cemeteries of Thebes, Athens.

Valmin, M.N. 1938. The Swedish Messenia Expedition, Lund.

Van Damme, T.M. 2017. Life after the Palaces: A Household Archaeology Approach to Mainland Greece during Late Helladic IIIC. Unpublished PhD dissertation, UCLA.

Vitale S., 2006. 'The LH IIIB - LH IIIC transition on the Mycenaean Mainland. Ceramic phases and terminology', Hesperia 75, 177-204.

Vitale, S. 2013. 'Local Traditions and Mycenaeanization in Central Greece: A Preliminary Report on the Late Helladic IIA to Late Helladic IIIB Pottery from Mitrou, East Lokris', in Mazarakis Ainian, A. and Doulgeri-Intzesiloglou, A. (eds), Proceedings of the 3rd Archaeological Meeting of Thessaly and Central Greece 2006-2008. From Prehistory to the Contemporary Period, Volos 12-15 March 2009, Volos, 1147-58.

Walberg, G. 1998. Excavations on the Acropolis of Midea. Results of the Greek-Swedish Excavations. The Excavations on the Lower Terraces 1985-1991, Stockholm.

Walberg, G. 2007. Midea: The Megaron Complex and Shrine Area. Excavations on the Lower Terraces, 1994-7, Philadelphia.

Warren, P. and Hankey, V. 1989. Aegean Bronze Age Chronology, Bristol.

Wiencke, M.H. 2000. Lerna IV.1: The Architecture, Stratification, and Pottery of Lerna III, Princeton.

Wiener, M.H. 2003. 'The absolute chronology of Late Helladic III A2 revisited', $B S A$ 98, 239-50.

Wikander, Ö. 1986. Acquarossa. Vol. VI. The Roof-Tiles. Part 1. Catalogue and Architectural Context, Stockholm.

Wikander, Ö. 1988. 'Ancient roof-tiles: use and function', Opuscula Atheniensia 17, 203-16.

Winter, N.A. 1993. Greek Architectural Terracottas: From the Prehistoric to the End of the Archaic Period, Oxford.

Winter, N.A. 2009. Symbols of Wealth and Power: Architectural Terracotta Decoration in Etruria and Central Italy, 640-510 B.C., Ann Arbor.

Zacharias, N., Kaparou, M., Oikonomou, A., Kasztovszky, Z. 2018. 'Mycenaean Glass from the Argolid, Peloponnese, Greece: A Technological and Provenance Study', Microchemical Journal 141, 404-17.

Zavadil, M. 2007. 'Ein Haus für die Toten? Kammergräber mit Satteldach auf dem mykenischen Festland', in Alram-Stern, E. and Nightingale, G. (eds), KEIMELION: The Formation of Elites and Elitist Lifestyles from Mycenaean Palatial Times to the Homeric Period, Vienna, 353-80.

\section{CAPTIONS}

Fig. 1. Pan and cover tiles as found in the destruction layer inside the 'central room' in the Theodorou plot excavation (trenches B- $\Gamma$ ). Photograph by Ioannis Fappas. 
Fig. 2. Pan and cover tiles as found on the floor of the corridor in the Theodorou plot excavation (trenches $\Delta$-E). Photograph by Ioannis Fappas.

Fig. 3. Plan of the Theodorou plot showing LH IIIB building remains and distribution of tiles. Excavation trenches A-Z are also indicated. Drawing by Sotiris Kazakidis, updated by Yannis Galanakis.

Fig. 4. A selection of representative shapes from the Theodorou destruction assemblage (not in scale): a) from the 'central room'; b) from the open space between the 'central room' and the 'burnt room'; c) from the 'burnt room'. Photographs by Ioannis Fappas.

Fig. 5. Aerial view of the Theodorou plot. Photograph by Ioannis Fappas.

Fig. 6. View from the east of the 'Burnt' room and of the open space between this building and the 'central room' (visible in the upper left side of the picture). Photograph by Ioannis Fappas.

Fig. 7. View of the 'Central room' from the east. Photograph by Ioannis Fappas.

Fig. 8. Reconstruction drawings of the Theodorou plot LH IIIB building remains: a) version 1 , with opening near the north-east corner of the 'central room'; b) version 2 with no opening in the 'central room'; c) version 3, with opening on the east end of the 'central room'. The transverse wall, marked in light grey on the plans, was probably built in a later phase of the 'central room', before the building's destruction. Its construction blocked the east end from the rest of the 'central room'. Drawings by Yannis Galanakis.

Fig. 9. View of the bathtub and impression of the underside of a burnt basket. Photograph by Ioannis Fappas.

Fig. 10. View of the drain near the south end of the Theodorou plot. Photograph by Ioannis Fappas.

Fig. 11. The Theodorou plot Mycenaean building remains in relation to those found in nearby plots. Drawing by Yannis Galanakis (after Demakopoulou 1974, Aravantinos 1982, Aravantinos and Fappas 2015).

Fig. 12. Cover tile drawings showing where measurements were taken in the study of the material from the Theodorou plot. Drawing by Kalliopi Mitsopoulou annotated by Yannis Galanakis.

Fig. 13. Pan tile drawings showing where measurements were taken in the study of the material from the Theodorou plot. Drawing by Kalliopi Mitsopoulou annotated by Yannis Galanakis.

Fig. 14. Clay packing with reed imprints $(\Delta 15)$ found inside the 'burnt room' in the Theodorou plot. Photograph by Yannis Galanakis.

Fig. 15. Top: reconstruction drawing of the 'central room' in the Theodorou plot with a twosided pitched roof (angle set at $25^{\circ}$ ) and a door on the east side, viewed from the SE; bottom: reconstruction drawing of the 'central room' in the Theodorou plot with mono-plane roof (angle set at $15^{\circ}$ ) and a door on the east side, viewed from the SE. The drain is sketchily illustrated and may well have originally been covered over with stone slabs. The 'burnt room' is also sketchily shown. Drawings by Kali Kapsali with Yannis Galanakis. 
Fig. 16. Top: measurements of the reconstructed 'central room' with a two-sided pitched roof; bottom: measurements of the reconstructed 'central room' with a mono-plane roof. Drawings by Kali Kapsali with Yannis Galanakis.

Fig. 17. Cover tile K210.01 (K1) from the Theodorou plot, outer (left) and inner (right) views. Photographs by Yannis Galanakis.

Fig. 18. Drawings of cover tiles arranged according to size, from the Theodorou plot assemblage. Drawings by Kalliopi Mitsopoulou.

Fig. 19. Close-up photographs of the three sides of cover tiles showing toolmarks: (a) created by a rope or string; (b-c) created by two different toothed cutting tools. Photographs by Yannis Galanakis.

Fig. 20. Pan tile $\Sigma 216.01$ ( $\Sigma 9$ ) from the Theodorou plot, outer (left) and inner (right) views. Photographs by Yannis Galanakis.

Fig. 21. Drawings of pan tiles arranged according to size, from the Theodorou plot assemblage. Drawings by Kalliopi Mitsopoulou.

Fig. 22. Partial reconstruction of the Mycenaean tiled roof from the Theodorou plot. Drawing by Yannis Galanakis (after drawings of pan and cover tiles by Kalliopi Mitsopoulou).

Fig. 23. Fragment of pan tile no. $\Sigma 216(\Sigma 210.59)$ from the Theodorou plot. 'Nail-hole' visible on the tile's sidewall. Photograph by Yannis Galanakis.

Fig. 24. Underside of a pan tile fragment (body sherd from B216) with traces of straw. Photograph by Yannis Galanakis.

Fig. 25. Pan tile fragment no. $\Sigma 315.01$ with a trace of a human footprint on its upper surface. Drawing by Kalliopi Mitsopoulou. Photograph by Yannis Galanakis.

Fig. 26. A comparison of a pan tile from the Theodorou plot assemblage $(\Sigma 210.02(\Sigma 2))$ and a pan tile from the Stavris plot excavations (no. 1929-1930). Photographs by Yannis Galanakis.

Fig. 27. Drawings of two finely made pan tiles from the Stavris plot (nos 1929-1930 and 1932). Drawings by Kalliopi Mitsopoulou.

Fig. 28. Detail of the Stavris plot pan tile (no. 1931) showing incised $\Lambda$-shaped mark on sidewall. Photograph by Yannis Galanakis.

Fig. 29. A comparison of a pan tile from the Theodorou plot assemblage (K507.01 (K8)) and a pan tile from the Stavris plot excavations (no. 1932). Photographs by Yannis Galanakis.

Fig. 30. A pan tile from the Liangas plot excavation, top (left) and bottom (right) views. Photographs by Yannis Galanakis.

Fig. 31. One of the finest pan tiles from the Theodorou plot assemblage (no. $\Sigma 216.52(\Sigma 12)$. Top (left) and bottom (right) views. The upper surface has been carefully smoothed, while the underside has been left coarse. Photographs by Yannis Galanakis.

Fig. 32. The nine pan and cover tiles from the Theodorou plot sampled for further analysis. Photographs by Yannis Galanakis. 
Fig. 33. LED_OM images of the Theban tile samples showing various aplastic inclusions and voids: a) TH1 (pan tile), b) TH2 (cover tile), c) TH3 (cover tile), d) TH4 (cover tile), e) TH5 (pan tile), f) TH6 (pan tile), g) TH7 (pan tile), h) TH8 (pan tile), i) TH9 (pan tile). All images in magnification $\mathrm{x} 50$, except for $2 \mathrm{f}$ which has a magnification of $\mathrm{x} 10$. Prepared by Vasiliki Valantou and Nikolaos Zacharias.

Fig. 34 a) SEM image of pan tile sample TH6 (magnification x500) showing small and large size silica aggregates; b) SEM image of pan tile sample TH1 (magnification $\mathrm{x} 200$ ) showing carbonised plant matter. Photographs by Vasiliki Valantou and Nikolaos Zacharias.

Fig. 35. $\mathrm{Al}_{2} \mathrm{O}_{3} / \mathrm{SiO}_{2}$ versus $\mathrm{CaO}$ concentrations of the clay bodies. Cover tile samples marked with an $\mathrm{X}$ inside the box. All other tiles are of the pan type. Prepared by Vasiliki Valantou and Nikolaos Zacharias.

Fig. 36. Dendrogram of the nine samples based on major and minor trace elements (TH2, TH3, TH4 are pan tiles, all others are cover tiles). Prepared by Vasiliki Valantou and Nikolaos Zacharias.

Fig. 37. PCA plot based on SEM/EDS data (major and minor elements) p-XRF data (trace elements). White dot indicates cover tile sample. Inset plot: PCA vectors plot. Prepared by Vasiliki Valantou and Nikolaos Zacharias.

Fig. 38. a) Representative SEM image of pan tile sample TH6 (magnification x1000) showing continuous vitrification with bloating pores; b) Representative SEM image of pan tile sample TH7 (magnification x1000) showing non-vitrification state. Photographs by Vasiliki Valantou and Nikolaos Zacharias.

Fig. 39. a) Photomicrograph (x5) pan tile sample TH6 in XP, showing limestone inclusions; b) Photomicrograph (x5) pan tile sample TH1 in XP, showing elongated voids from burnt straw. Photographs by Vasiliki Valantou and Nikolaos Zacharias.

\section{MAPS}

Map 1. Map showing sites, where Mycenaean tiles have been discovered/reported. Pan and cover tiles indicated where known. Question mark indicates uncertain case. Asterisk denotes possible use of tiles in LH IIIC. Map by Yannis Galanakis.

Map 2. Map of the Kadmeia showing plots where Mycenaean tiles have been found: 1) S. Koropoulis Plot; 2) Agion Apostolon \& Kadmou Streets; 3) Papastamelos and Liokis Plots; 4) 'House of Kadmos'; 5) Antoniou Plot; 6) Stavris Plot; 7) Tzortzis Plot; 8) Tsigris-Makris Plot; 9) Ploumis Plot; 10) Pelopidou Street \& the 'Arsenal'; 11) Loukos Plot; 12) Stephas Plot; 13) Christodoulou Plot; 14) Liangas Plot; 15) Stamatis Plot; 16) Elektrai Gates; 17) D. Koropoulis Plot; 18) Theodorou Plot. Inset showing the area around the Theodorou plot. The course of the Mycenaean fortification wall is conjectural for the western part and southwestern part of the acropolis. More secure is its northern, eastern and part of the southern course (after Symeonoglou 1986, Aravantinos 1988, and recent discoveries). Inset map focuses on the Theodorou plot and nearby plots. Map by Yannis Galanakis.

\section{TABLES}

Table 1. Late Bronze Age sites that have yielded clay cover and pan tiles. Table prepared by Yannis Galanakis.

Table 2. Distribution of the cover and pan tiles from the Theodorou plot per excavation trench $(\mathrm{A}-\mathrm{Z})$. The numbers refer to the 588 entries entered in our main database (of which 
567 entries preserved information regarding trench provenance). Non-mendable fragments are not included here but their allocation per trench is mentioned in the main text. Table prepared by Yannis Galanakis.

Table 3. Percentage of the studied cover and pan tiles from the Theodorou plot per excavation trench (A-Z) based on numbers shown in Table 1. Table prepared by Yannis Galanakis.

Table 4. Percentage of large cover and pan tiles (i.e. intact examples and those equal to or larger than the $50 \%$ of the median length for each type) from the Theodorou plot per excavation trench (A-Z). Numbers are based on those shown in Table 1. Table prepared by Yannis Galanakis.

Table 5. Dimensions of cover tiles from the Theodorou plot assemblage. The number of examples used for these dimensions to be established are indicated in the second column. The last column gives measurements known of other Mycenaean tiles as given by Iakovidis $(1990,156)$. All measurements in $\mathrm{cm}$ unless otherwise indicated. Table prepared by Yannis Galanakis.

Table 6. Dimensions of pan tiles from the Theodorou plot assemblage. The number of examples used for these dimensions to be established are indicated in the second column. The largest fragmentarily preserved pan tiles from the Theodorou plot, such as $\Sigma 216.54(\Sigma 12)$, suggest an original weight closer to $11 \mathrm{~kg}$. The last column gives measurements known of other Mycenaean tiles as given by Iakovidis $(1990,155)$. All measurements in cm unless otherwise indicated. Table prepared by Yannis Galanakis.

Table 7. Summary of plots, presence of pan and cover tiles and dates of associated contexts within which these tiles are said to have been discovered. Table prepared by Yannis Galanakis.

Table 8. Catalogue with samples under analysis. Table prepared by Yannis Galanakis.

Table 9. Comparison of SEM/EDS values of the Soil 7 standard clay against the certified values (in $\mathrm{wt} \%$ ) where a high analytical accuracy of the quantitative data is verified, with the exception of aluminum and potassium values. Prepared by Vasiliki Valantou and Nikolaos Zacharias.

Table 10. Concentration of major and minor elements (in wt $\%$ ), of the tiles estimated by SEM/EDS in the form of oxides. Average value $(\mu)$ and standard deviation (s) of 3 measurements is reported (data in wt \%, normalised to $100 \%$, nd $=$ not detected). Prepared by Vasiliki Valantou and Nikolaos Zacharias.

Table 11. Concentration of trace elements of the tiles estimated by p-XRF (elemental composition in $\mu \mathrm{g} / \mathrm{g}$ ). Prepared by Vasiliki Valantou and Nikolaos Zacharias.

Table 12. Color description, using a Munsell Color Chart, calcium oxide content (in wt\%), vitrification state and firing temperature estimations from SEM/EDS. Abbreviations $=\mathrm{V}$ : extensive vitrification, NV: non-vitrification, IV: initial vitrification, CV: continuous vitrification. Prepared by Vasiliki Valantou and Nikolaos Zacharias. 


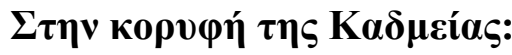

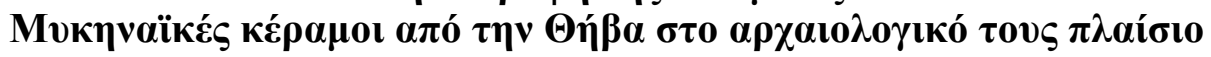

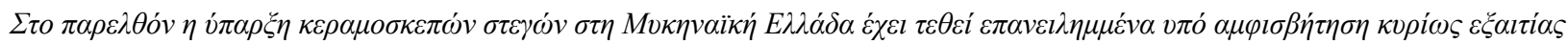

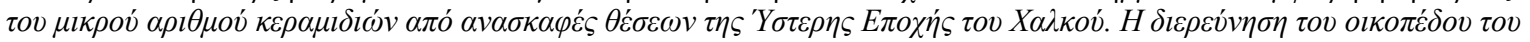

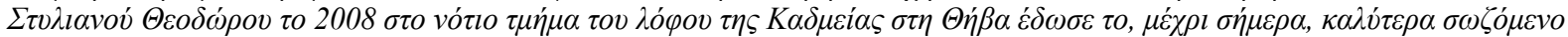

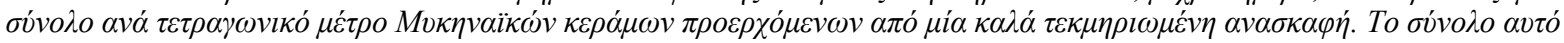

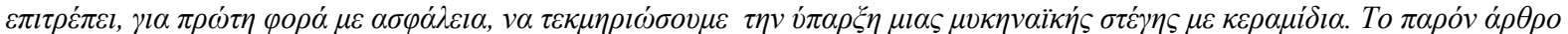

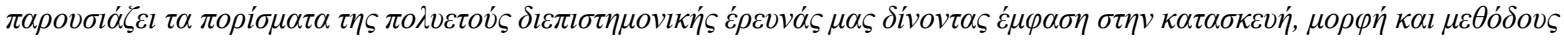

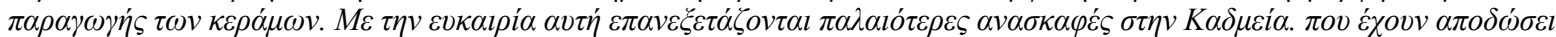

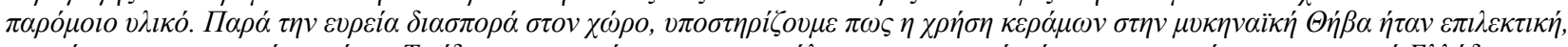

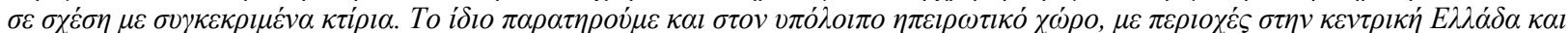

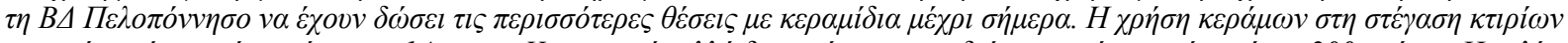

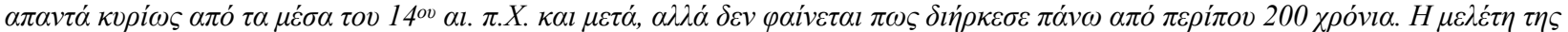

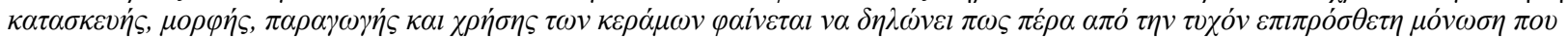

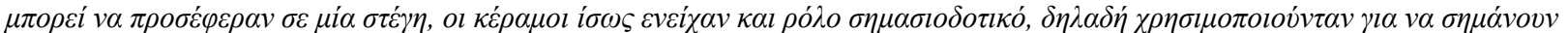

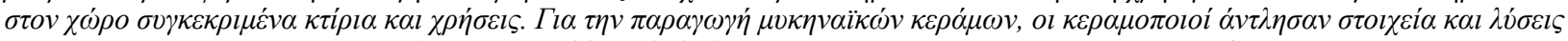

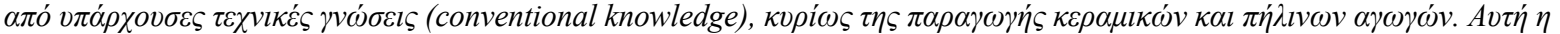

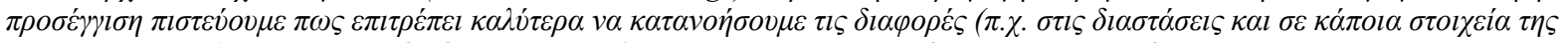

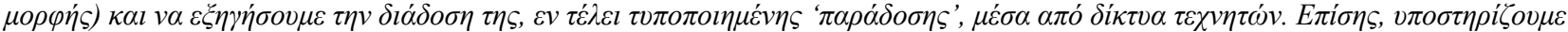

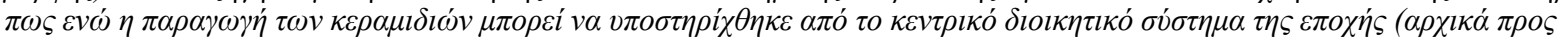

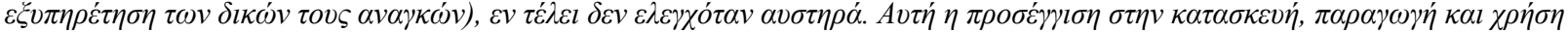

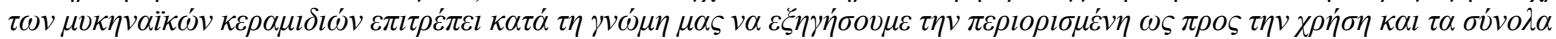

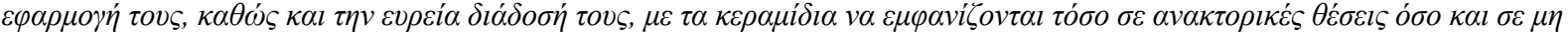

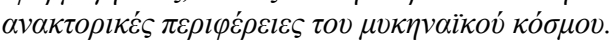




\section{ATOP THE KADMEIA: \\ MYCENAEAN ROOF TILES FROM THEBES IN CONTEXT}

\section{TABLES}

Table 1

\begin{tabular}{|c|c|c|c|c|}
\hline Site & Region & Tiles & $\begin{array}{l}\text { Context } \\
\text { Date(s) }\end{array}$ & Reference \\
\hline 1. Dimini & Thessaly & Few pan tiles & LH IIIB & $\begin{array}{l}\text { Adrymi-Sismani, } 1999-2001,86 \text {; Adrimi-Sismani } \\
\qquad 2007,164^{194}\end{array}$ \\
\hline 2. Aerino & Thessaly & Pan tiles? & LH IIIB? & Arachoviti 2000,364-9;2013,14 \\
\hline 3. Frantzis & Phthiotis & Few pan tiles & LH IIIB-C & Karantzali $2012,1215^{195}$ \\
\hline 4. Mitrou & Phthiotis & 4 cover +1 pan tile & LH IIIB & Skorda 2001-04, 420 \\
\hline 5. Kirrha & Phocis & Tile fragments & Early LBA? & Vitale $2012,1151,1158$ \\
\hline 6. Lefkandi & Euboea & Few pan tiles & LH IIIC & I.S. Lemos and A. Livieratou, pers. comm. \\
\hline 7. Gla & Boeotia & Many cover + pan tiles & LH IIIB & Iakovidis $1989 ; 1990 ; 2001$ \\
\hline 8. Thebes & Boeotia & Very many cover + pan tiles & LH IIIA2-C & This article \\
\hline 9. Glypha & Boeotia & A few possible pan tiles & LH IIIB-C? & van Damme 2017, $104 \&$ pers. comm. \\
\hline 10. Eleon & Boeotia & Very many cover + pan tiles & LH IIIB-C & Burke et al. 2020 \\
\hline 11. Prophetes Elias & Boeotia & $\begin{array}{l}\text { Three cover tile fragments; one } \\
\text { pan tile fragment } \\
196\end{array}$ & LH IIIA2-C? & $\begin{array}{l}\text { Brown 1905-1906; Mountjoy 1983, 70; van } \\
\text { Damme 2017, } 99 \text { \& pers. comm. }\end{array}$ \\
\hline 12. Athens & Attica & Two fragments of pan tiles? & LH IIIB-C? & Broneer 1939, 408-9, figs. 90-91b,c \\
\hline 13. Mycenae & Argolid & $\begin{array}{l}\text { Cover }+ \text { pan tiles (various } \\
\text { locations, small numbers) }\end{array}$ & LH IIIA2-B? & $\begin{array}{l}\text { E.g. Iakovidis 1990, 152, n. 49; 2006, 43-93, 112, } \\
\text { 148-55, 165-6; Onassoglou 1995, } 146\end{array}$ \\
\hline 14. Chania & Argolid & Few cover + pan tiles & LH IIIB & Palaiologou $2015,69-70$ \\
\hline 15. Berbati & Argolid & Few cover + pan tiles & LH IIIB & Åkerström 1941 \\
\hline 16. Midea & Argolid & $\begin{array}{l}\text { Cover + pan tiles (various } \\
\text { locations, small numbers) }\end{array}$ & LH IIIA2-C & $\begin{array}{c}\text { Walberg } 1998,48,88-95,237-8, \text { pls. 104-6, 141; } \\
2007,66,169, \text { pl. } 196\end{array}$ \\
\hline 17. Tiryns & Argolid & $\begin{array}{l}\text { Cover }+ \text { pan tiles (various } \\
\text { locations, small numbers) }\end{array}$ & LH IIIB-C & $\begin{array}{l}\text { Schäfer and Grossman 1975, 58-9, } 83 \text { (nos. 192- } \\
\text { 193), figs. 44-5, pl. 56; Schäfer 1980, 6, n. 22, } \\
\text { pls. 39.3-4; Maran and Papadimitriou 2016, } 52\end{array}$ \\
\hline 18. Aigeira & Achaea & Pan tile & LH IIIC? & Alzinger 1978, 150, fig. 3; Darcque 2005, 80 \\
\hline 19. Chalandritsa & Achaea & Many pan tiles & LH IIIB-C & Kolonas $2009,7-11^{197}$ \\
\hline 20. Ayios Vasileios & Laconia & Few cover + pan tiles & LH IIIA/B? & Personal inspection (Y. Galanakis, 2013) \\
\hline 21. Malthi & Messenia & Many? ${ }^{198}$ & LH? & Valmin $1938,173-85$ \\
\hline
\end{tabular}

\footnotetext{
194 These tiles were found in megaron A and their use appears to be associated with the presence of a clay gutter in that both systems were used to draw water away.

${ }^{195}$ Karantzali $(2012,1215)$ suggests that tiles may have been used for only part of the roof.

196 Mountjoy $(1983,70)$ mentions three pieces of 'clay pipe' among the material stored in the National Museum in Athens. She dates the pottery from Prophetes Elias from LH IIIA2 to LH IIIC. We would like to thank Kostas Nikolentzos, Head of the Prehistoric Collections at the National Archaeological Museum, for confirming the number and types of fragments from this excavation currently in storage in Athens.

197 The LH IIIB houses at Chalandritsa are said to comprise rectangular or trapezoidal rooms with a ground floor and a loft the loft apparently covered by a tiled roof were a 'considerable number of tile fragments' is mentioned.

198 The dimensions for one 'tile' found in the 'megaron' by Valmin $(1938,174)$ corresponds in length $(66 \mathrm{~cm})$ and thickness $(1.5 \mathrm{~cm})$ to pan tiles, but the 'slightly curving construction' and width ('at least $0.28 \mathrm{~m}$ ') makes us wonder as to whether this example belonged to a drain. Similarly, Blegen $(1945,37-8)$ was not convinced by Valmin's date ('Middle Helladic') nor the attribution of thousands of fragments to tiles, considering most of the fragments as belonging to storage jars. Unfortunately, as no photos or drawings exist it is impossible to settle this issue completely.
} 


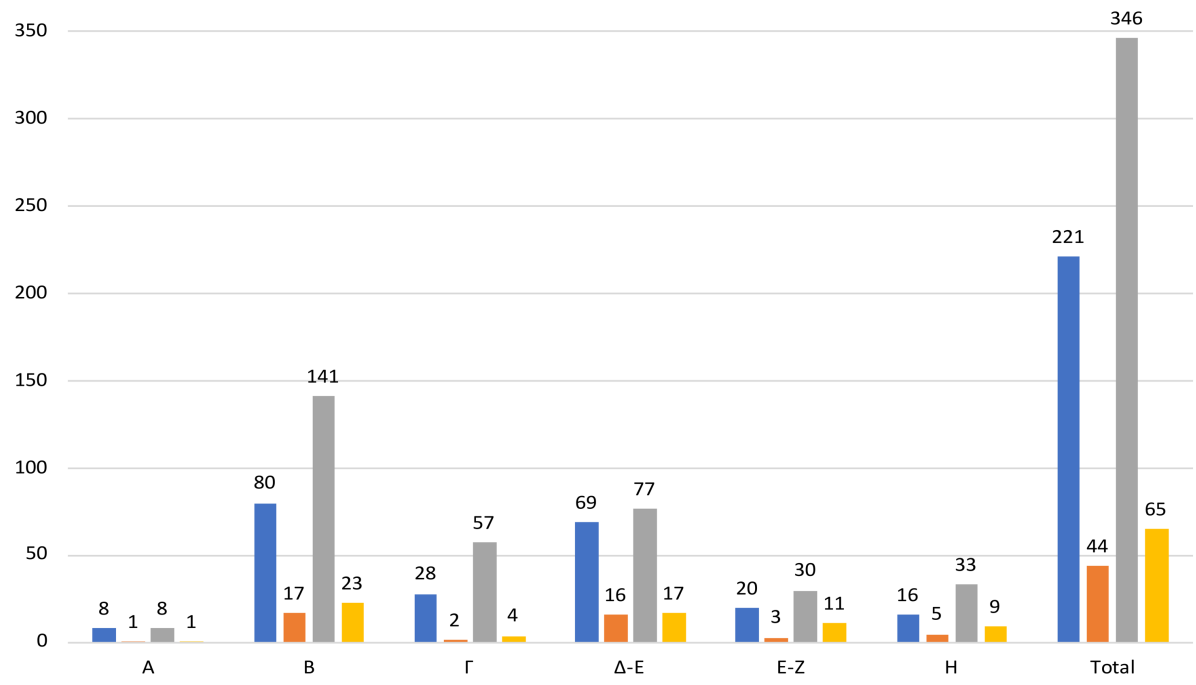

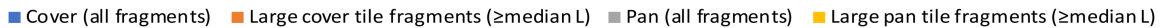

Table 2

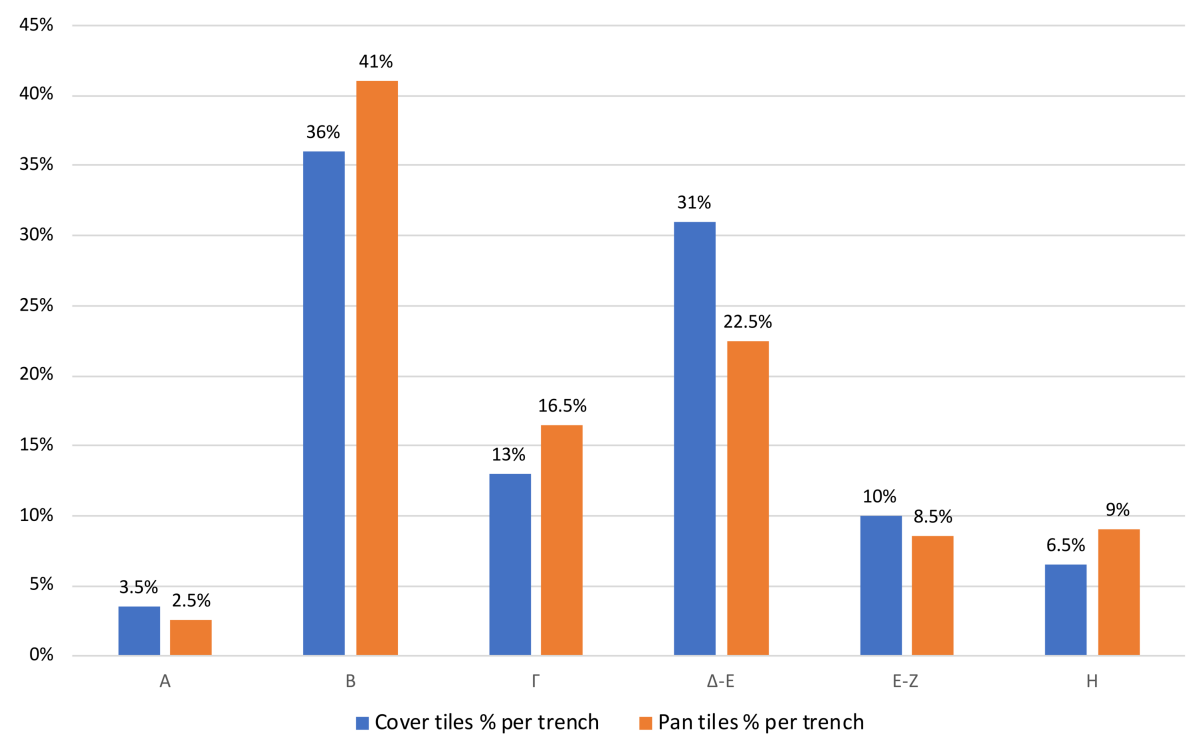

Table 3

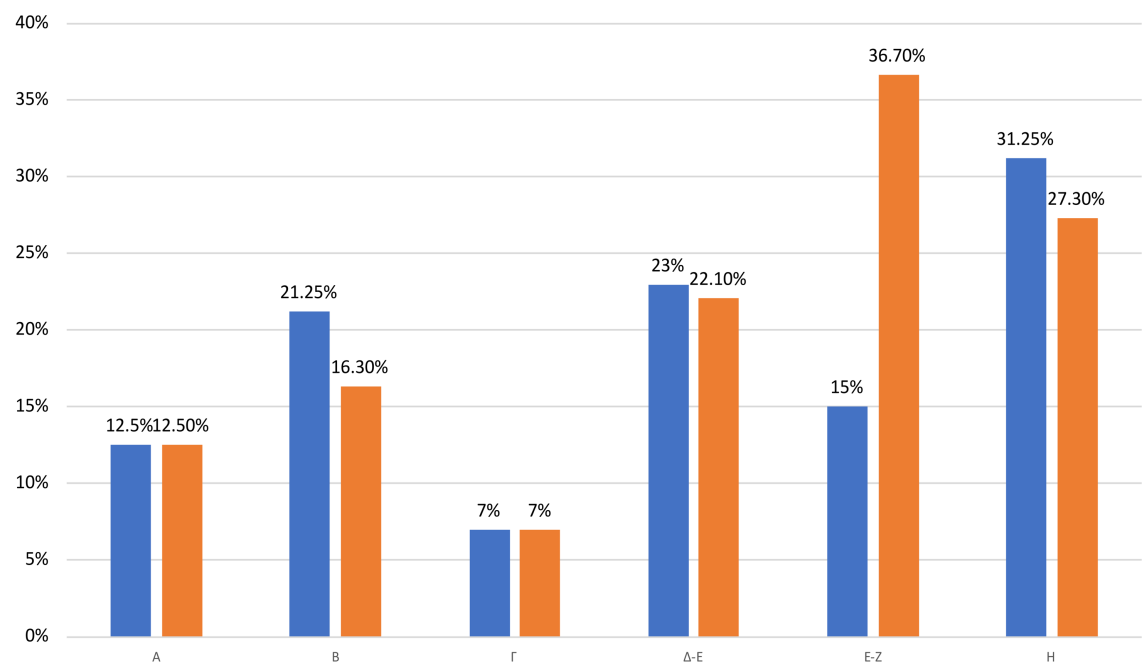

॥ of large cover tiles tiles over all cover tiles recorded $\quad$ \% of large pan tiles tiles over all pan tiles recorded

Table 4 


\begin{tabular}{|l|c|c|c|c|c|c|}
\hline Cover tiles measurements & $\begin{array}{c}\text { No. of } \\
\text { examples used }\end{array}$ & Minimum & Maximum & Average & Median & $\begin{array}{c}\text { Measurements of other } \\
\text { known cover tiles }\end{array}$ \\
\hline Length & 6 & 37.6 & 55.7 & 46.3 & 45.4 & $40-46$ \\
\hline External width AB (rim) & 20 & 8 & 12.9 & 10.8 & 10.9 & $14-16.5$ \\
\hline External width CD (base) & 25 & 13 & 19.8 & 15.7 & 15.6 & $18.5-21.5$ \\
\hline External width EF (body) & 32 & 11.2 & 18.2 & 15 & 14.9 & \\
\hline Internal width GH (rim) & 23 & 11.2 & 16.5 & 13.3 & 13.1 & \\
\hline Internal width IJ (base) & 11 & 8 & 10.9 & 9.3 & 9.2 & \\
\hline Thickness end 1 (rim) & 99 & 0.4 & 1.7 & 0.8 & 0.8 & \multirow{2}{*}{$0.7-1.4$} \\
\hline Thickness end 2 (base) & 108 & 0.4 & 2.3 & 1.2 & 1.1 & \\
\hline Thickness side & 173 & 0.4 & 2.2 & 1.1 & 1.1 & \\
\hline Height end 1 (rim area) & 15 & 3.9 & 8.2 & 6.1 & 5.7 & \\
\hline Height end 2 (base area) & 32 & 5.2 & 11.2 & 8.1 & 8.3 & \\
\hline Weight & 6 & $1.4 \mathrm{~kg}$ & $2 \mathrm{~kg}$ & $1.7 \mathrm{~kg}$ & $1.73 \mathrm{~kg}$ & \\
\hline
\end{tabular}

Table 5

\begin{tabular}{|l|c|c|c|c|c|c|}
\hline \multicolumn{1}{|c|}{ Pan tiles measurements } & $\begin{array}{c}\text { No. of } \\
\text { examples used }\end{array}$ & Minimum & Maximum & Average & Median & $\begin{array}{c}\text { Measurements of other } \\
\text { known pan tiles }\end{array}$ \\
\hline Length & 9 & 52 & 68.2 & 60 & 60.5 & $46-66$ \\
\hline External width AB (wide) & 17 & 38 & 51.4 & 44.8 & 45.2 & $33-50$ \\
\hline External width CD (narrow) & 10 & 38 & 46 & 42.3 & 42.6 & $31-40$ \\
\hline External width EF (body) & 18 & 39 & 50.5 & 43.7 & 43.8 & \\
\hline Internal width GH (wide) & 17 & 35 & 49.5 & 42.9 & 43 & \\
\hline Internal width IJ (narrow) & 9 & 34.7 & 40 & 39.3 & 39.2 & \\
\hline Thickness end 1 & 64 & 0.5 & 2.5 & 1.5 & 1.4 & \multirow{2}{*}{$1.4-2.8$} \\
\hline Thickness end 2 & 109 & 0.5 & 2.9 & 1.8 & 1.8 & \\
\hline Thickness side & 343 & 0.4 & 3.5 & 1.6 & 1.7 & \multirow{2}{*}{4} \\
\hline Sidewall height 1'199 & 310 & 3.7 & 9.7 & 6.2 & 6.1 & \\
\hline Sidewall height 2 & 41 & 4 & 8.2 & 6.3 & 6.2 & \\
\hline Weight & 8 & $7 \mathrm{~kg}$ & $11 \mathrm{~kg}$ & $9 \mathrm{~kg}$ & $8.85 \mathrm{~kg}$ & \\
\cline { 1 - 3 }
\end{tabular}

\section{Table 6}

\begin{tabular}{|c|c|c|c|}
\hline Plot/Location & Function & Cover/Pan tiles & Date \\
\hline 1. S. Koropoulis Plot & Residential & Pan (many) & LH IIIB1 \\
\hline 2. Agion Apostolon \& Kadmou streets & Workshop? & $?$ (few) & LH IIIB \\
\hline 3. 'House of Kadmos' & Residential-Workshop-Storage & $?$ (few) & LH IIIA2/B1 \\
\hline 4. Papastamelos and Liokis Plots & Residential? & Pan & LH IIIB1 \\
\hline 5. Tzortzis Plot & Storage-Workshop & Cover + Pan & LH IIIA2/B1201 \\
\hline 6. Stavris Plot & Storage & Cover + Pan (many) & LH IIIB2? \\
\hline 7. Antoniou Plot & Residential? & $?$ & LH IIIB \\
\hline 8. Tsigris-Makris Plot & Unknown & Pan (numerous) & LH IIIB2 $^{202}$ \\
\hline 9. Ploumis Plot & Unknown & $?$ (numerous) & LH IIIB? \\
\hline 10. Pelopidou Street \& the 'Arsenal' & Administration-Workshop-Storage & Cover + Pan (many) & $\begin{array}{c}\text { LH IIIA2, } \\
\text { LH IIIB2/C early }\end{array}$ \\
\hline 11. Loukos Plot & Workshop & $?$ & LH IIIB1? \\
\hline 12. Stephas Plot & Residential & $\begin{array}{c}\text { Cover + Pan } \\
\text { (numerous) }\end{array}$ & LH IIIB1 \\
\hline 13. Christodoulou Plot & Administration?-Worskhop-Storage & $?$ & LH IIIB \\
\hline 14. Liangas Plot & Administration-Workshop & Cover + Pan (many) & LH IIIB2 \\
\hline 15. Stamatis Plot & Workshop-Storage & ? & LH IIIB \\
\hline 16. Elektrai Gates & Unknown & $\begin{array}{c}\text { Pan only? } \\
\text { (numerous) }\end{array}$ & LH IIIB? \\
\hline 17. D. Koropoulis Plot & Workshop & Cover + Pan (many) & LH IIIB1 \\
\hline 18. Theodorou Plot & Residential-Workshop? & Cover + Pan (many) & LH IIIB1/2 early \\
\hline
\end{tabular}

Table 7

\footnotetext{
${ }^{199}$ Measurement of height for the sidewalls has been taken from outside (base of pan to top of sidewall).

${ }^{200}$ We suspect that this measurement was taken from inside the pan. Taking into account the thickness of pan tiles, then this measurement is compatible with the one we give here from the Theodorou plot material. E.g. at Tiryns, some of the pan tiles are $6.7 \mathrm{~cm}$ in height and at Chania $6.5-8 \mathrm{~cm}$ (measurements in both cases probably taken, like in our case, from the base of the pan). ${ }^{201}$ Andrikou 2006, 56.
}

202 Andrikou 2006, 58. 


\begin{tabular}{|l|c|c|}
\hline Database number & Lab code & Tile Type \\
\hline$\Sigma 210.1(\Sigma 1)$ & TH1 & Pan tile \\
\hline K210.2 $(\mathrm{K} 5)$ & TH2 & Cover tile \\
\hline K203+210.19 (K2) & TH3 & Cover tile \\
\hline K205-206.04 & TH4 & Cover tile \\
\hline$\Sigma 805+806.03$ & TH5 & Pan tile \\
\hline$\Sigma 715.01$ & TH6 & Pan tile \\
\hline$\Sigma 514.01(\Sigma 31)$ & TH7 & Pan tile \\
\hline$\Sigma 216.52(\Sigma 12)$ & TH8 & Pan tile \\
\hline$\Sigma 210.02(\Sigma 2)$ & TH9 & Pan tile \\
\hline
\end{tabular}

Table 8

\begin{tabular}{lc|cccccccc} 
& & $\mathrm{Na}_{2} \mathbf{O}$ & $\mathbf{M g O}$ & $\mathbf{A l}_{2} \mathbf{O}_{3}$ & $\mathrm{SiO}_{2}$ & $\mathbf{K 2 O}$ & $\mathbf{C a O}$ & $\mathrm{TiO}_{2}$ & $\mathbf{F e O}$ \\
\hline \multirow{2}{*}{ Soil 7} & SEM/EDS & 0.38 & 2.40 & 14.38 & 48.88 & 2.25 & 26.37 & 0.62 & 4.73 \\
& Certified Values & 0.42 & 2.40 & 11.38 & 49.35 & 1.87 & 29.23 & 0.64 & 4.71
\end{tabular}

Table 9

\begin{tabular}{|c|c|c|c|c|c|c|c|c|c|c|}
\hline sample/oxide & & $\mathrm{Na}_{2} \mathrm{O}$ & MgO & $\mathrm{Al}_{2} \mathrm{O}_{3}$ & $\mathrm{SiO}_{2}$ & $\mathrm{P}_{2} \mathrm{O}_{5}$ & $\mathrm{~K}_{2} \mathrm{O}$ & $\mathrm{CaO}$ & $\mathrm{TiO}_{2}$ & $\mathrm{FeO}$ \\
\hline \multirow[t]{2}{*}{ TH1 } & $\mu$ & 0.96 & 5.8 & 17.43 & 55.51 & 0.22 & 3.60 & 8.15 & 0.84 & 7.51 \\
\hline & $\mathrm{s}$ & 0.17 & 0.17 & 1.17 & 1.53 & 0,30 & 0.39 & 0.45 & 0.50 & 1.39 \\
\hline \multirow[t]{2}{*}{ TH2 } & $\mu$ & 1.10 & 4.71 & 17.59 & 54.08 & 0.11 & 4.68 & 6.88 & 1.12 & 9.68 \\
\hline & $s$ & 0.18 & 0.60 & 0.72 & 2.22 & 0.10 & 0.05 & 1.90 & 0.32 & 1.56 \\
\hline \multirow[t]{2}{*}{ TH3 } & $\mu$ & 0.83 & 5.11 & 14.13 & 48.89 & 0.21 & 3.50 & 18.07 & 0.68 & 8.55 \\
\hline & $\mathrm{s}$ & 0.14 & 1.03 & 1.01 & 0.92 & 0.27 & 1.21 & 2.70 & 0.18 & 2.21 \\
\hline \multirow[t]{2}{*}{ TH4 } & $\mu$ & 0.78 & 5.53 & 15.54 & 52.73 & 0.23 & 3.21 & 13.72 & 0.84 & 7.28 \\
\hline & $\mathrm{s}$ & 0.17 & 0.28 & 0.28 & 1.46 & 0.20 & 0.40 & 1.39 & 0.10 & 0.23 \\
\hline \multirow[t]{2}{*}{ TH5 } & $\mu$ & 0.71 & 6.58 & 14.18 & 53.79 & nd & 3.16 & 12.39 & 0.60 & 8.59 \\
\hline & $\mathrm{s}$ & 0.45 & 0.04 & 2.31 & 0.44 & - & 0.28 & 1.10 & 0.40 & 0.95 \\
\hline \multirow[t]{2}{*}{ TH6 } & $\mu$ & 1.06 & 5.08 & 16.06 & 56.09 & nd & 3.57 & 9.23 & 0.72 & 8.19 \\
\hline & $\mathrm{s}$ & 0.31 & 0.96 & 1.90 & 6.18 & - & 0.28 & 4.23 & 0.48 & 2.61 \\
\hline \multirow[t]{2}{*}{ TH7 } & $\mu$ & 0.50 & 4.16 & 16.91 & 55.96 & 0.18 & 4.27 & 8.67 & 0.44 & 8.89 \\
\hline & s & 0.10 & 0.38 & 0.52 & 3.00 & 0.20 & 0.33 & 1.30 & 0.24 & 2.08 \\
\hline \multirow[t]{2}{*}{ TH8 } & $\mu$ & 0.91 & 5.24 & 16.01 & 56.01 & 0.14 & 4.12 & 9.10 & 0.75 & 7.73 \\
\hline & $\mathrm{s}$ & 0.15 & 0.11 & 0.35 & 1.10 & 0.13 & 0.10 & 0.93 & 0.23 & 0.35 \\
\hline \multirow[t]{2}{*}{ TH9 } & $\mu$ & 0.79 & 5.33 & 14.61 & 49.83 & nd & 2.33 & 19.35 & 0.77 & 7.01 \\
\hline & $\mathrm{s}$ & 0.28 & 0.08 & 0.86 & 2.18 & - & 0.32 & 3.39 & 0.44 & 0.03 \\
\hline
\end{tabular}

Table 10

$\begin{array}{llllllllll} & \text { Cr } & \text { Mn } & \text { Ni } & \text { Cu } & \text { Zn } & \text { Rb } & \text { Sr } & \text { Zr } & \text { Pb } \\ \text { TH1 } & 129 & 299 & 212 & 41 & 56 & 123 & 149 & 101 & 11 \\ \text { TH2 } & 127 & 342 & 254 & 77 & 89 & 128 & 103 & 95 & 13 \\ \text { TH3 } & 116 & 363 & 421 & 61 & 62 & 83 & 262 & 71 & 11 \\ \text { TH4 } & 124 & 327 & 288 & 82 & 81 & 82 & 211 & 111 & 12 \\ \text { TH5 } & 137 & 412 & 490 & 72 & 73 & 101 & 160 & 103 & 14 \\ \text { TH6 } & 150 & 376 & 267 & 59 & 77 & 128 & 121 & 114 & 12 \\ \text { TH7 } & 163 & 470 & 380 & 66 & 82 & 97 & 140 & 103 & 16 \\ \text { TH8 } & 113 & 303 & 234 & 52 & 66 & 121 & 126 & 95 & 11 \\ \text { TH9 } & 102 & 340 & 301 & 72 & 77 & 79 & 291 & 122 & 12\end{array}$

Table 11 


\section{MAPS}

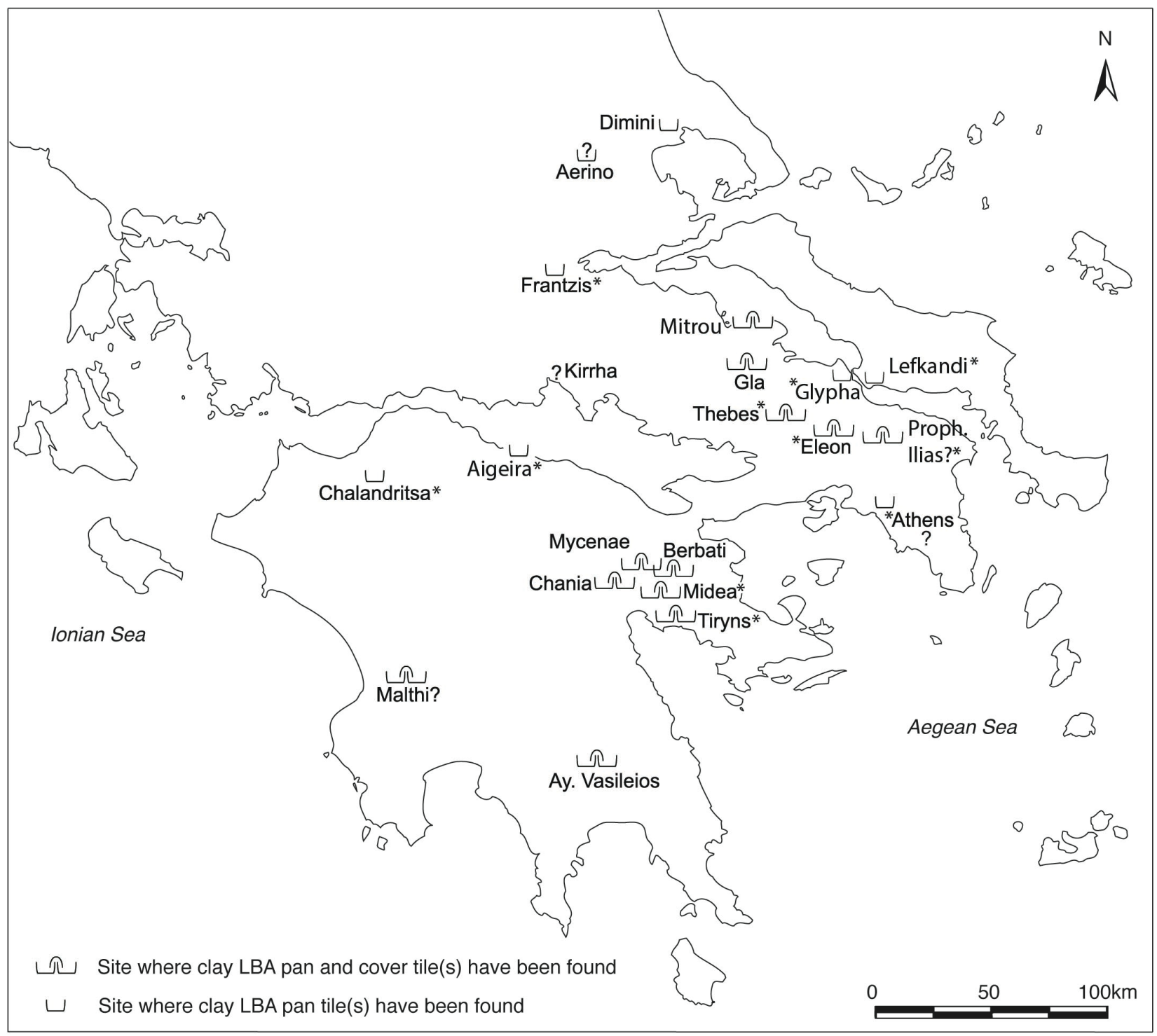

Map 1 


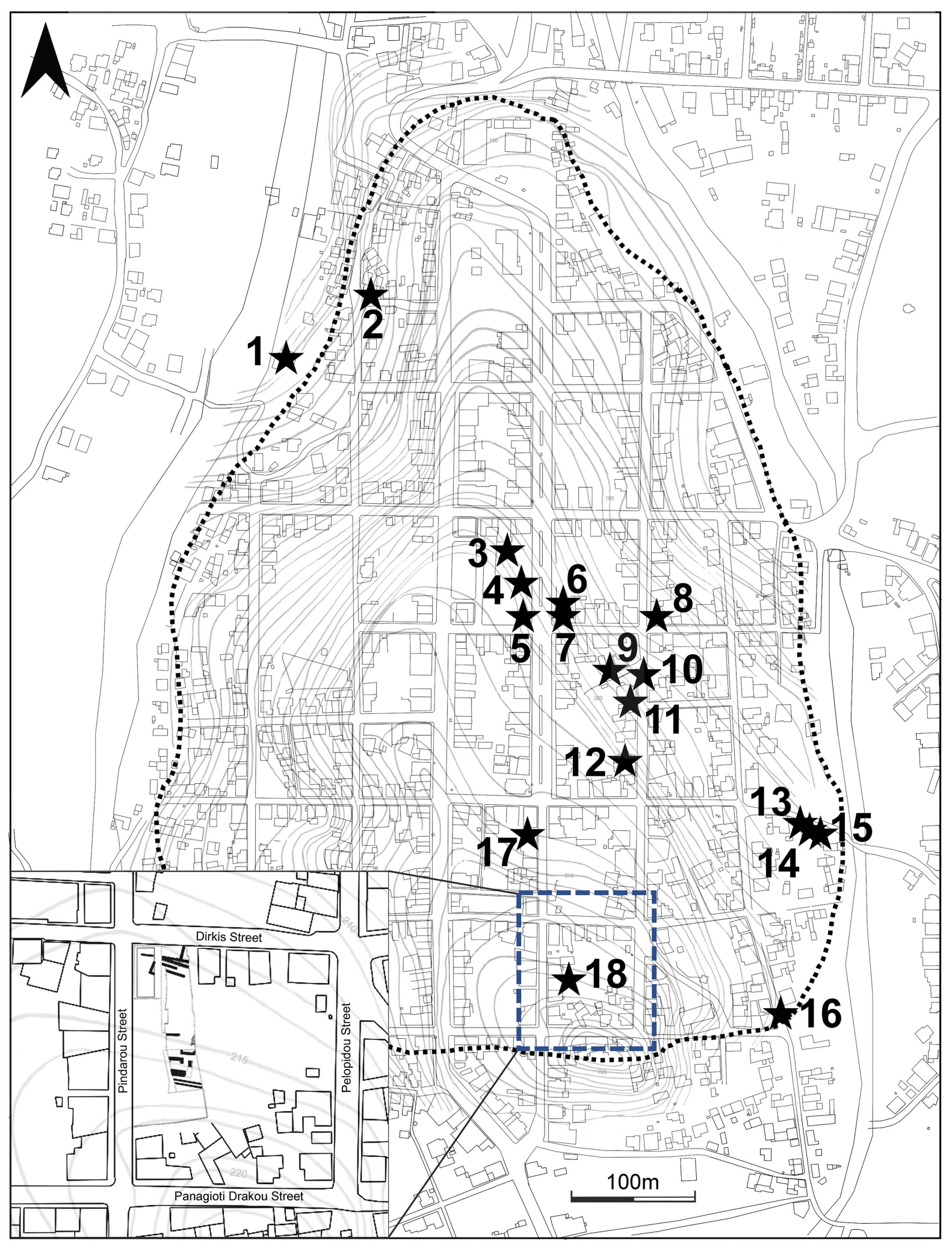

Map 2 


\section{FIGURES}

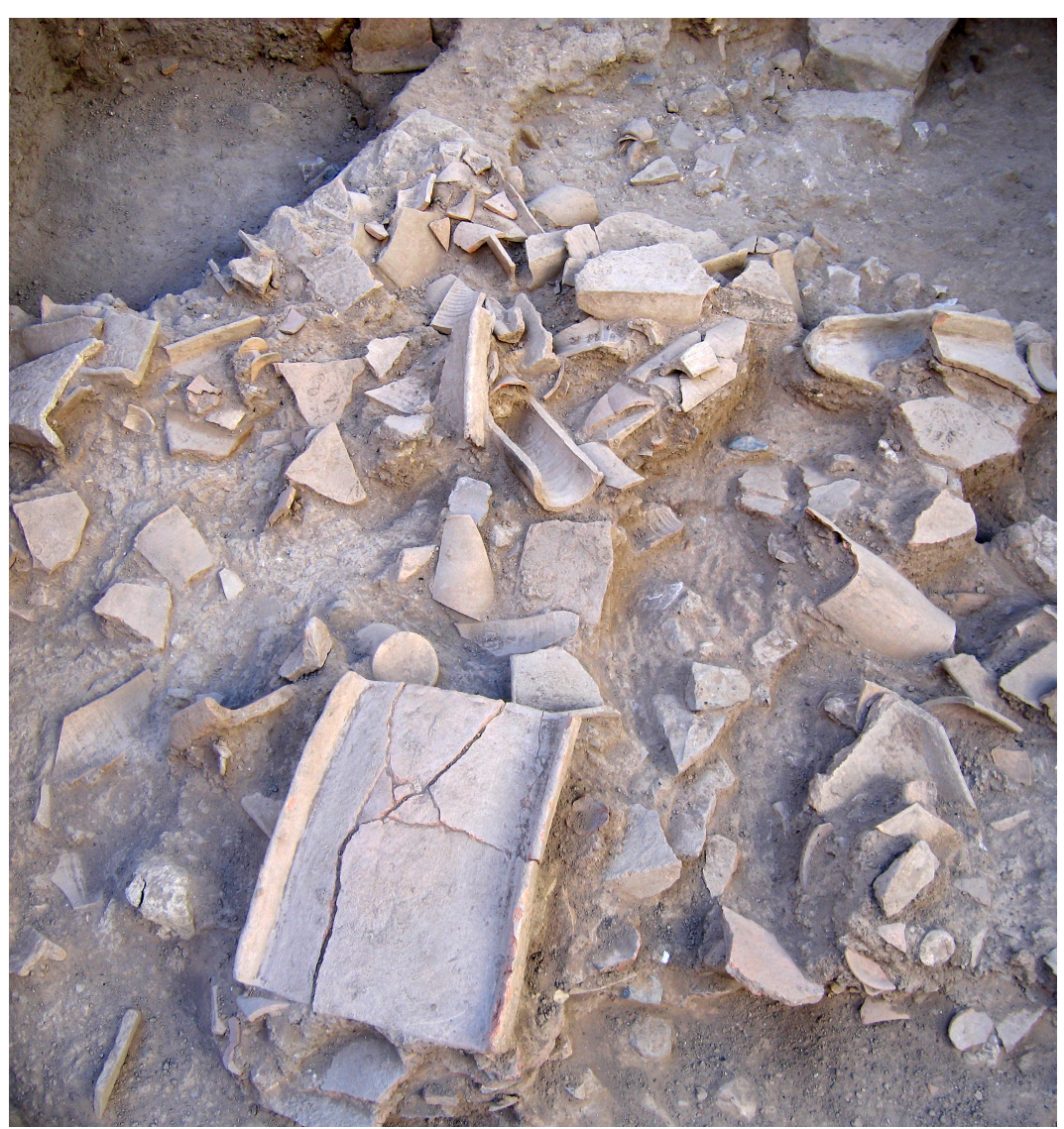

Figure 1

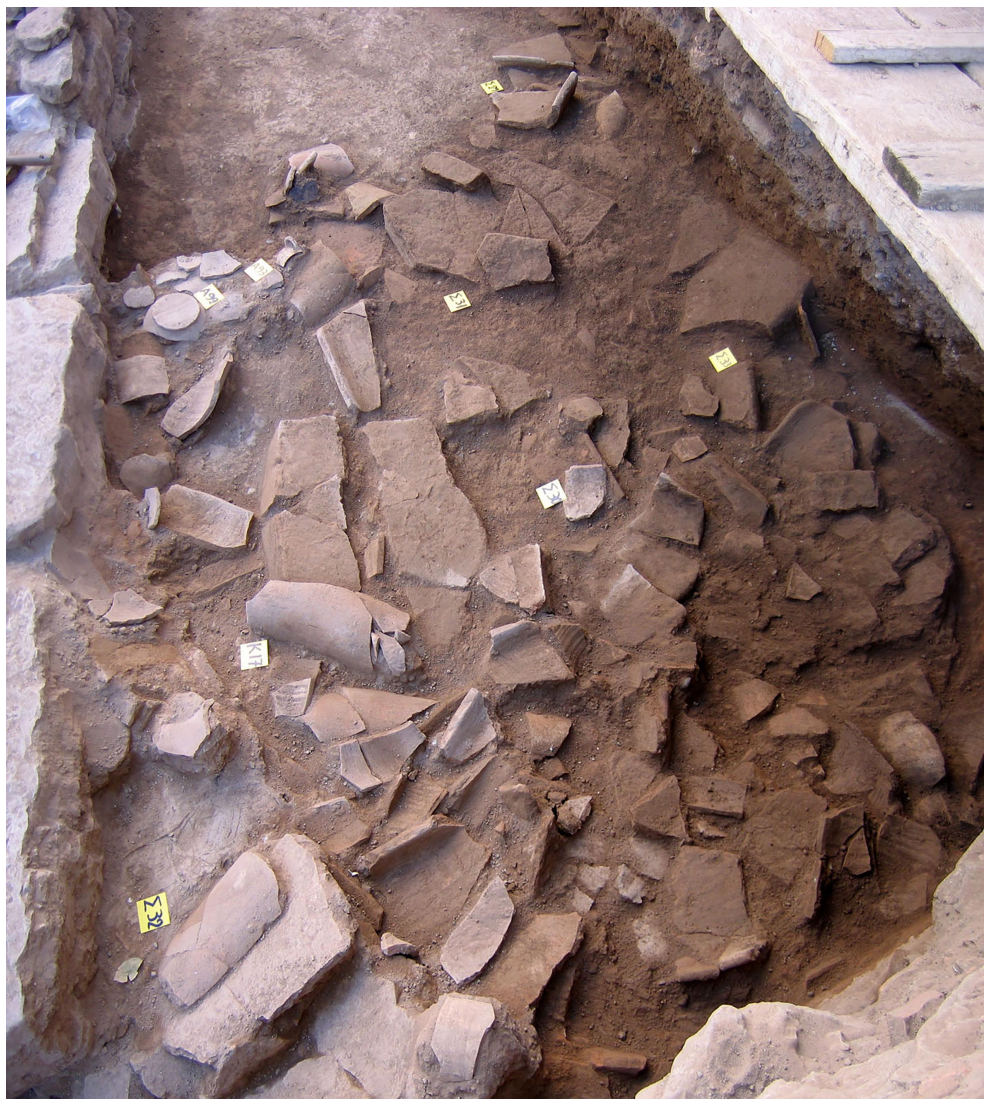

Figure 2 


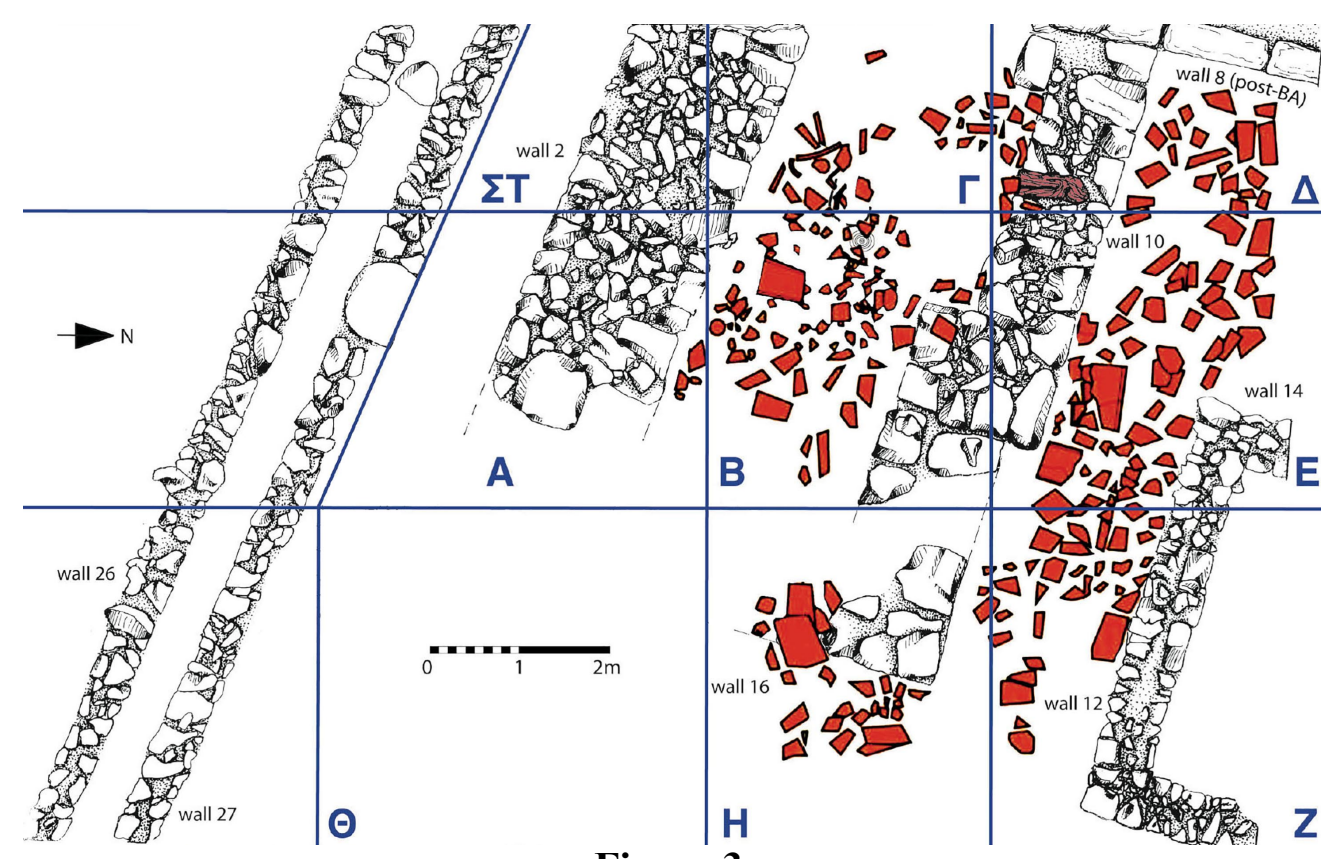

Figure 3
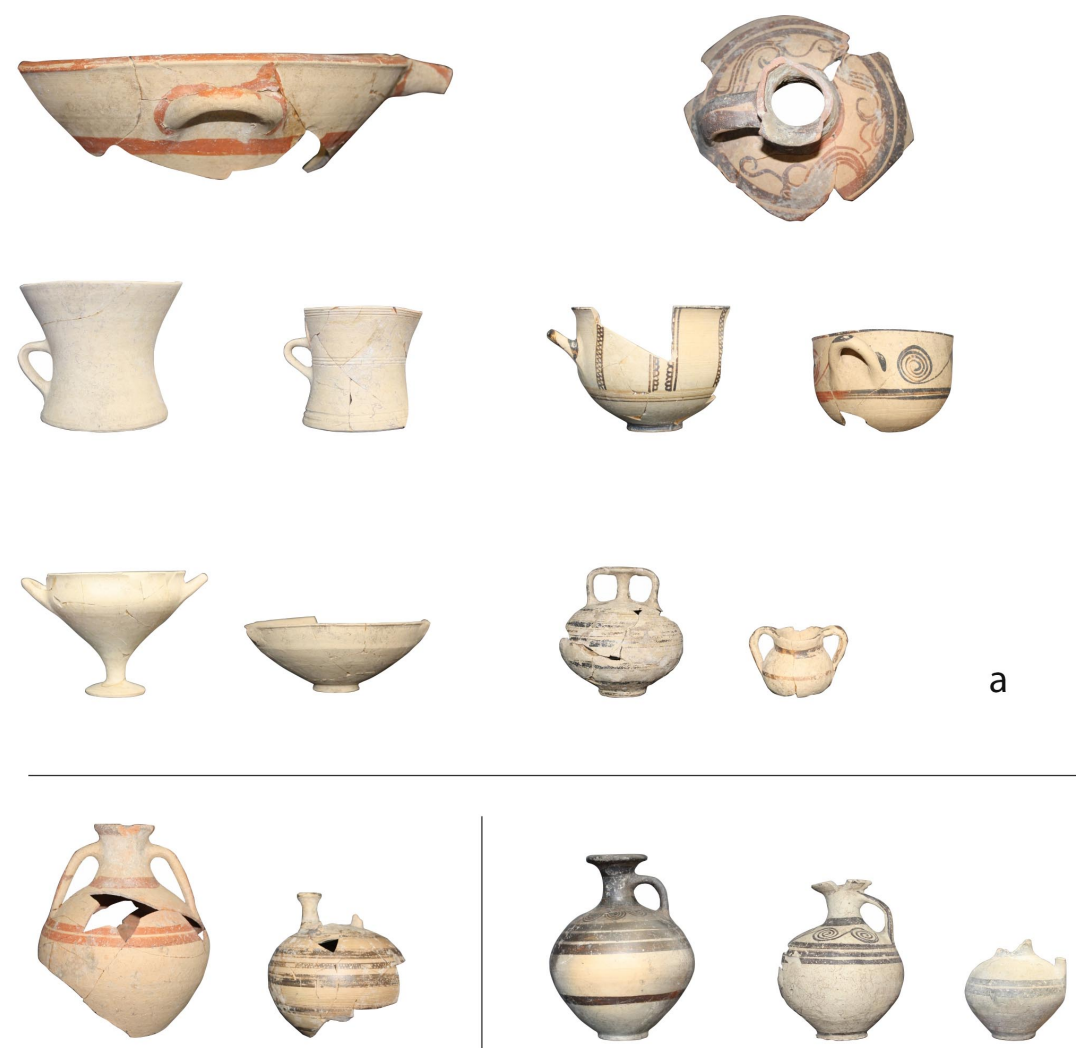

b
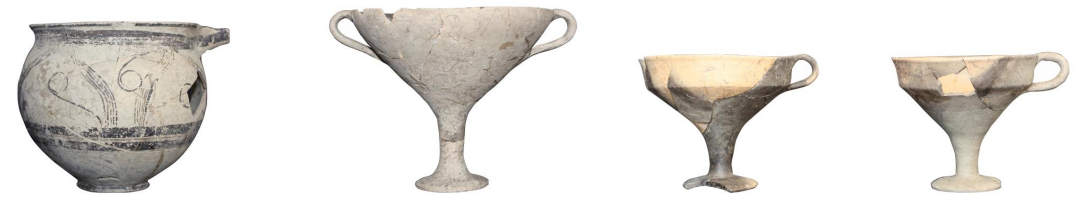

Figure 4a-c 


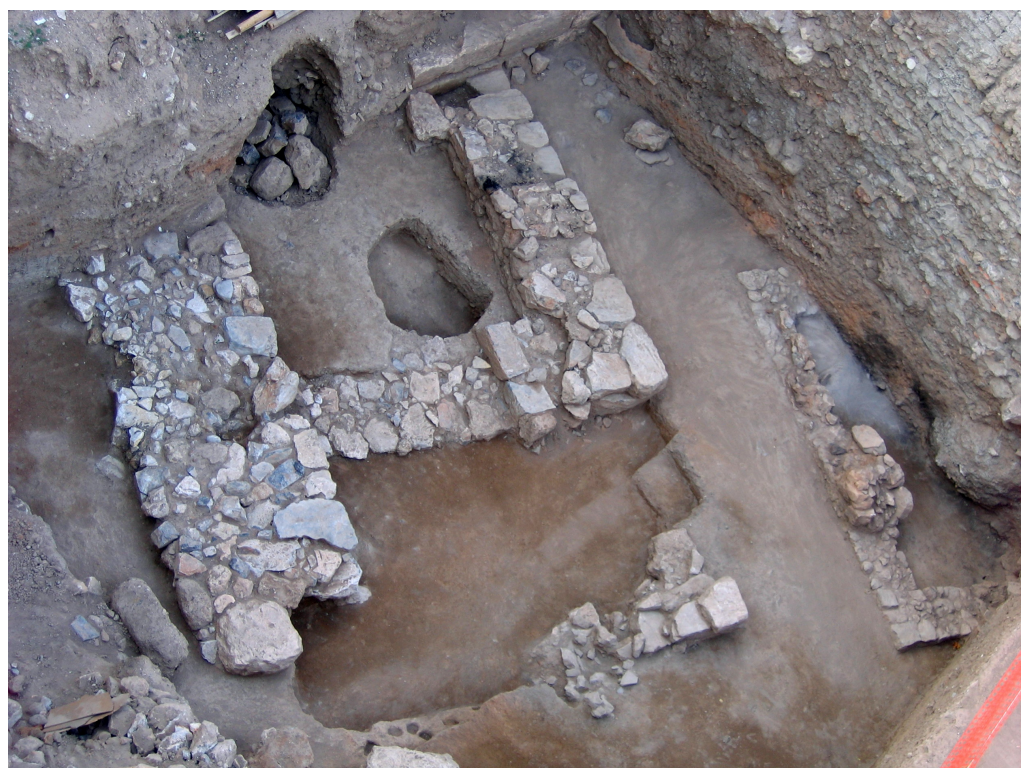

Figure 5

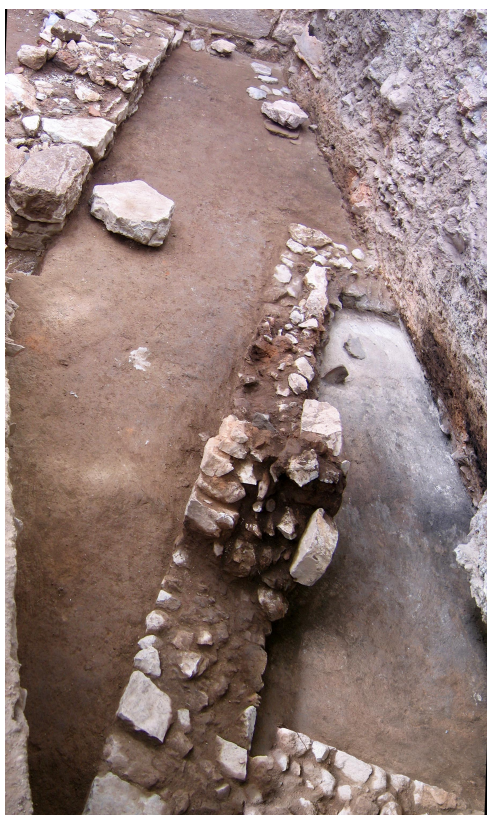

Figure 6

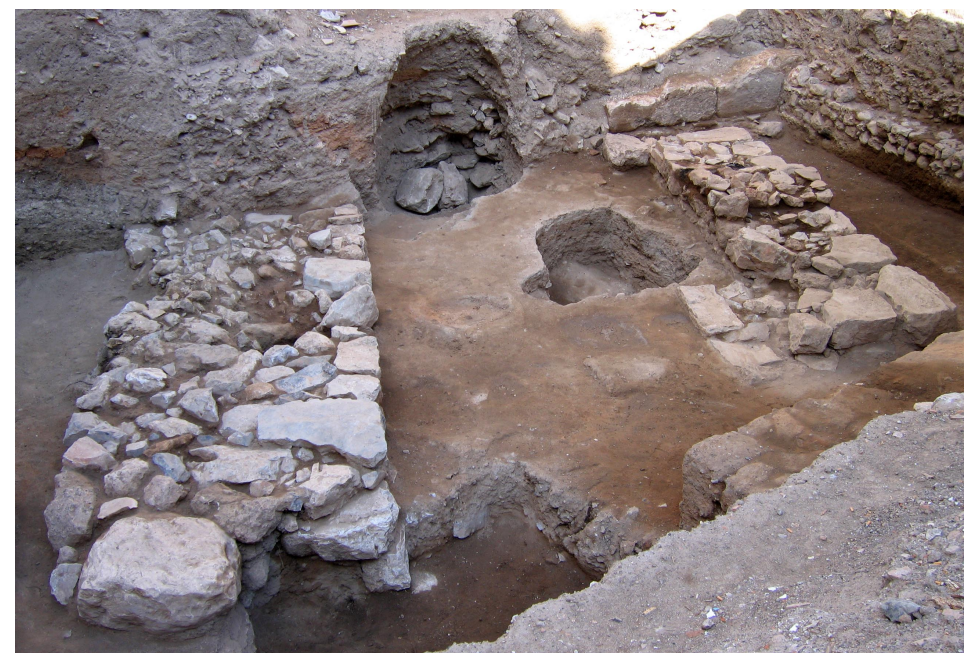

Figure 7 

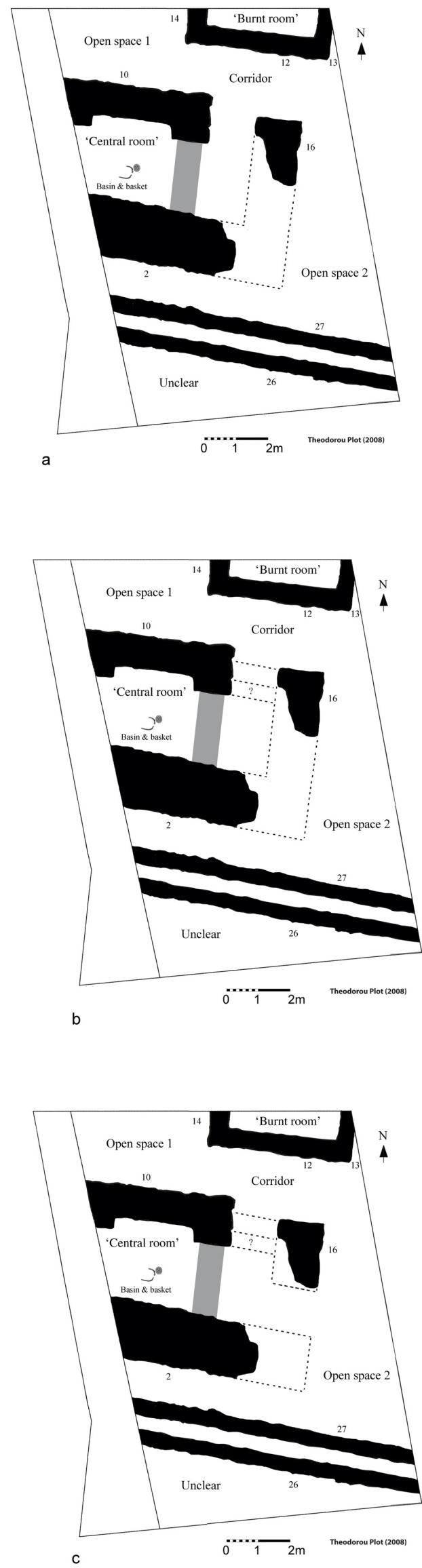

Figure 8a-c 


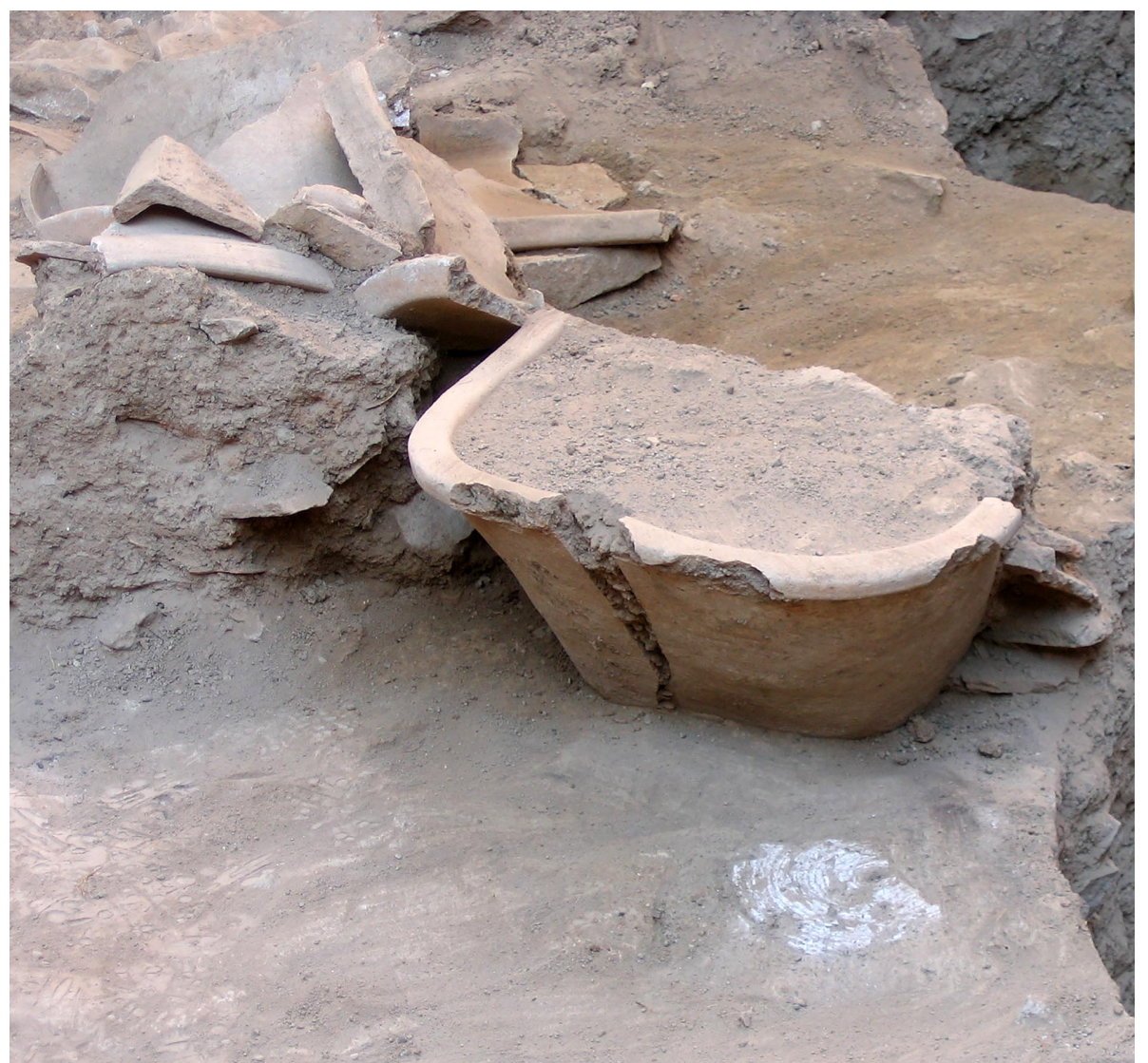

Figure 9

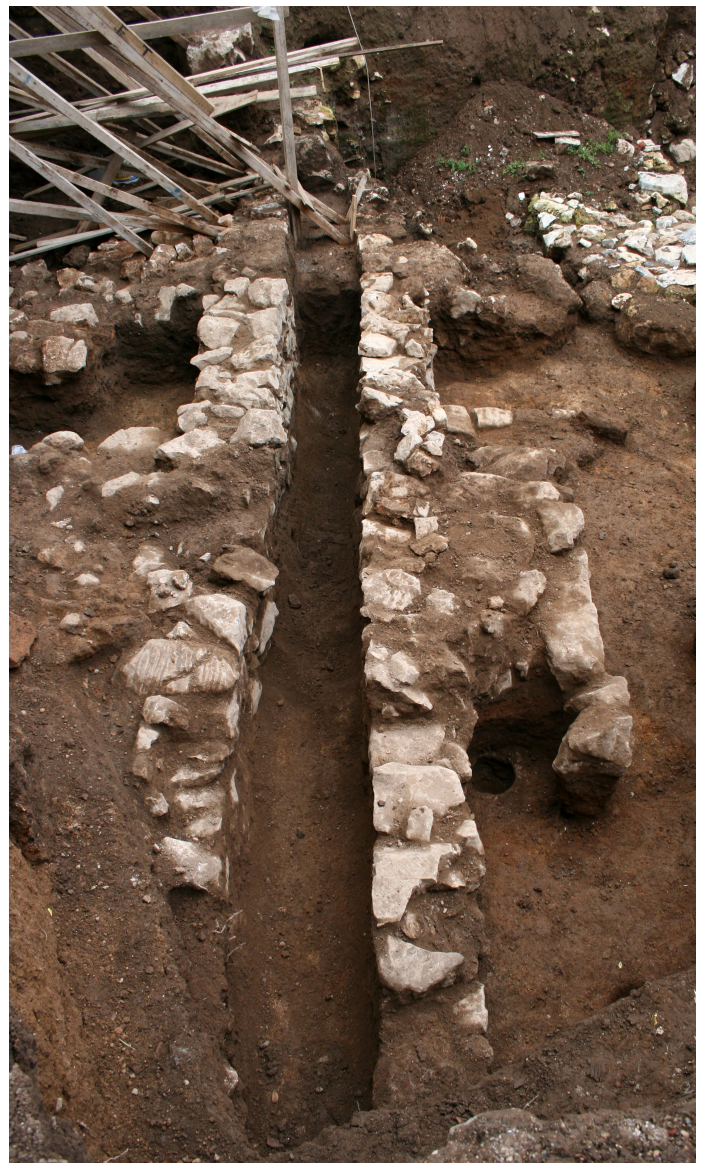

Figure 10 


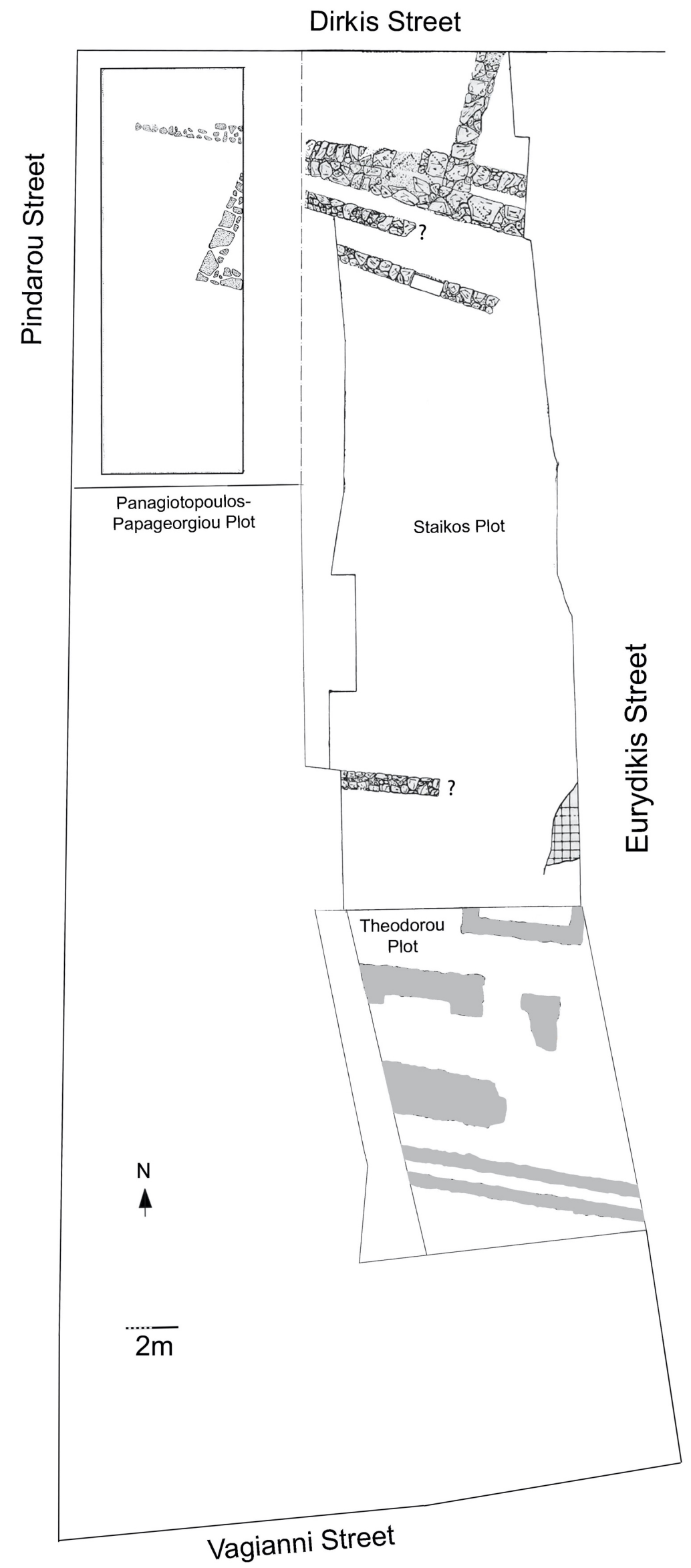

Figure 11 

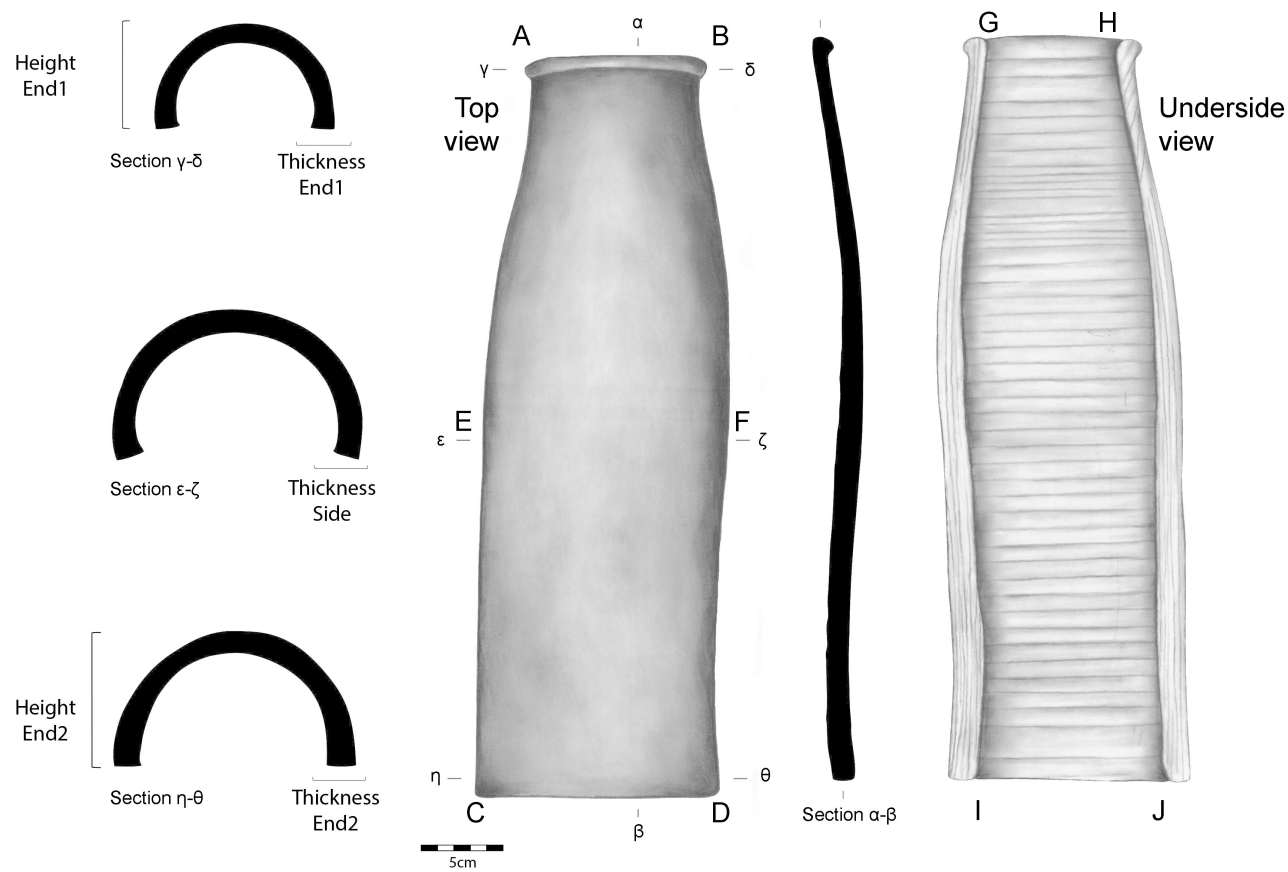

Figure 12

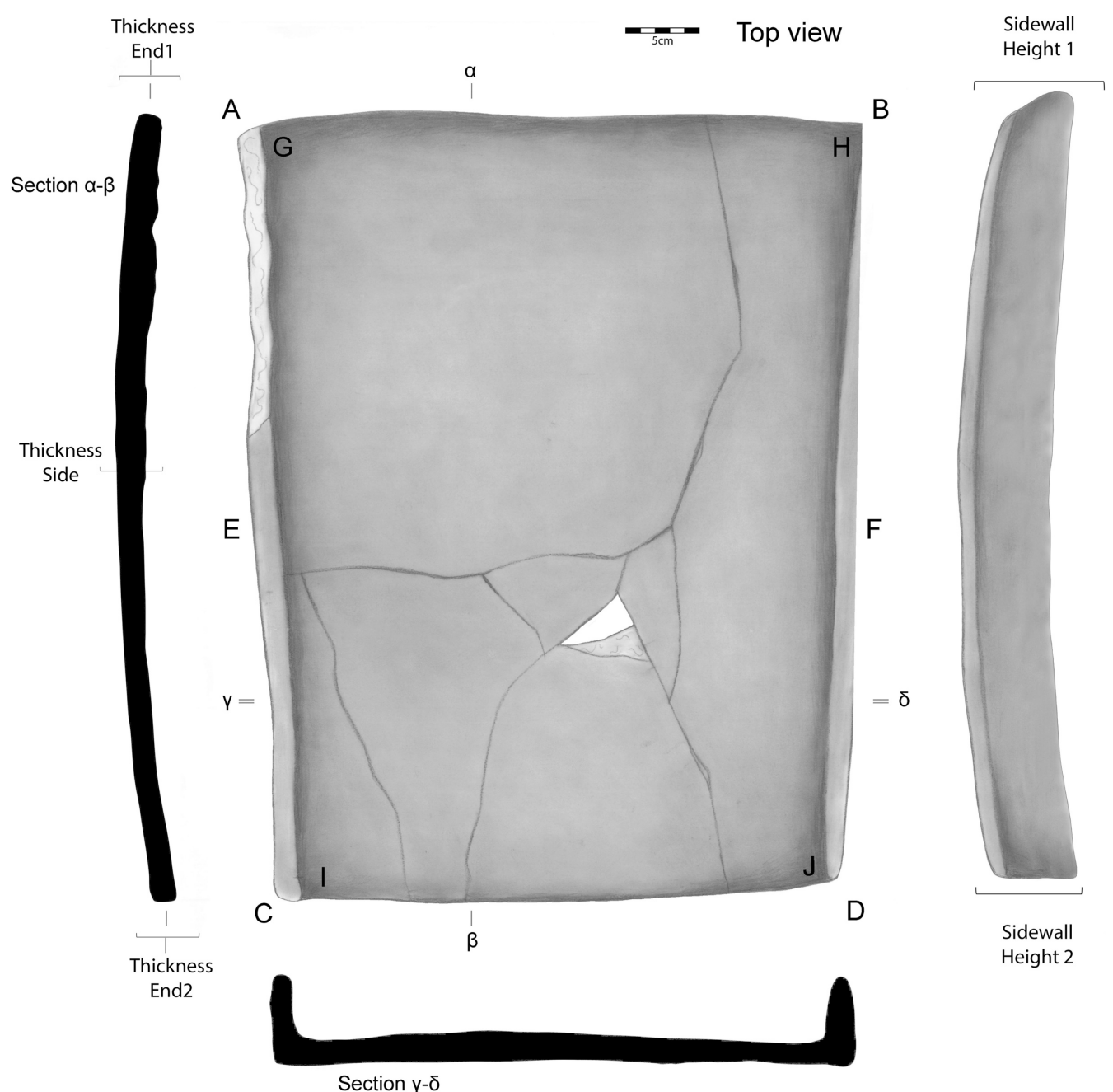

Figure 13 


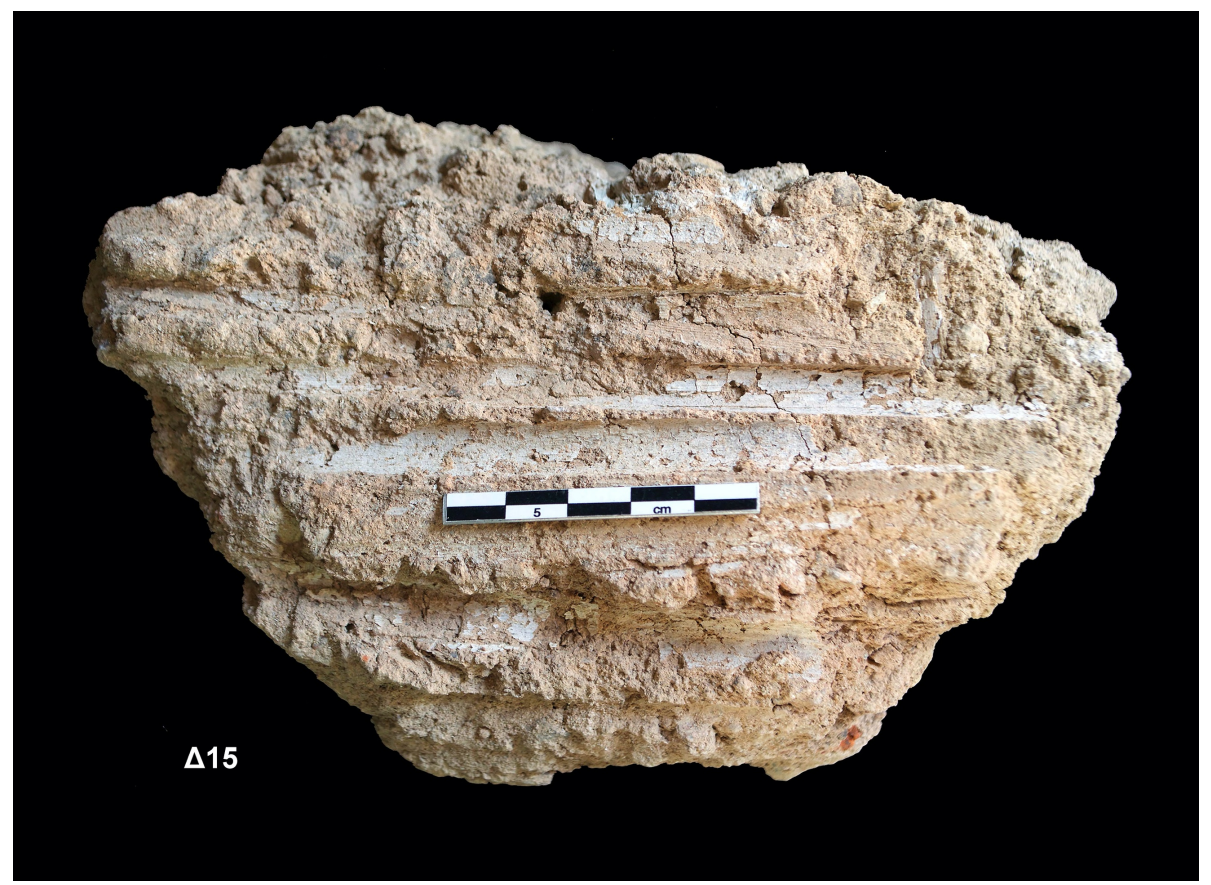

Figure 14
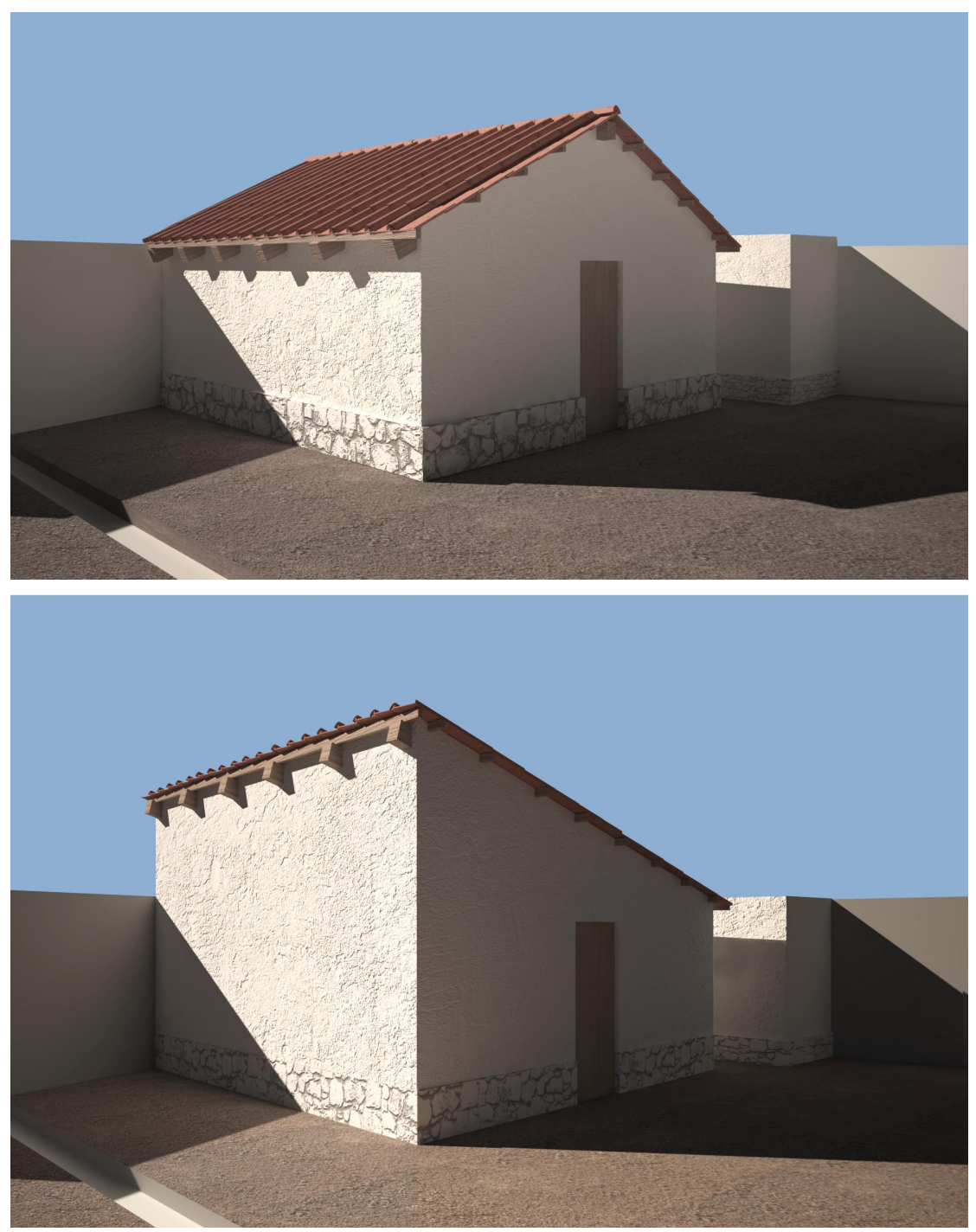

Figure 15a-b 

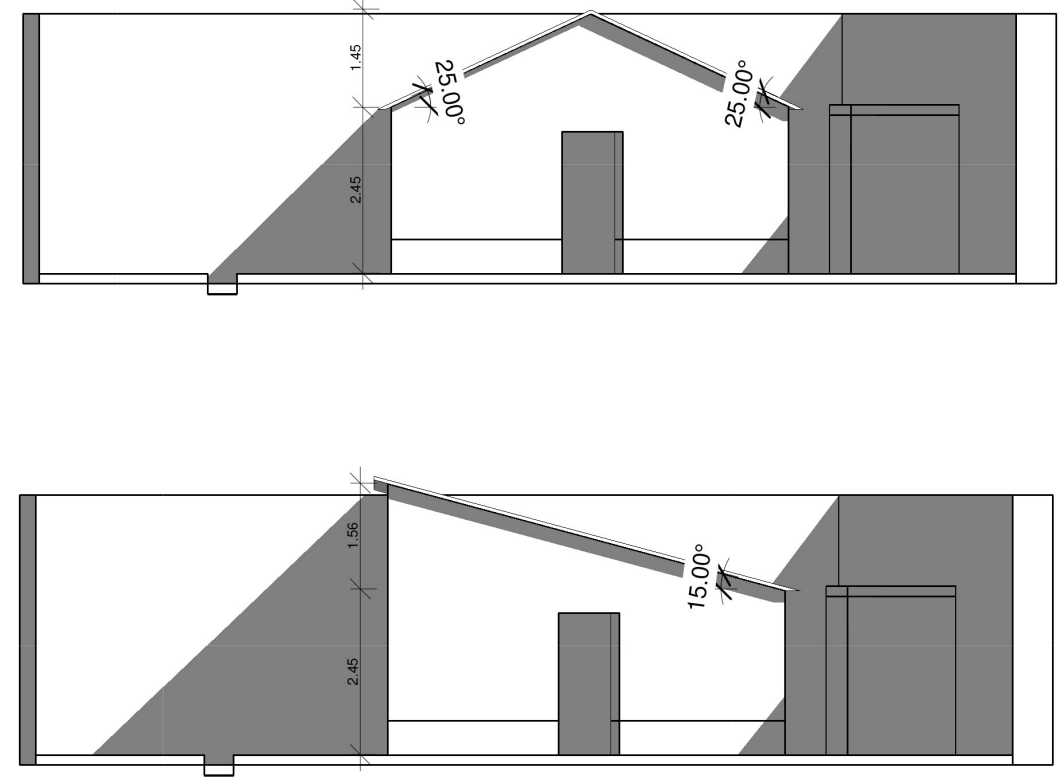

Figure 16a-b

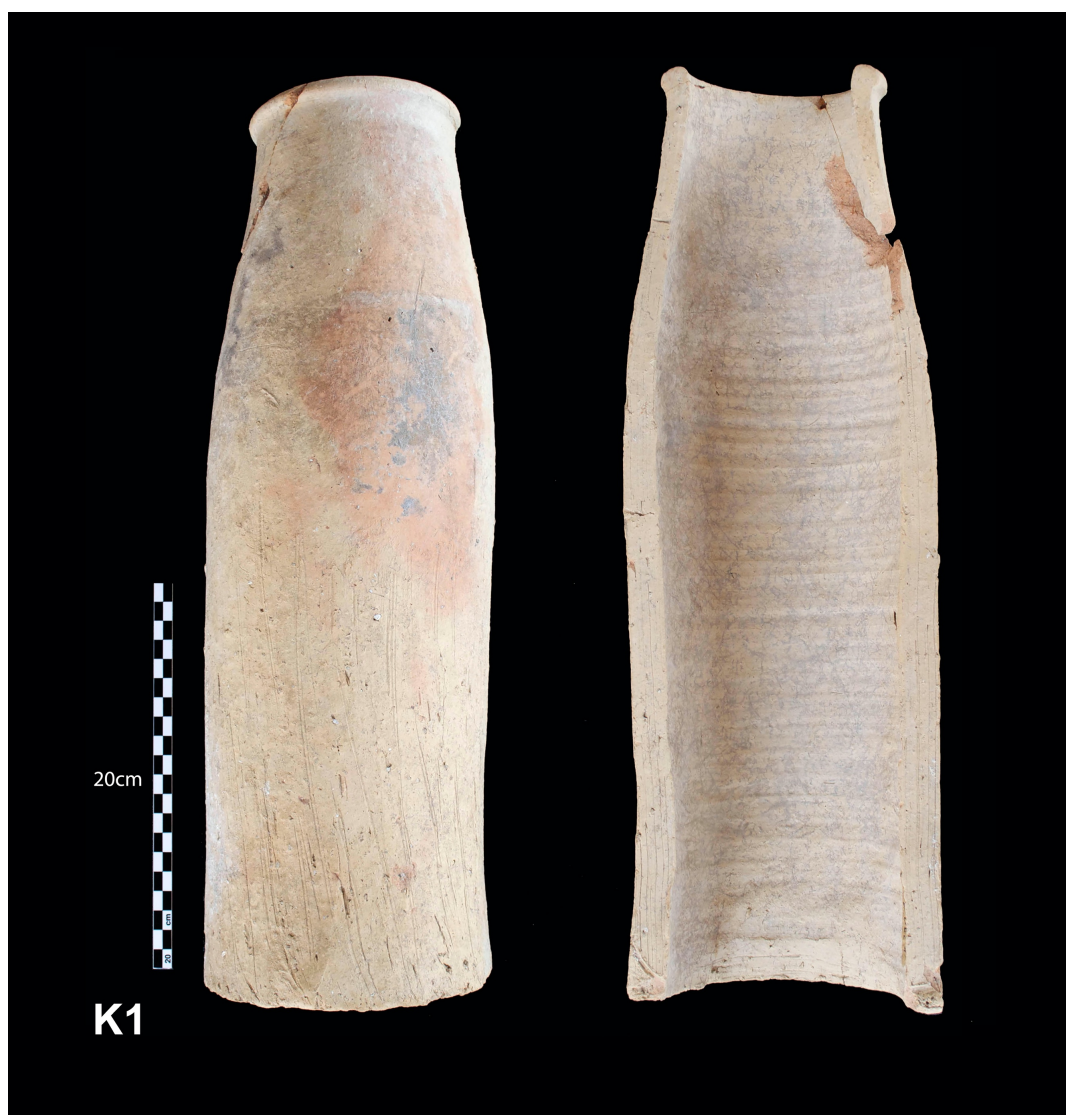

Figure 17 

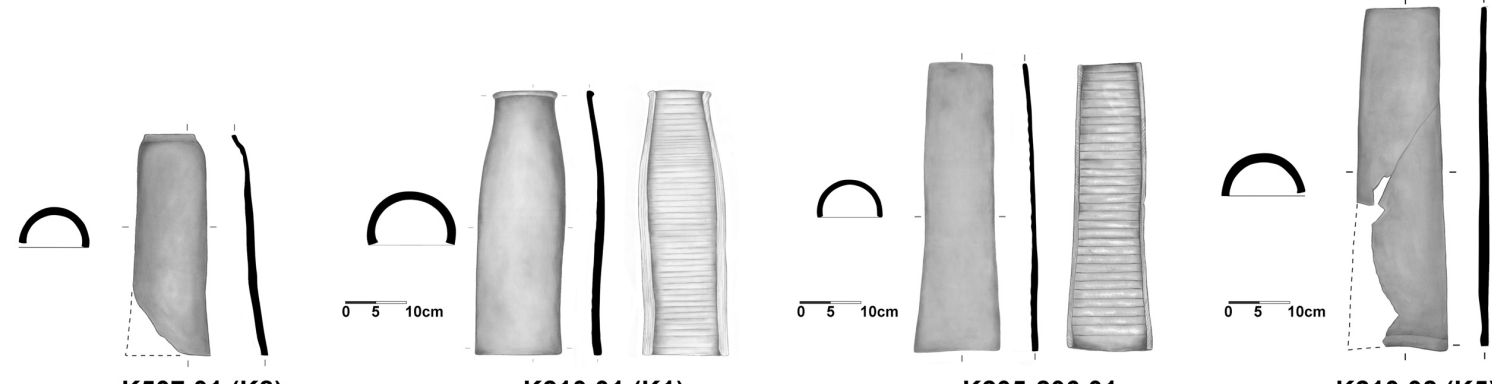

K507.01 (K8)

K210.01 (K1)

K205-206.01

K210.02 (K5)

Figure 18

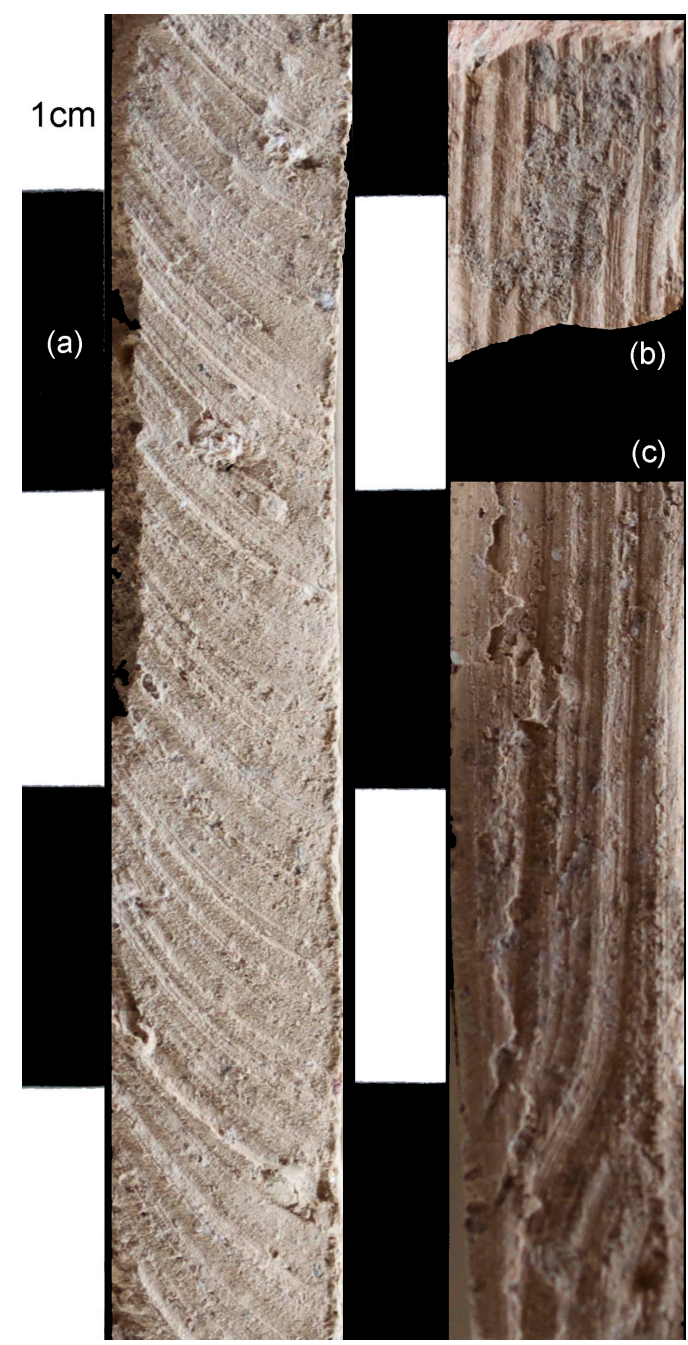

Figure 19 


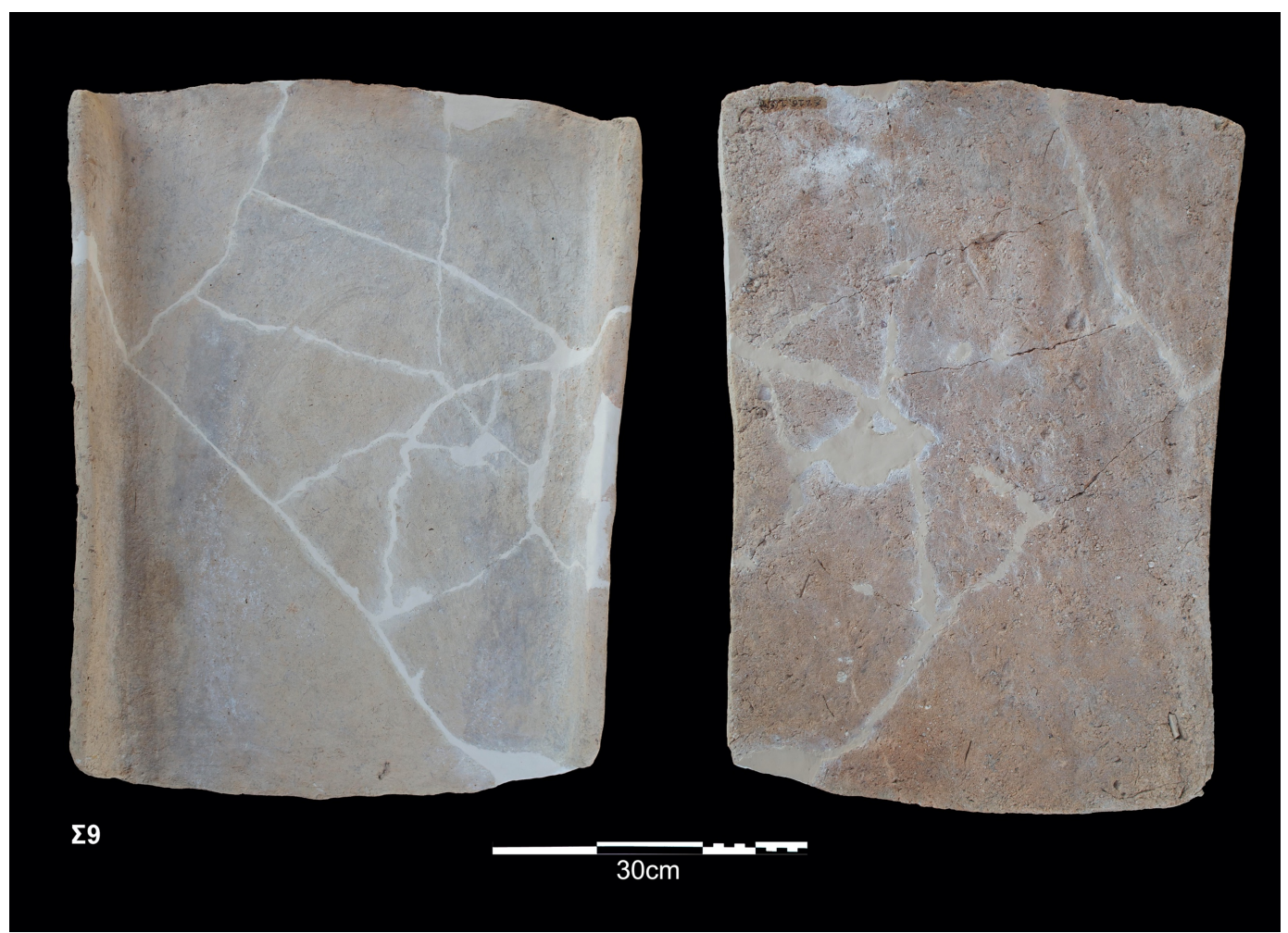

Figure 20
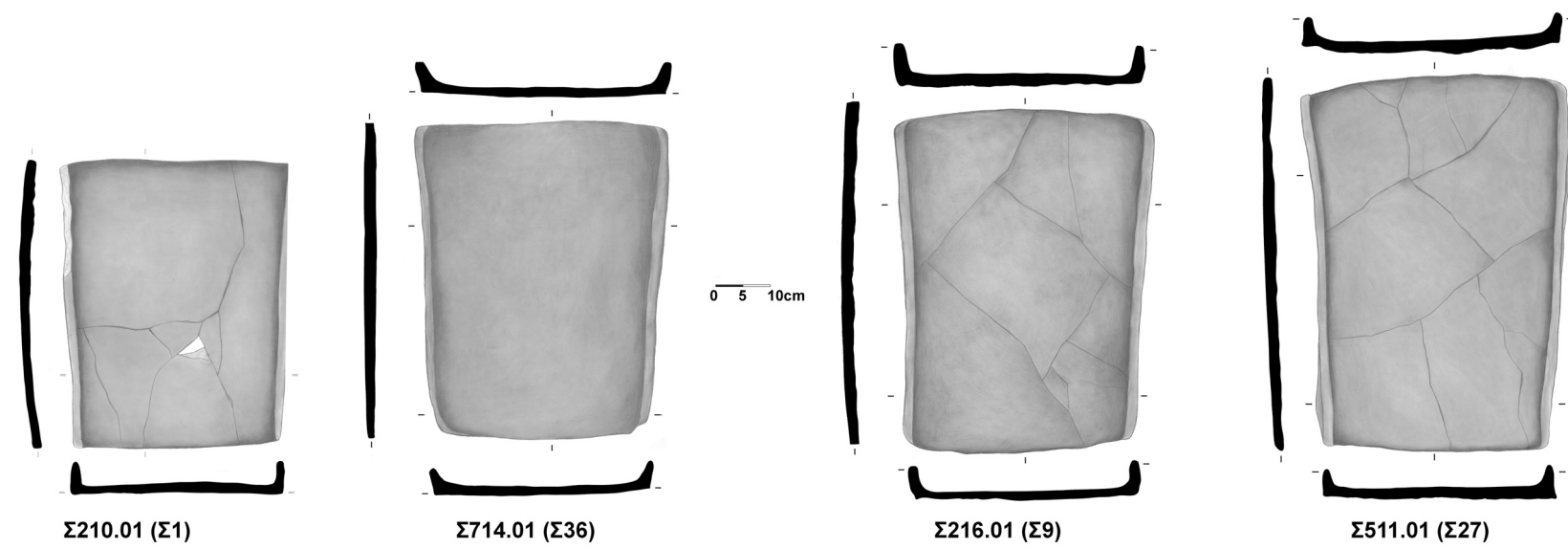

Figure 21 


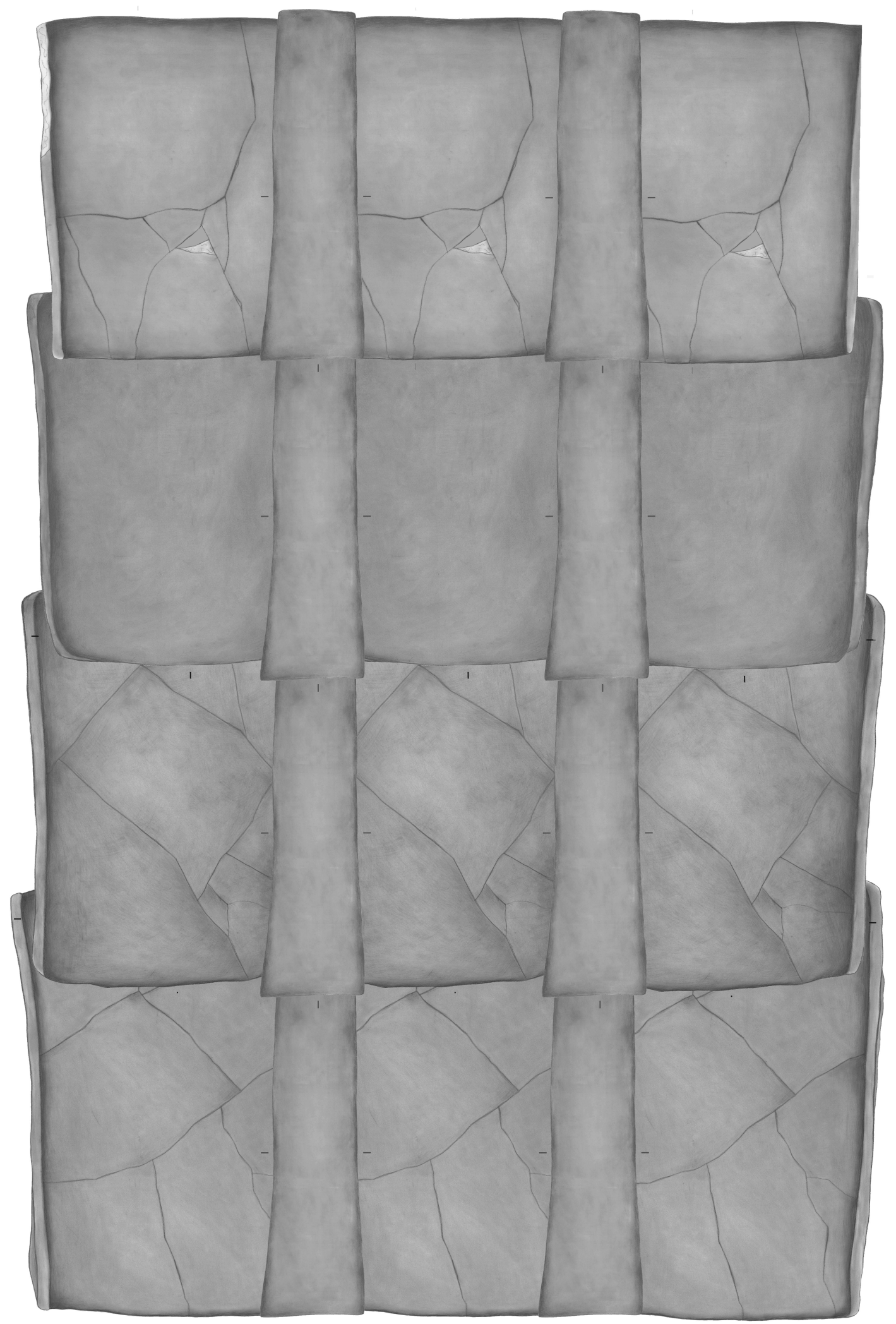

$10 \mathrm{~cm}$

Figure 22 


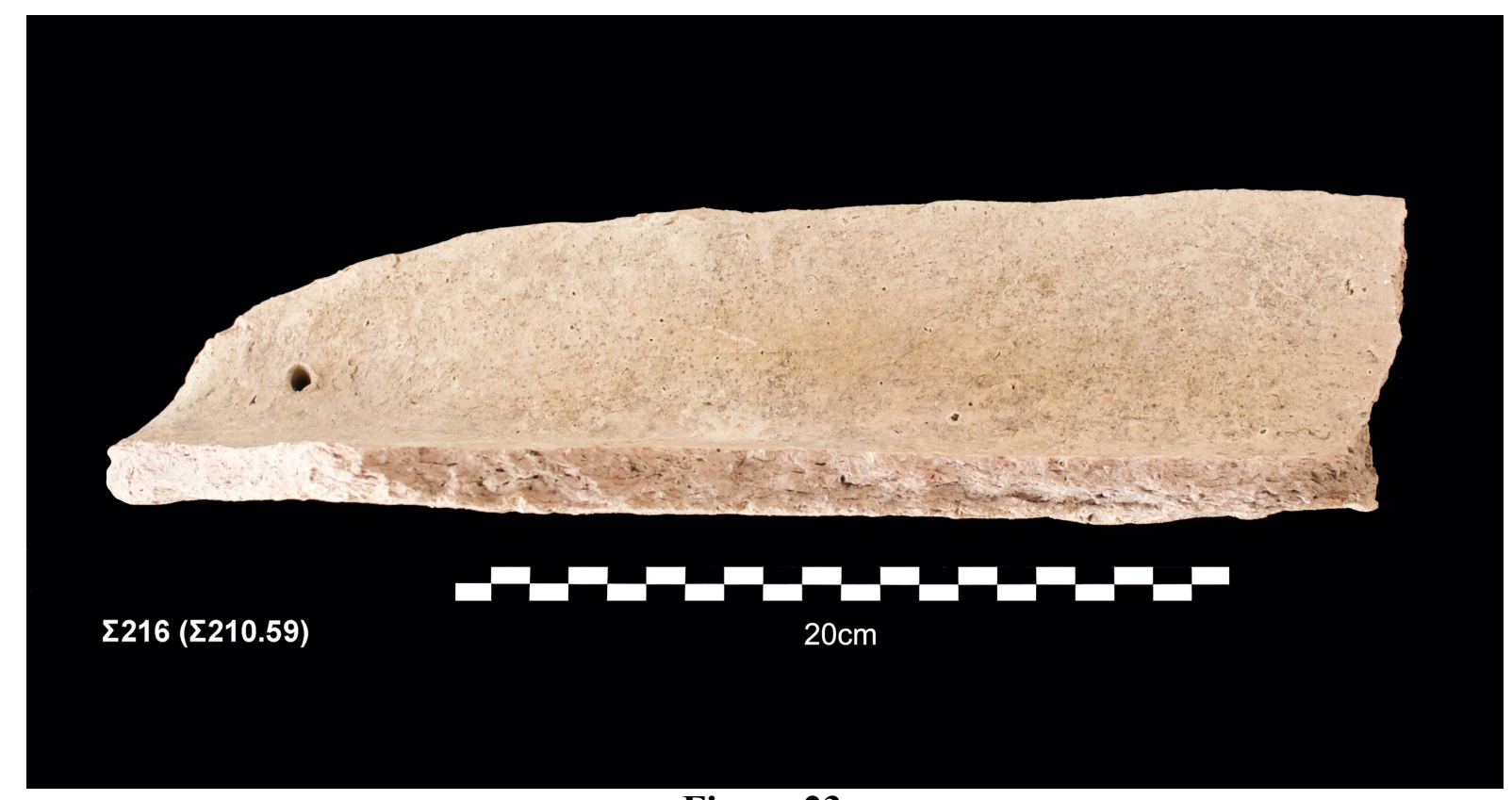

Figure 23

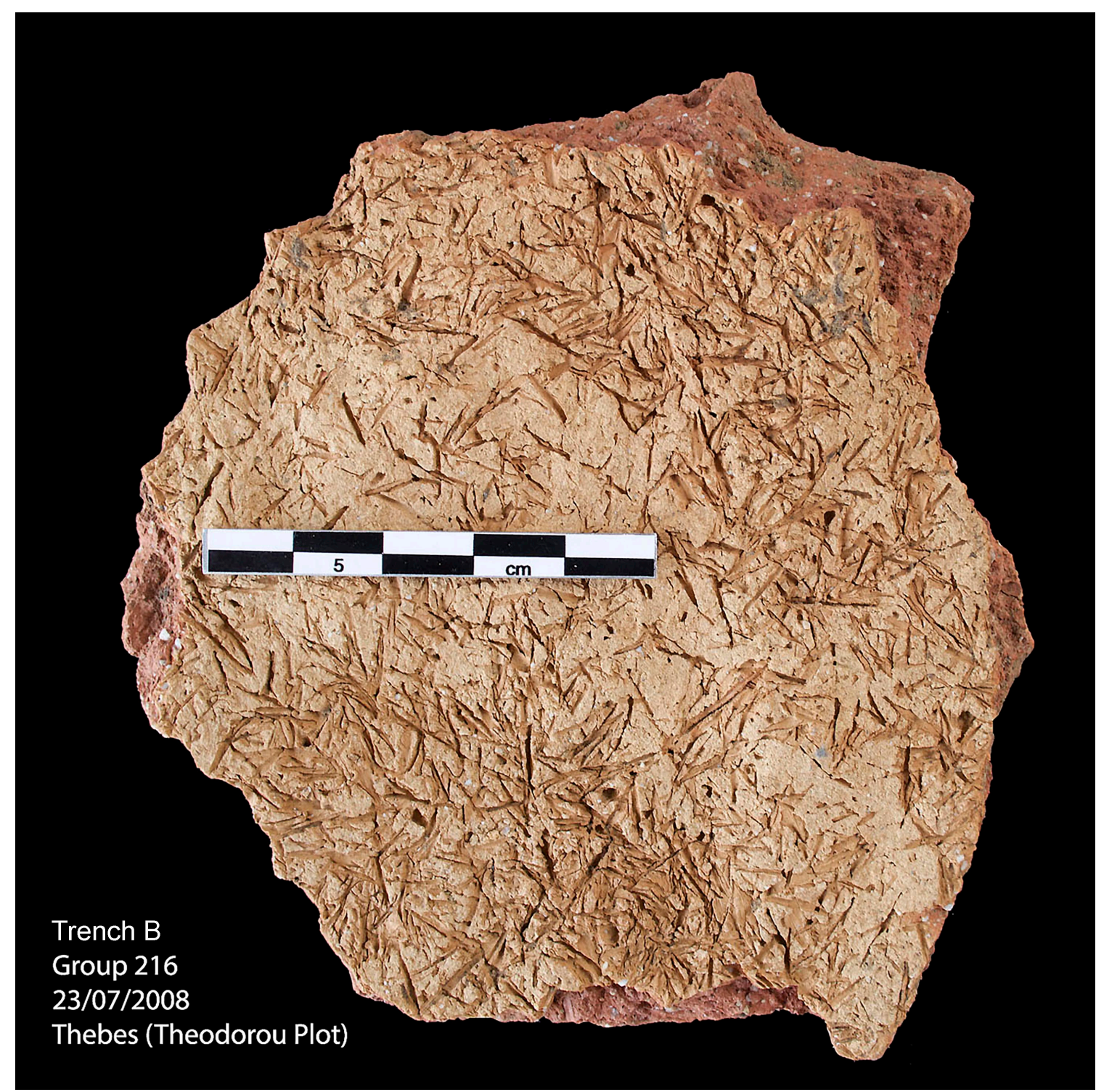

Figure 24 


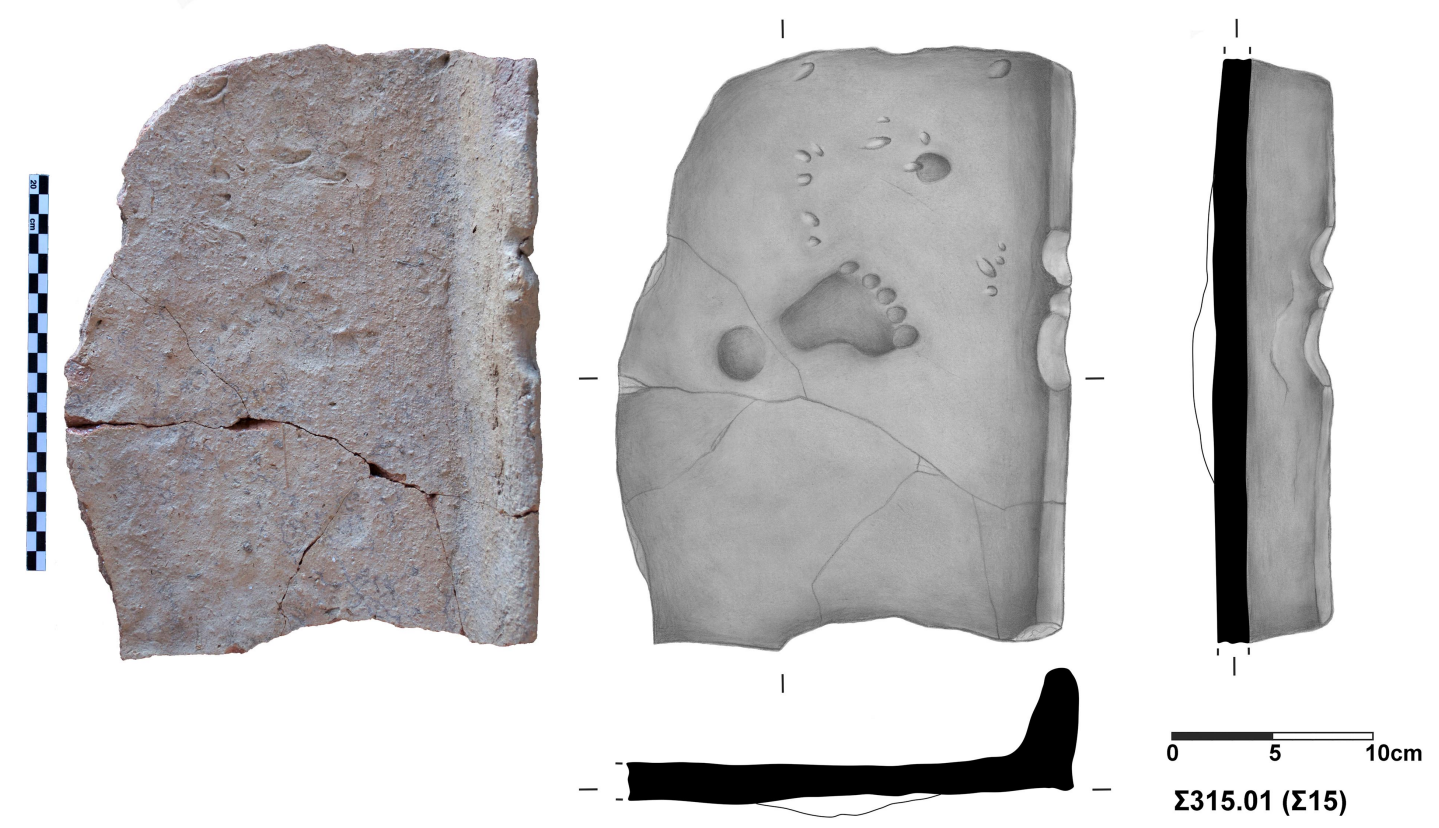

Figure 25

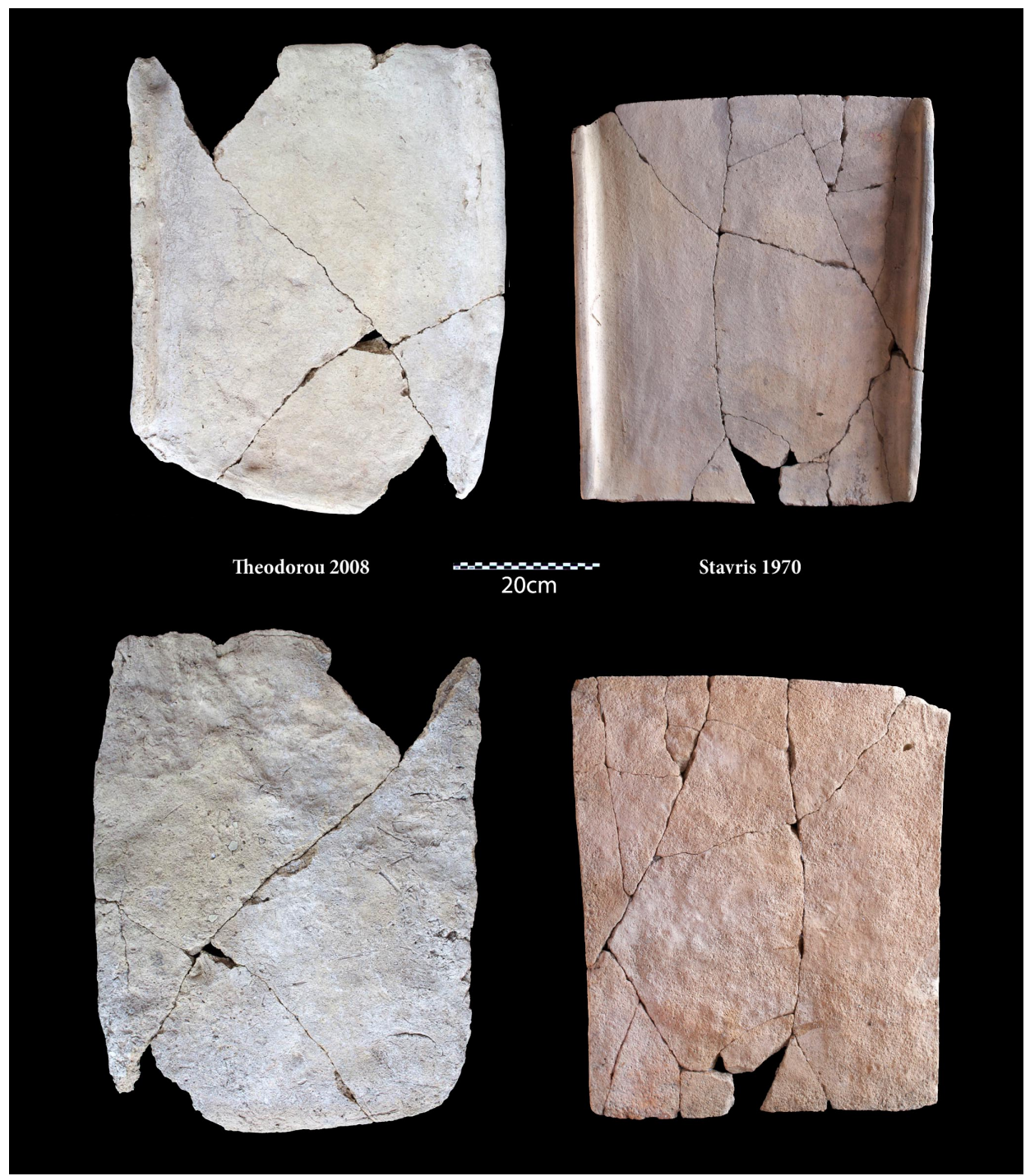

Figure 26 


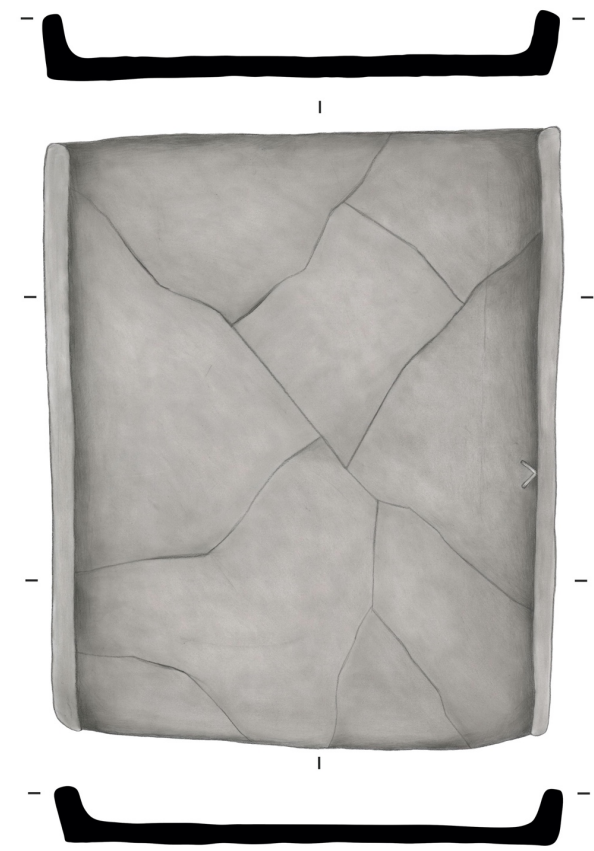

Stavris Plot (nos. 1929-1930)

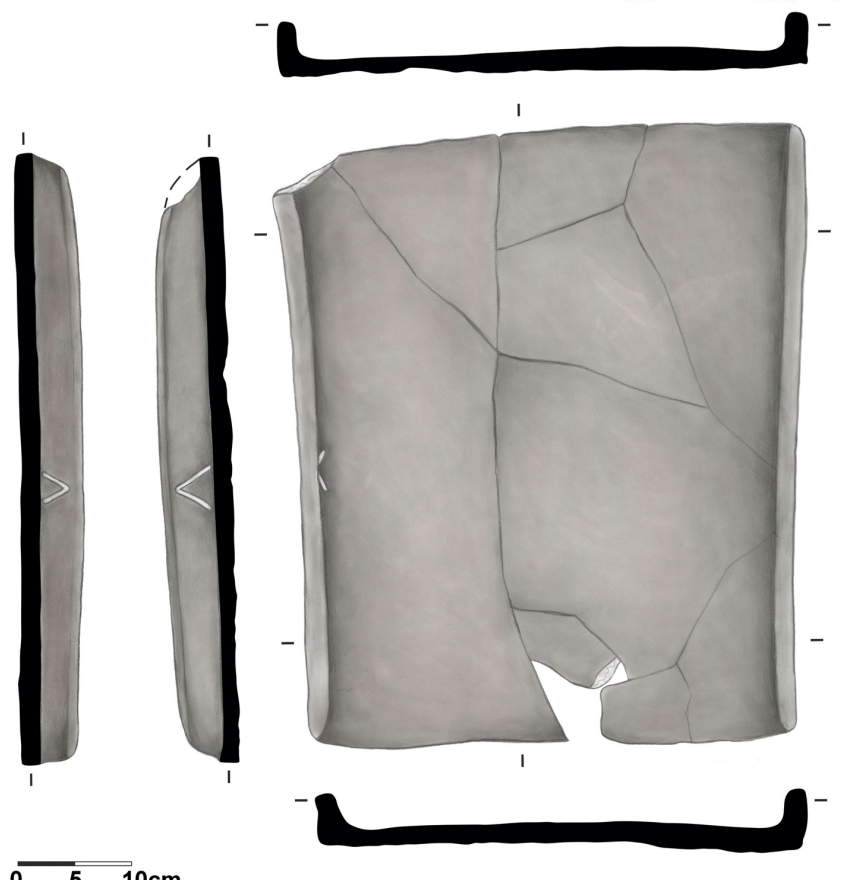

Stavris Plot (no. 1931)

Figure 27

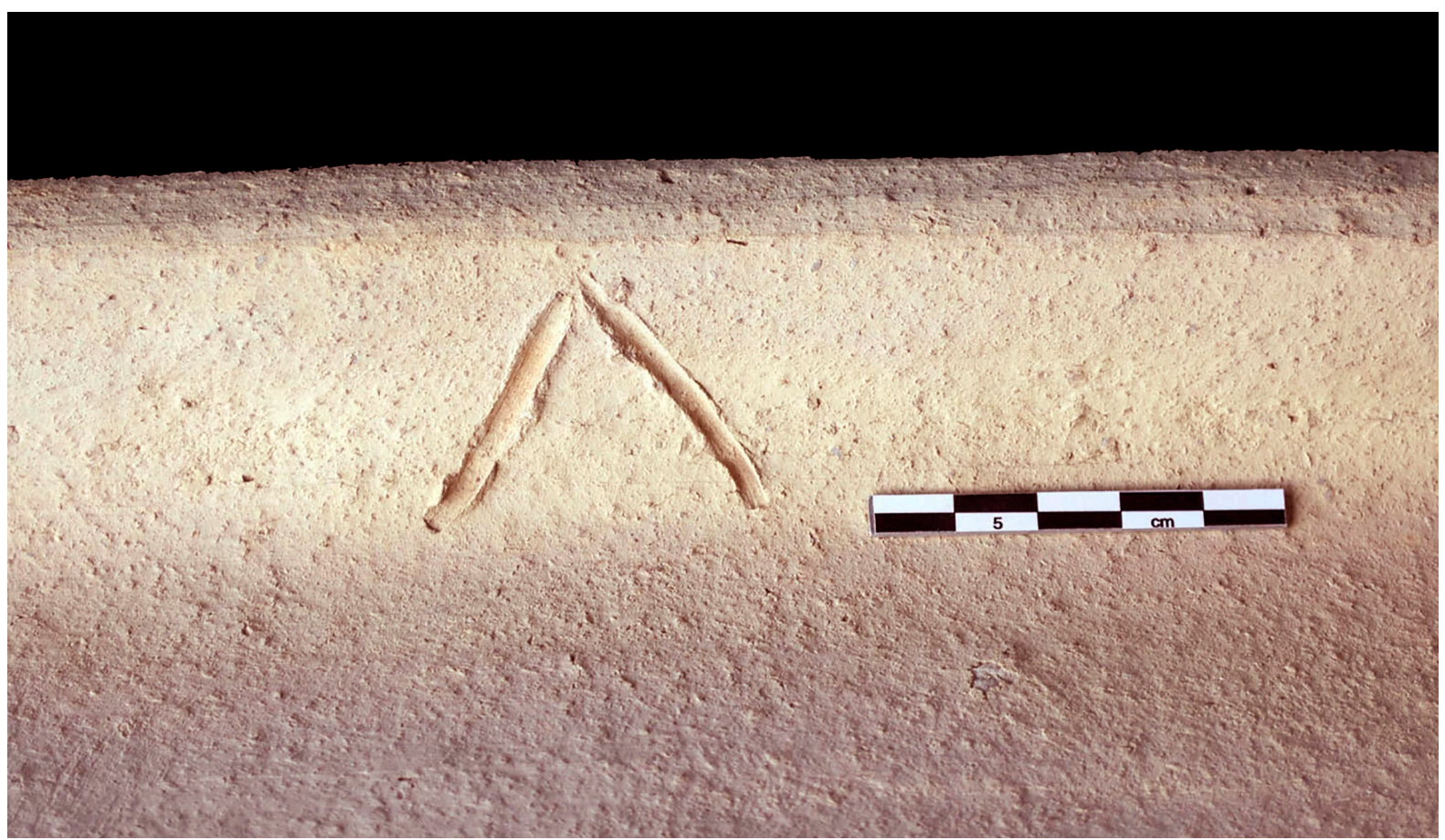

Figure 28 


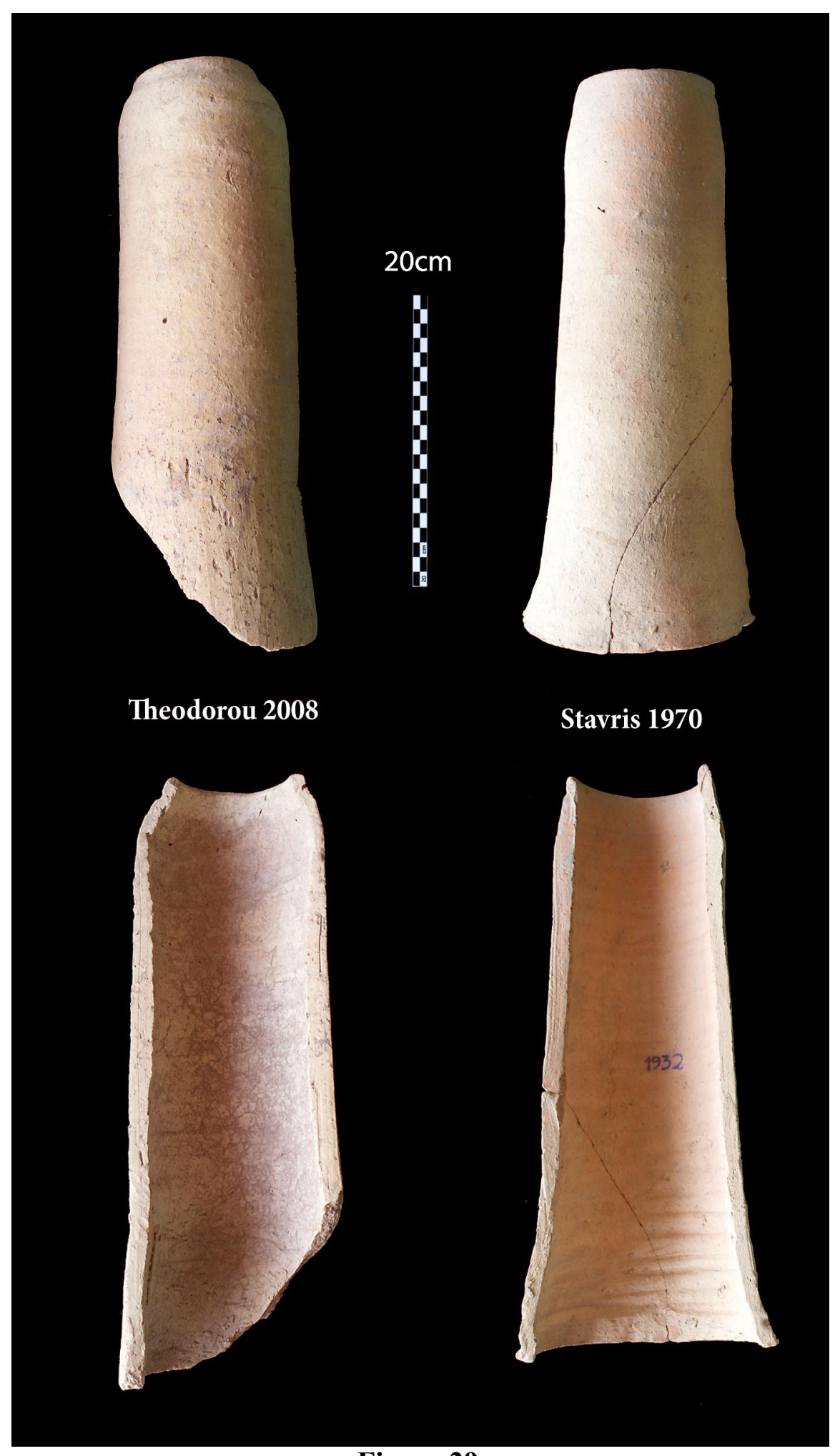

Figure 29 


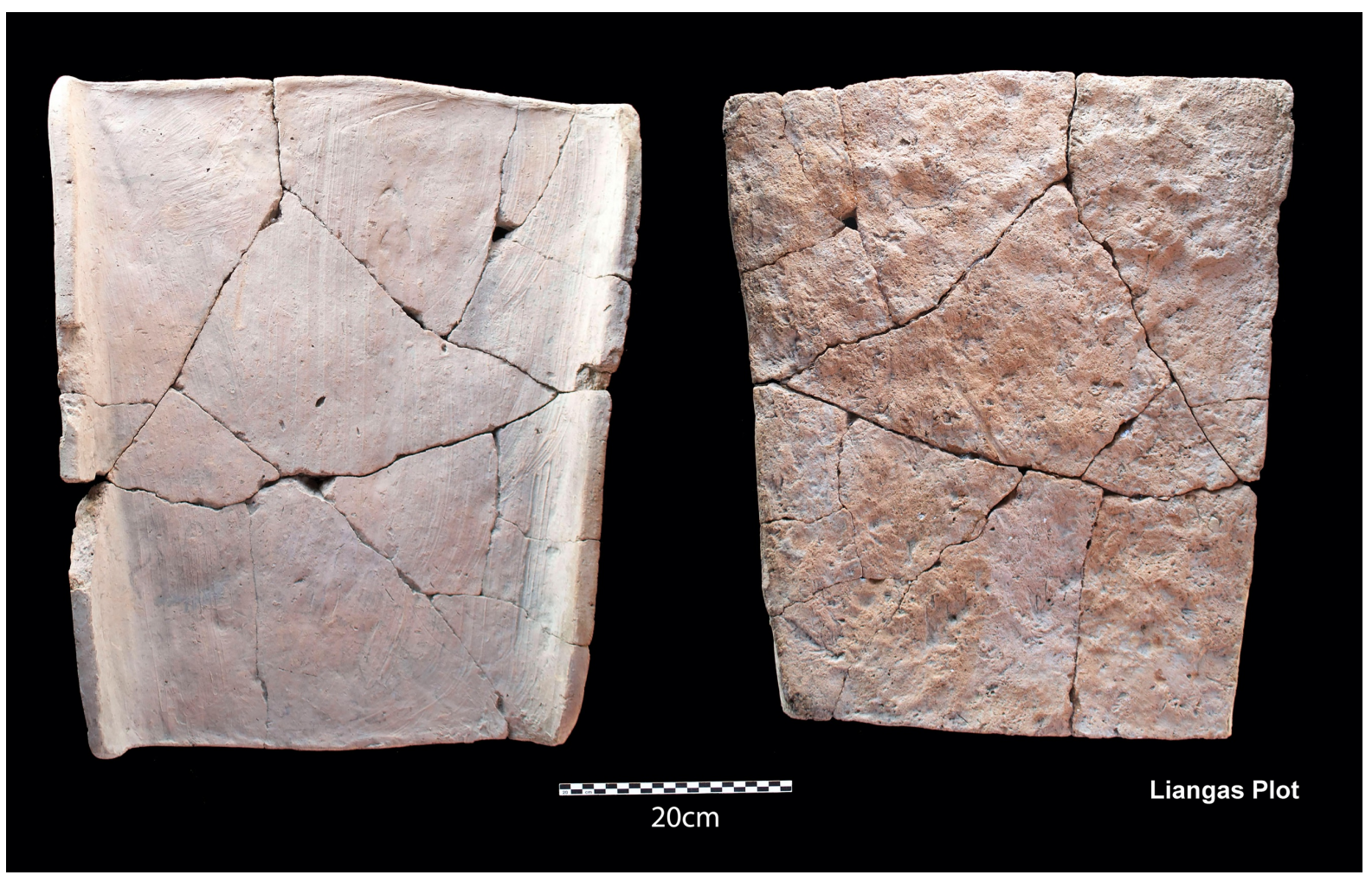

Figure 30

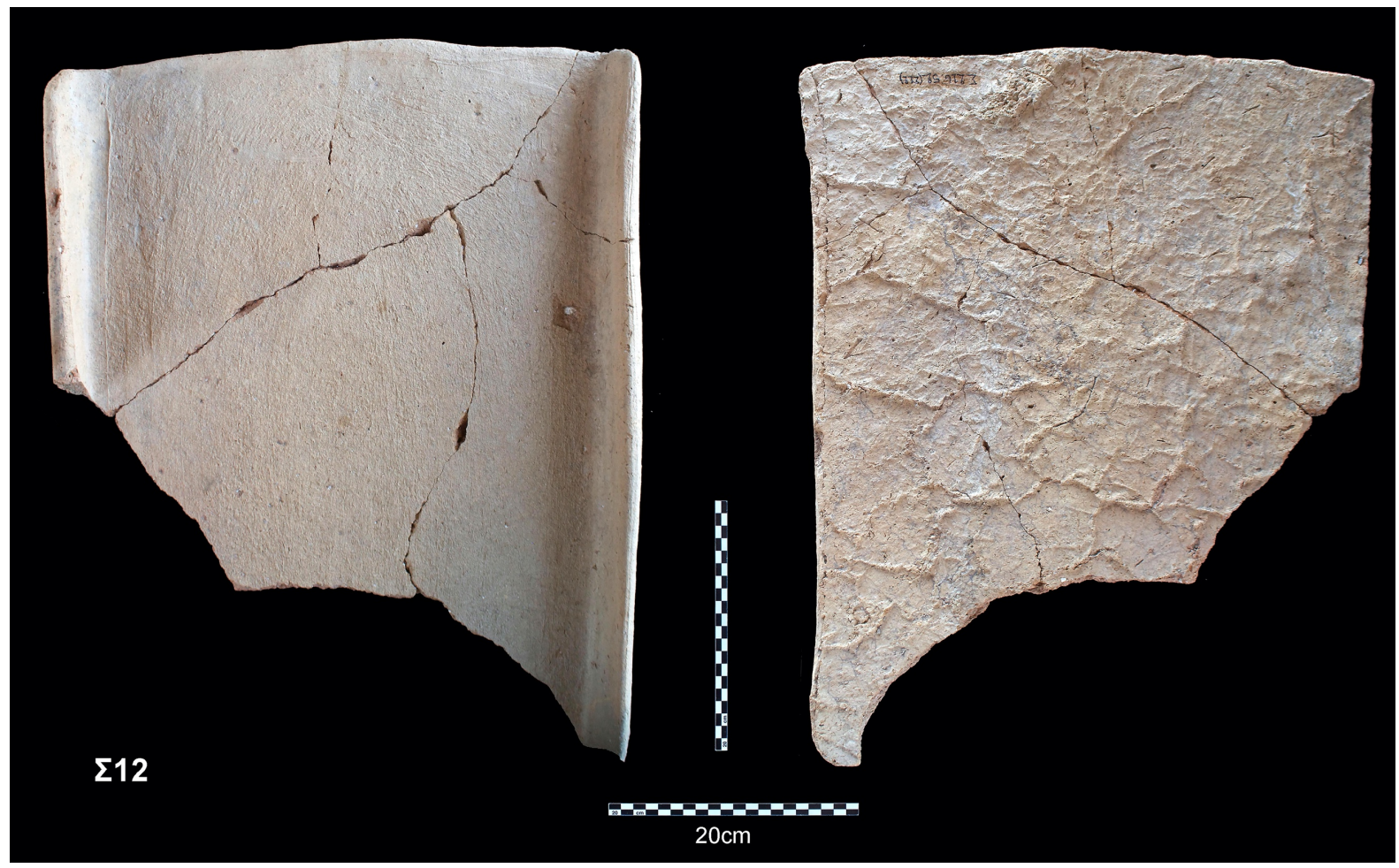

Figure 31 


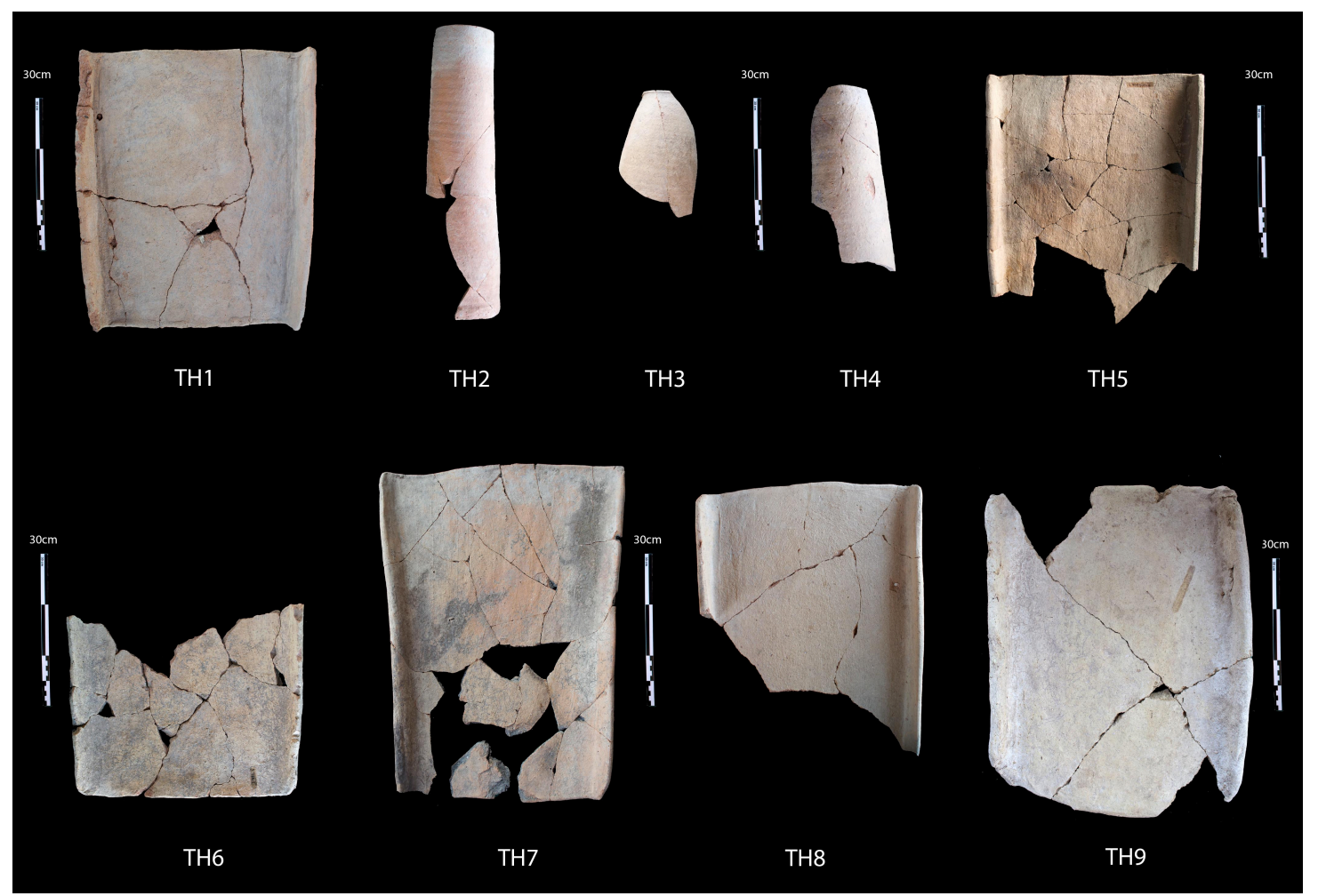

Figure 32
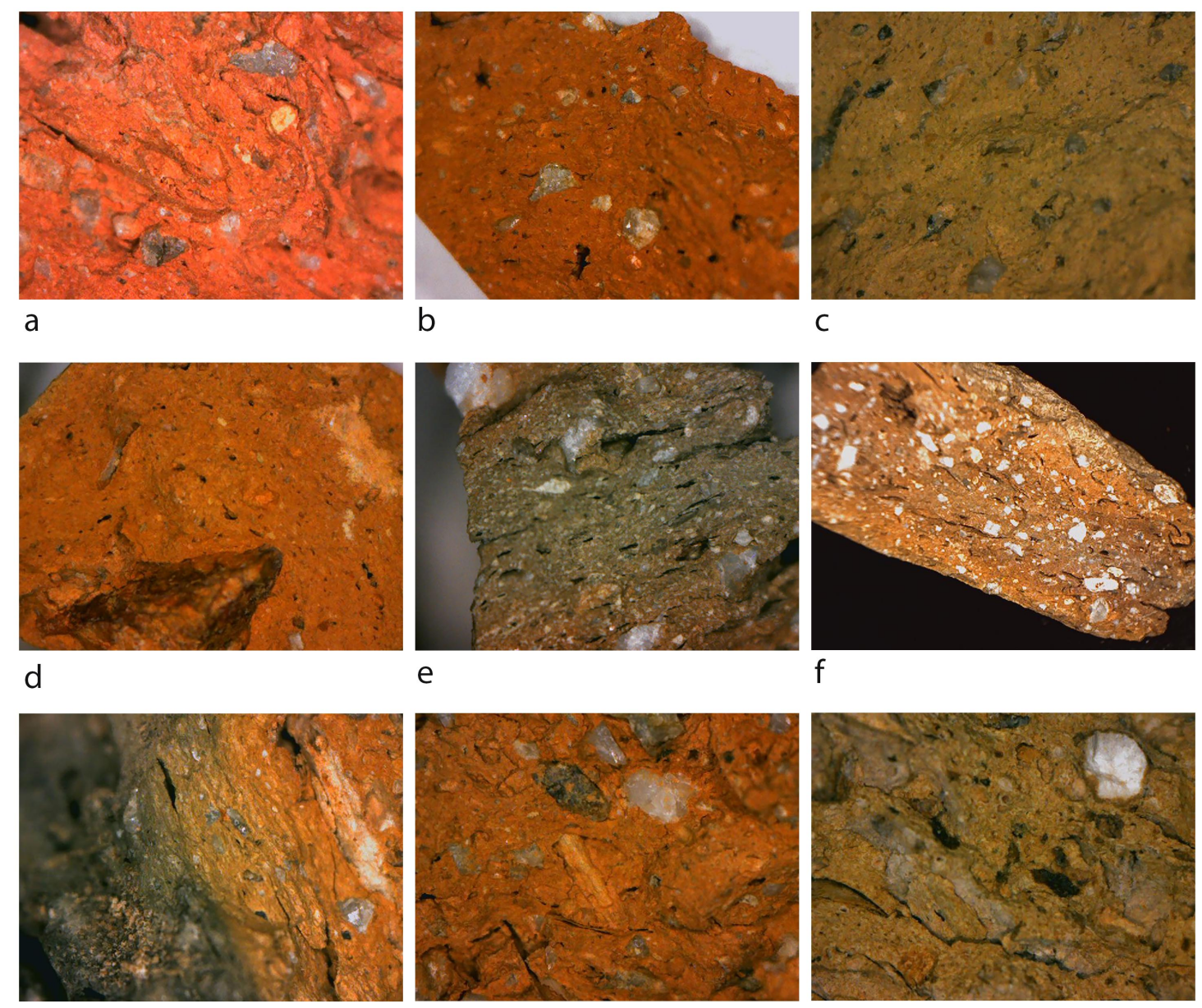

g
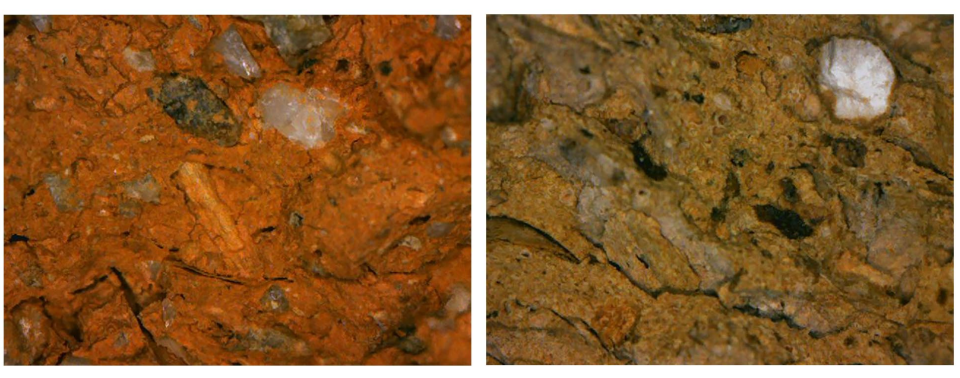

Figure 33a-i 


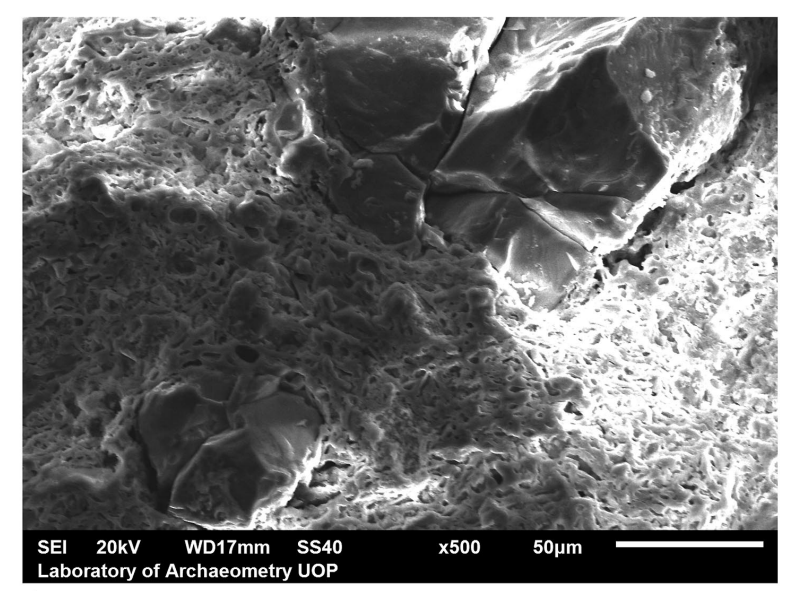

a

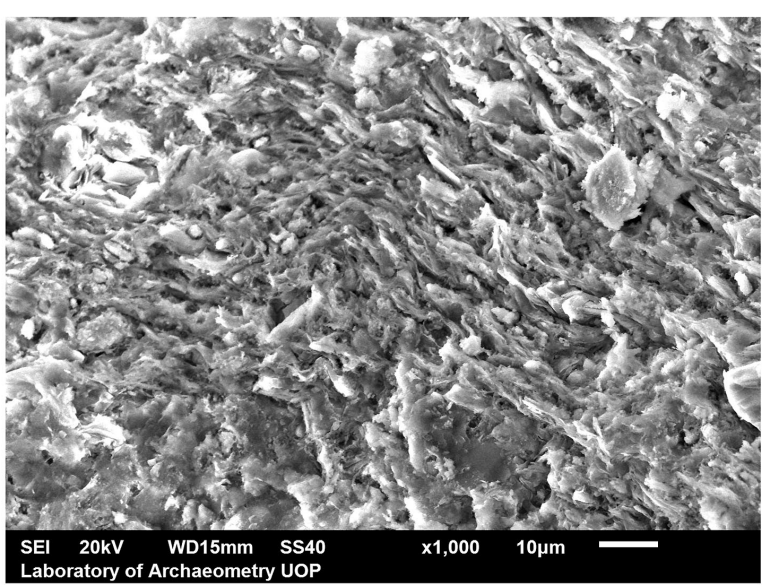

$b$

Figure 34a-b

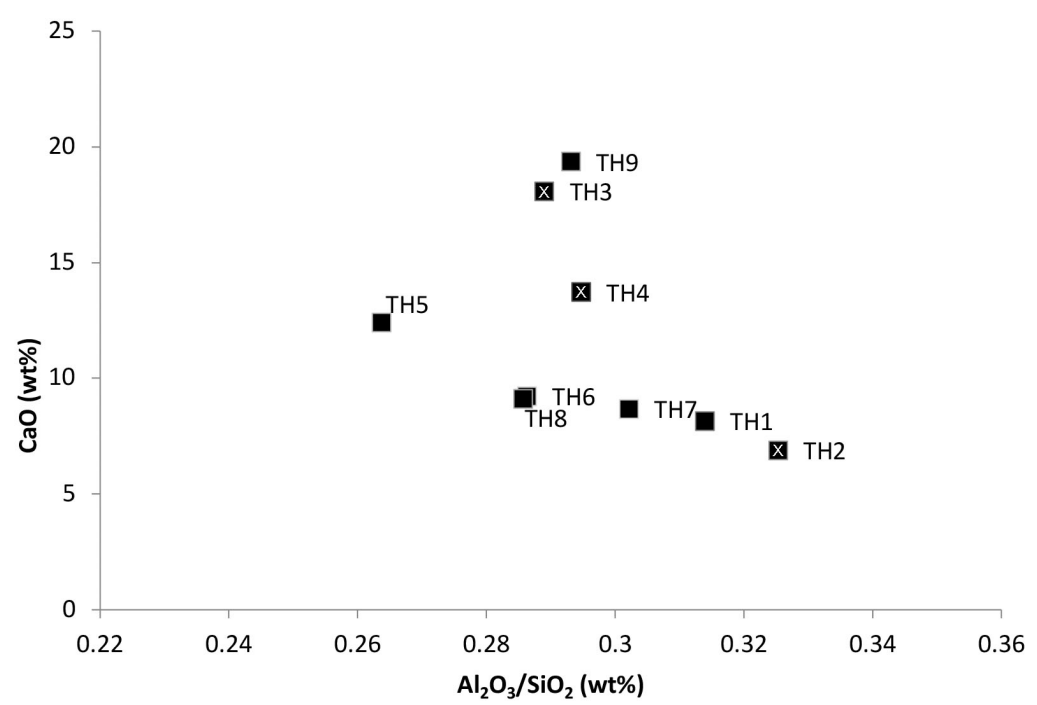

Figure 35

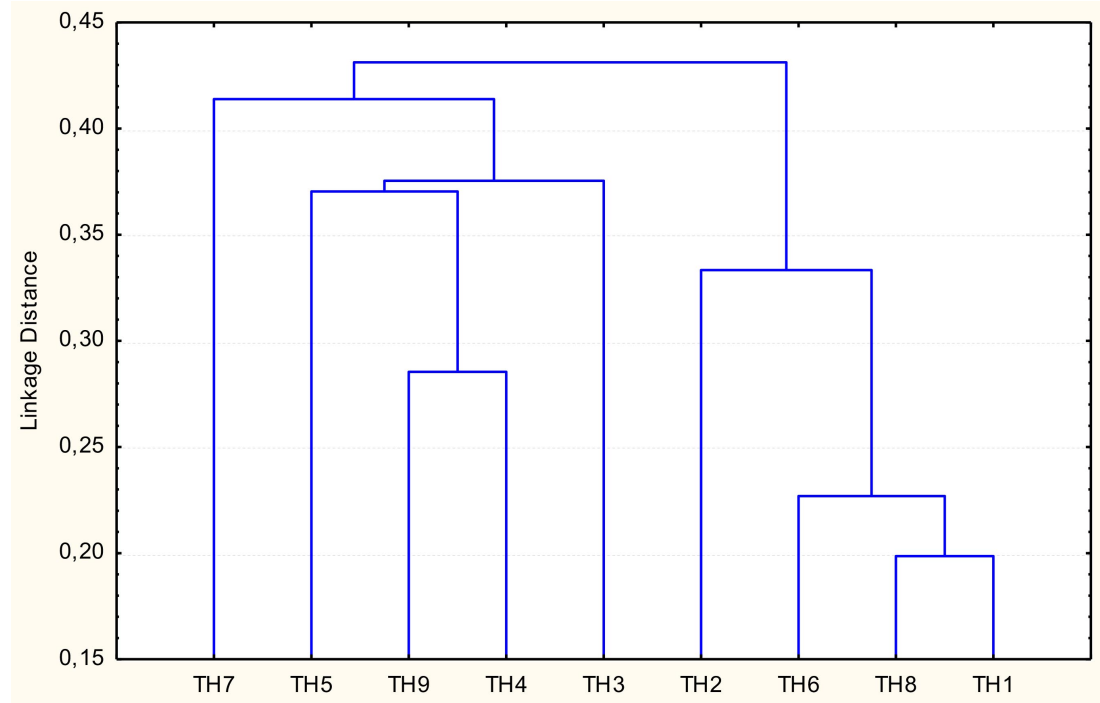

Figure 36 


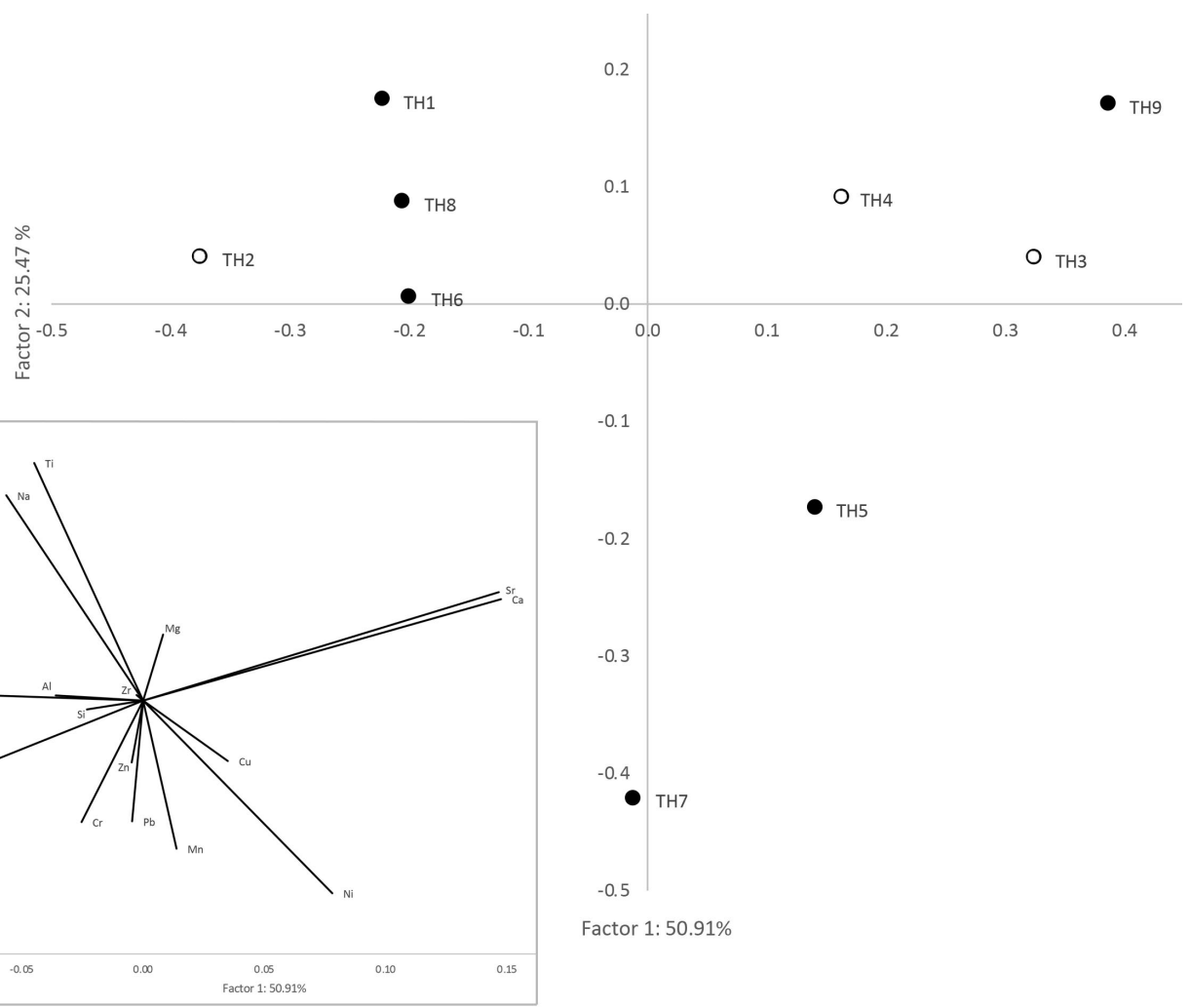

Figure 37

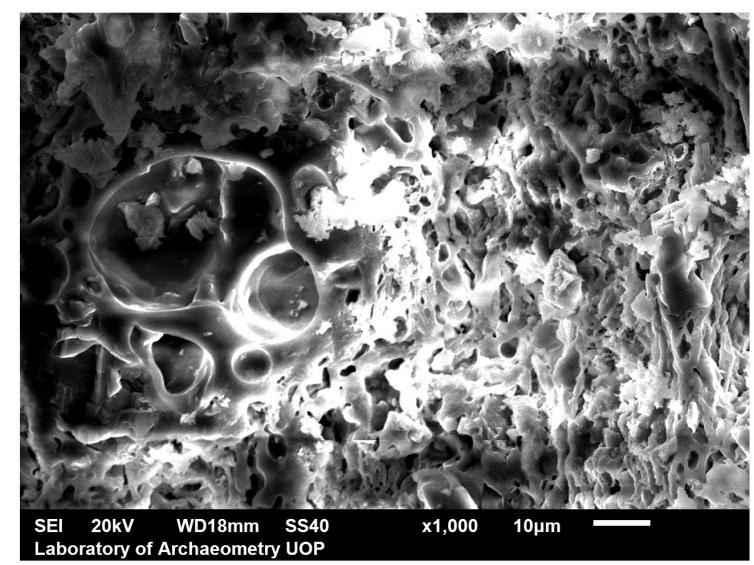

a
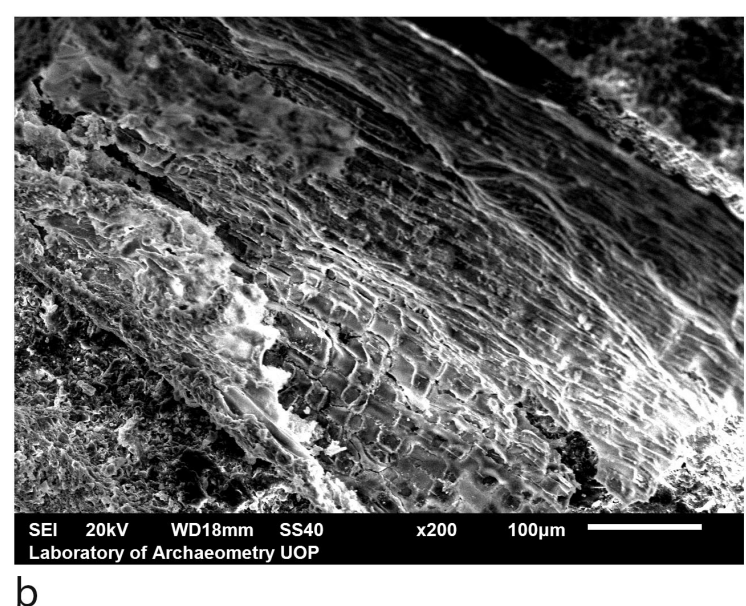

Figure 38a-b

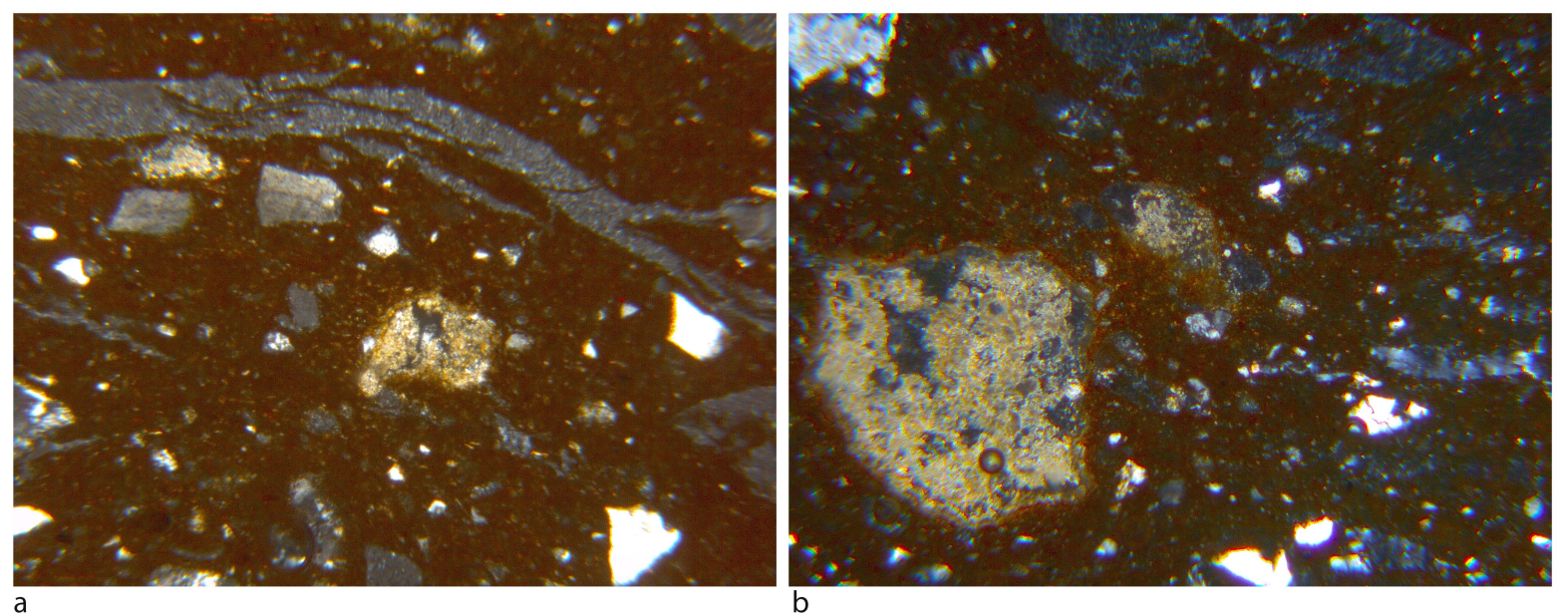

Figure 39a-b 